\title{
FINANCIAL RISK ATTITUDE AND BEHAVIOR: DO PLANNERS HELP INCREASE CONSISTENCY?
}

\author{
A dissertation \\ presented to
}

the Faculty of the Graduate School

at the University of Missouri

In Partial Fulfillment

of the Requirement for the Degree

Doctor of Philosophy

by
DONALD ERIC PARK

Dr. Deanna L. Sharpe, Dissertation Co-Advisor

Dr. Rui Yao, Dissertation Co-Advisor

DECEMBER 2013 
(C) Copyright by Donald Eric Park 2013 All Rights Reserved 
The undersigned, appointed by the dean of the Graduate School, have examined the dissertation entitled

\section{FINANCIAL RISK ATTITUDE AND BEHAVIOR: DO PLANNERS HELP INCREASE CONSISTENCY?}

Presented by Donald Eric Park,

a candidate for the degree of doctor of philosophy

and hereby certify that, in their opinion, it is worthy of acceptance

Dr. Deanna L. Sharpe, Co-advisor

Dr. Rui Yao, Co-advisor

Dr. Robert O. Weagley

Dr. Stephen R. Jorgensen

Dr. Michael S. Finke 


\section{ACKNOWLEDGEMENTS}

I would like to express my gratitude to committee members Dr. Deanna L. Sharpe who started as the chair of my committee and was joined as co-chair by Dr. Rui Yao to bring it to complication. Thank you also to committee members: Personal Financial Planning Department Chair Dr. Robert O. Weagley, College of Human Environmental Sciences Dean Stephen R. Jorgensen and Dr. Michael S. Finke from Texas Tech University. I thank you all for taking the time to serve on my committee and your kind support during my graduate studies at the University of Missouri.

I would like to specifically thank Dr. Sharpe for her patience and constantly editing my revisions. I would also like to thank Dr. Yao for her encouragement, without which I could not have pushed through the statistical methodology issues and SAS programing.

Thanks also to my family: parents Don and Shirley Park, who inspired me since I can remember, brother Samuel Park and sister Valerie Altemueller. Finally, thank you to daughter Samantha Park. 


\section{TABLE OF CONTENTS}

ACKNOWLEDGEMENTS .......................................... ii

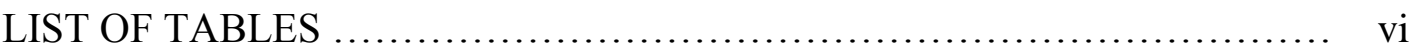

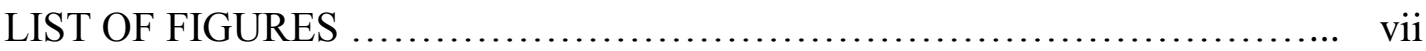

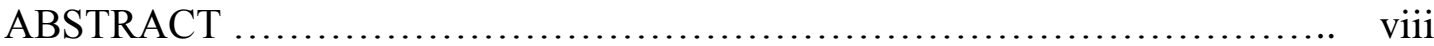

CHAPTER I: INTRODUCTION ......................................... 1

1.1 Motivations and Justifications ................................... 1

1.2 Contributions of the Study ...................................... 15

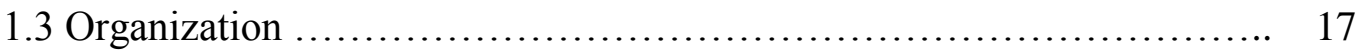

CHAPTER II: REVIEW OF LITERATURE ............................... 18

2.1 Concepts of Risk and Risk Tolerance ............................. 18

2.2 Empirical Measures of Risk Tolerance …........................... 19

2.2.1 Objective Measures of Risk Tolerance ......................... 19

2.2.2 Subjective Measures of Risk Tolerance ......................... 25

2.2.3 The Effect of Subjective Risk Tolerance on Objective

Risk Tolerance .............................................. $\quad 30$

2.2.4 Determinants of Risk tolerance .............................. 32

2.2.5 Effect of Consulting a Financial Planner on Risk Tolerance:

Attitudes and Behavior .................................... 34

CHAPTER III: CONCEPTUAL MODEL AND HYPOTHESES .............. 37

3.1 A Conceptual Model ................................................... 37

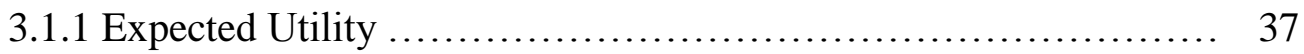

3.1.2 Information Search ............................................ 39 


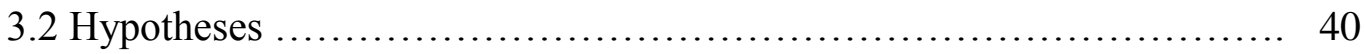

CHAPTER IV: DATA AND EMPIRICAL METHODOLOGY ................ 42

4.1 Data .................................................................. 42

4.2 Dependent Variable (Outcome Variable, Consistency) .................. 43

4.3 Independent Variables .......................................... 47

4.3.1 Survey Years and Source of Information ....................... 47

4.3.2 Demographic Characteristics of the Respondent and the Household ................................................. 49

4.3.3 Economic Characteristics of the Household ..................... 51

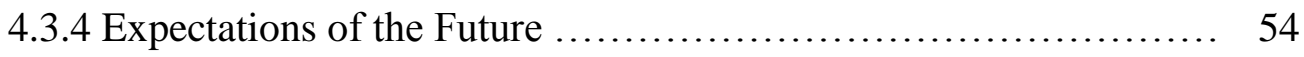

4.4 Method of Analysis .............................................. 54

4.4.1 Sample Selection ......................................... 54

4.4.2 Matching Demographic Characteristics and Respondent-reported Household Risk Tolerance .................................. 55

4.4.3 Multiple Imputation and the Repeated-imputation Inference Technique ............................................... 56

4.4.4 Age-Period-Cohort Analysis ................................. 57

4.4.5 Descriptive and Multivariate Analyses ......................... 59

CHAPTER V: RESULTS ............................................ 67

5.1 Sample Characteristics ............................................ 67

5.1.1 Sample Characteristics in Each Survey Year .................... 67

5.1.2 Sample Characteristics by Information Source .................. 80

5.1.3 Consistency in Risk Attitude and Behavior by Source of Information and Survey Year ............................... 93 
5.1.4 Consistency in Risk Attitude and Behavior by Sample

Characteristics and Survey Year

5.2 Logistic Results of Consistency in Risk Attitude and Behavior

5.2.1 Some Financial Risk Tolerance vs. Investment Asset Ownership ...

5.2.2 High Financial Risk Tolerance vs. Equity Ownership

5.3 Hypothesis Tests Results

6.1 Summary of Results at the First Level of Consistency

6.2 Summary of Results at the Second Level of Consistency

6.3 Discussion

6.3.1 Taking less Portfolio Risks than Desired

6.3.2 Taking more Portfolio Risks than Desired 142

6.4 Implications for Financial Planners

6.5 Implications for Policy Makers 146

6.6 Limitations and Implications for Future Research 147

BIBLIOGRAPHY 151

VITA 159 


\section{LIST OF TABLES}

Table Page

1 Sample Characteristics in Each Survey Year ....................... 68

2 Sample Characteristics by Source of Information ................... 81

3 Consistency in Risk Attitude and Behavior by Source of Information And Survey Year .............................................. 94

$4 \quad$ Consistency in Risk Attitude and Behavior by Sample Characteristics And Survey Year ............................................. 100

5 Logistic Analysis of Consistency in Risk Attitude and Behavior ......... 123

6 Hypothesis Tests: Consistency in Risk Attitude and Behavior among Information Sources ........................................... 132 


\section{LIST OF FIGURES}

Figure $\quad$ Page

1a Definition of First Level Consistency in Reported Risk Tolerance

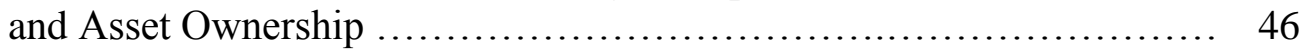

1b Definition of Second Level Consistency in Reported Risk Tolerance

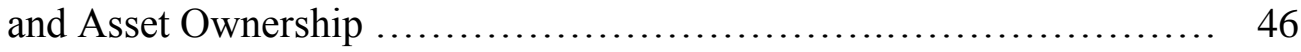

2a Relationship between Each Two Sources of Information at the First Level ..................................................... 65

2b Relationship between Each Two Sources of Information at the Second Level ...................................................65 


\title{
FINANCIAL RISK ATTITUDE AND BEHAVIOR: DO PLANNERS HELP INCREASE CONSISTENCY?
}

\author{
Donald Eric Park
}

\author{
Dr. Deanna L. Sharpe, Dissertation Co-Advisor \\ Dr. Rui Yao, Dissertation Co-Advisor
}

\begin{abstract}
This study used the 1998-2007 Survey of Consumer Finances to investigate the effect of various sources of information on households' consistency in financial risk attitude and behavior. Categories of financial information sources were: 1) self and social network; 2) financial planner; 3) financial institutions; 4) media; and 5) other sources. Consistency was measured at two levels. The first level consistency was between being willing to take some versus no financial risks and investment ownership. Households were considered to be consistent at this level if they were willing to take some financial risks in exchange for some investment returns and had some investment assets or if they were unwilling to take any financial risks and did not have any investment assets. The second level of consistency was between being willing to take high versus low financial risks and equity ownership. Households were considered to be viii
\end{abstract}


consistent at this level if they were willing to take high financial risks and had some equity in their portfolio or if they were unwilling to take high financial risks but had some equity assets in their portfolio.

Findings from controlled and uncontrolled analyses showed that households searching information from various sources when making savings and investment decisions were not equally likely to be consistent in their risk attitude and behavior at either level. Results from the controlled analyses suggest that working with a financial planner increased households' likelihood of being consistent in their risk and attitude at the first level but decreased their likelihood of being consistent in their risk and attitude at the second level. It seemed at the second level of consistency financial planners may have influenced households to take on more equity exposure than was desired.

Study results indicate that a mismatch between a household's risk attitude and investment behavior was not rare. The outcome of mismatches could include opportunity cost for households that forgo higher returns typically associated with equity investments as well as adverse emotional reactions to market downturns that can lead to realized losses for households that had over exposure to equities.

The objective of a financial planner should be to make sure household members understand the risks of financial products in their portfolio, and how their portfolio would perform over time, not only during periods when the market is up but also during periods when the market is down. If using a financial planner adds value to households' financial wellbeing, those who use a financial planner would be expected to act consistent with their stated risk tolerance. Insofar as consistency is desirable, the implication would be 
for consumers to consider using financial planners. If, however, using a financial planner does not make a difference or even decreases the probability of consistency between an individual's risk tolerance and risk behavior, then the financial planning industry should reassess their value proposition and/or improve their services.

This study examined efficacy of financial information sources, focusing particularly on financial planners. Study results are important because it is likely that, at some future date, a regulatory body might be responsible for not only assuring truth in investments but their efficacy as well. Having consistency in household risk attitude and behavior is important for households, their financial planners, consumer educators and researchers. A mismatch in risk attitude and behavior may cause opportunity cost or unnecessary realized financial loss, which is counterproductive to households striving to reach their financial goals. Although research has been conducted on household risk attitude and behavior, this research is the first to investigate the influence of various sources of information on the correlation between the risk level that households report they want and what they have.

Future research needs to examine how to accurately measure the financial risk tolerance for all household types, how to help households identify their true risk tolerance level, and how to help them act consistently with their risk tolerance when making savings and investment decisions. 


\section{CHAPTER I}

\section{INTRODUCTION}

\subsection{Motivations and Justifications}

Several key factors in households' financial lives have simultaneously come into critical alignment, producing challenges not faced before. The financial world has become more complex. At the same time, households have been forced to shoulder more individual responsibility for the outcomes of their financial choices, while the sheer volume of financial information and sources for financial information exploded. People living in the United States today have spent their entire lives in systems that promised them long-term financial benefits at some future point. Along with long-term employment came the reasonable likelihood that someone in a household would be a participant in a defined benefit pension plan. Social Security stood ready to provide a significant portion of a household's necessary retirement income; even non-working spouses qualified to receive a lifetime income benefit at retirement. Historically, if a household was prudent and saved, the choices were fairly straight forward and the risks clear and understandable.

No longer are these the circumstances for most households today. Defined benefit pension plans that promised a life time income after the conclusion of a career are nearly a thing of the past. Each year more defined benefit plans are being closed and new 
plan creation is nearly non-existent. Replacing the defined benefit retirement plans are defined contribution plans that shift the responsibility of saving and investing to the participant.

Defined benefit plans, as the name implies, defined the result (benefit), adding certainty to participants' future financial lives. Defined contribution plans, on the other hand, simply defined or specified the contribution, leaving the result in question. This shift of responsibility puts more emphasis on the willingness and abilities of the household to save for their own financial future.

Increasing longevity is another factor that is affecting the planning of household financial lives. In 1950, people around the world were expected to live to age 47.7 and, in North America to age 68.7. By 2010, life expectancies had risen to age 69.3 worldwide and to age 79 in North America (United Nations, 2012). People's life spans are expected to continue rising to age 75.6 globally and to age 83.2 in North America by year 2045 (United Nations, 2012). "Longevity risk" is a term heard more and more in discussions of household financial wellbeing. Longevity risk can be viewed from two perspectives: corporate entities (e.g. pension sponsors and insurance companies) and households. Corporate entities are concerned with funding liabilities arising from defined benefit pension payments as well as with insurance companies' potential exposure to annuity payment guarantees and long-term care benefits. Households are concerned about their longevity risk as well. Households wish to live long lives. However, if households live too long, their investment pool of resources may be exhausted in their later years, diminishing their level and standard of living. 
When the Social Security system was started in 1935 , life expectancy was 61.7 years of age and the earliest a participant could start receiving benefits was age 65 (Social Security Administration, 2013). Early in the history of the Social Security System there were over 40 people paying into the system for each recipient. By 2010, there were less than 3 workers per retiree. That ratio is projected to be less than 2 by 2030 (Social Security Administration, 2013). Increased longevity coupled with decreased fertility is producing an increasing problem for workers and the systems designed to support them in their old age.

Although Social Security benefits were never meant to be a sole source of retirement income, the benefits it paid out quickly evolved to become a significant source of income for most recipients and, in many cases, nearly their sole income source. The Social Security administration now warns participants that the system is underfunded and, unless the current funding and/or the payout path is changed, future benefits will have to be reduced. As it stands in 2013, the Social Security system will deplete the system's trust fund reserves by 2033 and will only be able to pay $77 \%$ of promised benefits after that time (Social Security Administration, 2013). Consequently, what had been sound foundations for retirement income, namely the defined benefit monthly income pension plans and the monthly Social Security check, have become uncertain for future retirees.

A male retiring at age 65 in year 2010 has a $60 \%$ chance of living to age 80 . A female age 65 retiring in year 2010 has a $71 \%$ chance of living until age 80 . If the two are a couple, the chance one of them survives until age 80 is $88 \%$. A 65 year old man has a $40 \%$ chance of reaching age 85 , whereas a woman has a $53 \%$ chance and one in a 
couple has a 72\% chance (Society of Actuaries, 2012). Age 90 is likely to be reached by $20 \%$ of men, $31 \%$ of women; $45 \%$ of the time, one of a couple age 65 will get there. Age 95 will be reached by $6 \%$ of men. For women, the chances are twice that at $12 \% ; 18 \%$ of the time, one person of a 65 year old couple will get there. Of couples age $65,4 \%$ of the time, one of them will survive to age 100; separately, the chances are $1 \%$ for men and $3 \%$ for women.

All these factors have left households to fend for themselves financially to some degree. Unfortunately, households have proven to not be well adapted to taking good care of themselves financially (Gathergood, 2012). The final part of the household financial resource pool, following defined benefit pensions and Social Security, is reliance on own initiatives and savings. Regrettably, given the confluence of a number of unfavorable financial conditions, households are facing personal saving challenges as never before. Unprecedented tumultuous stock markets and declining economic conditions challenge the current generation to make the best financial decisions and, by default, require them to wager their financial lives on the outcome.

One of the basic canons of economic theory is that if something has value, more is better. So, when the sheer volume of financial information ramped up dramatically it should have represented an improvement in financial decision-making. Internet accessibility has grown to the point that a significant majority of U.S. households have it available to obtain financial planning information. In 1984 (the first year the Census Bureau asked about computers), only $8.2 \%$ of households had computers at home. It was not until 1997 that the U.S. Census Bureau asked survey participants about having an 
internet connection in the home: $18 \%$ of households did (File, 2013). According to the U.S. Census Bureau, by the first year of the new millennium (2001), over $50 \%$ of households had both a computer at home and an internet connection (File, 2013). By 2011 , computers were in over three quarters of households $(75.6 \%) ; 7$ in ten $(71.7 \%)$ had an internet connection. The internet had become a viable source of all sorts of information, including financial information (File, 2013).

For the most part, the tsunami of information available has proven to be a mixed blessing (Carlson, 2003; Ho \& Tang, 2001). To make a rational decision, a household not only needs to have complete access to information, but also the ability to process the information. Sheer volume of data is not helpful; having a sufficient understanding of it all is what matters. It brings to mind the analogy "drinking from a fire hose." If someone is in dire need of water, a glass full is a very beneficial. On the other hand, drinking full force from a fire hose may not be helpful and can also cause all sorts of new additional problems. To some extent, the flood of financial information from the internet has been useful for consumers, but in some respects, it has also exacerbated the problem of information overload. Too much information can paralyze the decision making process. Some researchers have gone so far as to suggest that financial literacy is not a solution. Rather, having a paid financial professional assist in household financial decisions is a necessity. According to Willis (2008, p. 53), "nothing is inherently wrong with consumers or the modern, complex, and ever-changing financial services marketplace, but the interaction between the two creates welfare-impairing outcomes." 
A "perfect storm" is a situation where events that very rarely occur together do indeed happen at the same time, resulting in a dramatically magnified worst-case situation. The coming together of the pension plan devolution, the strain on Social Security's resources due to increased longevity and declining fertility rates, during a time that financial market volatility and substantial decline challenged the baby boom generations' financial plans, has generated the perfect storm in financial planning clients' lives and in the financial planning profession. "Perfect" in this case is not reason to celebrate, but instead cringe and make preparations.

Society has an obvious vested interest in the outcome of all these problems coming together. The better prepared individual households are to meet their financial challenges, the less likely they will be to rely on public financial resources. Households' financial success could also affect wealth distribution to future generations through intergenerational transfers. At this critical time, to have a successful financial future, it is more important than ever that households understand the financial situation they face, realize what they should do, and actually do what they plan to do.

A significant amount of research and resources has been dedicated to encouraging, designing, and evaluating the effectiveness of financial education programs for various age groups. Most of the measurements of the financial educational efforts have surrounded testing and improving financial literacy (i.e. the basics of the financial world such as the definitions and characteristics of financial products), and assessing whether or not households understood their financial situation and the actions they needed to take to secure to maintain or improve their financial wellbeing. Understanding households' level 
of financial literacy, including how the information is delivered and becomes usable is important if the financial planning system is to be improved. Hilgert, Hogarth and Beverly (2003) made a direct connection between possession of knowledge and taking actions that foster better outcomes. Do students that complete a financial education course gain financial literacy and, when tested at some later period did they retain the knowledge? Huston (2010) suggested that indeed financial literacy or knowledge is measurable. Given the importance placed on financial literacy education, this dissertation examines whether the sources of information that households use have differential effects on household financial behavior.

For households to make effective financial decisions, it is critical that the households understand the factors that affect their behavior and reduce the unknowns. Unknowns have always produced uncertainty and erratic behavior, many times not in the households' best interest. Better understanding of circumstances in any situation can reduce emotional responses. Information alone is not enough. According to Hertzum et al. (2002), for information to have influence on people, the source must be trusted. Therefore, it is not just what sources are available, but how much people trust the source that will affect what is used. Bandura (2010) suggested that for people to be motivated to take action, they must believe that the action will influence the outcome. So, taking comments of both Hertzum et al. (2002) and Bandura (2010) into consideration suggests that before action occurs, the source of information must not only must be trusted but also people must think acting on the information will have some positive effect as well. 
Lin and Lee (2004) examined information sources available for people to use and who might use which sources. Specifically, the authors used the 2000 to 2001 Macro Monitor data set to consider five information sources: the internet, friends/family, literature, media and professional services. In contrast, this dissertation examines beyond the basic relationship between information source and household financial behavior to also examine whether a financial planner's involvement contributes to the result. Specifically, does using a financial planner increase a household's probability of acting consistently with their stated risk tolerance level? It is true that households might utilize financial planners for different reasons. They could use a planner if they do not have adequate knowledge about investments and need additional education. They could also use a planner if they possess adequate knowledge, understand the importance, and either do not have the time or do not have the inclination to take on the task. The reason households use a financial planner should not affect the result if they do use one.

Whether or not households use a financial planner, the financial world they live in is complex. Investment assets are subject to risks. Fluctuations in value and returns over time are necessary to produce investment risk premiums. If all investments had the same investment risk profile, all would eventually gravitate to realize the same rate of return over time. Investment risk premiums are the returns in excess of what a household can earn by allocating money to a risk-free financial product, for example, a savings account at a bank or a short term treasury bill. Today's investment markets offer an array of risk associated with financial products and, as such, are complex to navigate for people who do not have substantial financial knowledge. 
Households seek professional financial services because financial professionals are more knowledgeable than they are (Larson, 1993). Lusardi and Mitchell (2011) concluded that households with more financial knowledge were more likely to plan for retirement and to succeed in this planning. They also found that those who did plan for retirement were more likely to rely on formal methods such as financial experts. If financial knowledge increases rationality in investing, using financial professionals should increase the likelihood of being consistent in financial attitude and financial behavior. Kramer and Lensink (2012) conclude that people who use planners realize better returns and take less risk.

Households can obtain financial information from a variety of sources. It is interesting to consider the possible relationships between information source and action. With the evolution of the internet and its wealth of information, it is entirely possible that people might suffer from data overload and struggle to sort it all out. Financial planners as well as other information sources face the challenge of not just getting data but executable knowledge in the hands and minds of individuals. Do households who use financial planners benefit more as compared with using other information sources? Professionals from all walks of life experience similar frustrations in having well thought out plans executed by their clients. Medical doctors advise patients to have a healthier diet, exercise more and take other precautions that are in their best interest. Attorneys advise clients on actions they should take to better arrange their legal affairs. Financial planners give clients advice on how to best manage their financial affairs. Common among these and other sorts of professionals is the benign neglect of advice after it has 
been provided. Patients and clients alike continue not taking action on the advice they received, and, ironically, may have paid for, many times suffering the consequences of their inaction at critical times. The patient could have eaten better and taken their medication, but instead ends up in the hospital emergency room with a dire health condition that could have been prevented. The attorney's client's estate suffers unnecessary taxes and the financial planner's client ends up in retirement with inadequate resources, all of which might have been avoided.

A major area of concern in financial planning is the households' acceptance of a necessary level of risk to accomplish their goals. There are many ways to determine an appropriate risk level. This dissertation reviews the methodology of determining a households' risk tolerance, measures a portfolio's risk level and examines whether individual households act consistently with their own self-reported risk tolerance when making savings and investment decisions.

To realize the value of advice, the advice should be acted upon by developing and executing a plan. Granted, households might incorrectly assess their risk tolerance and a portfolio's risk might be inaccurately evaluated - but that is not the focus of this dissertation. Regardless of accuracy in personal risk assessment, if patients or clients are to benefit from the advice that they receive from professionals, they must act on that advice.

There are different perspectives on the role that bias may play in decision-making. Savage (1954) suggested that people have biases that make their choices less than optimal. Kahneman and Tversky (1979) suggest that individual biases are important 
parts of a person's risk profile. Bluethgen, et al (2008) suggest that an individual's behavioral risk tolerance bias may be an important part of an individual's character such that financial planners should not "tinker" with it.

If financial planners wish to be effective, they need to know how clients perceive the advice that they give and how clients can be motivated to act on that advice. Only after knowing these things can they try to make a real difference in clients' lives.

Households have had plenty of reasons to question the rationale of their investment choices, even when working with a financial planner. Throughout history, investment markets have proven to be uncertain and recent history has been no exception. The following news and events occurred during the 1998-2010 time period when the SCF data used for this study were collected. Since the late 1990s, the market has gone through several cycles. The 2000 "Tech Bubble Bust" followed quickly after the "Asian Contagion" of the late 1990s. For one of few times in history, The New York Stock Exchange closed for several days after the terrorist attack of 9-11-2001. The year 2001 also brought the historic scandals associated with the failure of two of the world's largest public companies, Enron and WorldCom. Government regulators responded with the passage of the Sarbanes Oxley legislation in 2002. In 2003, investment markets trembled when the U.S. invaded Iraq. After a brief period of relative calm, stock market indexes reached record highs in the fall of 2007 only to be knocked down by the "Sub-Prime" loan debacle and the "Housing Bubble Bust". In 2008, once respected Wall Street financier Bernard Madoff was arrested for having perpetrated the biggest Ponzi scheme ever; the economy entered into the "Great Recession" and a "bear" market began that 
would not end until the spring of 2009. By that time, the equity markets had lost half their value. It would be the spring of 2013, more than 5 years later, before the markets would return to old highs again. Like a deer caught in the glare of a car's headlights, people looked for a sign that it was safe to invest again. Investment information had again become an important resource for troubled households.

During times of market and economic turmoil, households many times may react in ways inconsistent with their long-term stated financial goals and risk tolerance. Overreacting to short-term events can be both financially and psychologically disruptive and stressful, negatively affecting households' long-term financial success. In addition, a short term reactive mode may produce unnecessary realization of portfolio losses, and impose opportunity cost in future time periods. Investment behavior directly affects household wealth accumulation (Keister, 2000). Therefore, it is important that households allocate their savings in a manner that is consistent with their intended goals.

Households may have varying motivations for seeking information. Sometimes households are looking for advice or information because of the lack of knowledge, other times households are simply looking to validate conclusions they may have already come to or avoid disasters that might occur by pursing obviously wrong courses of action. Hackethal, Haliassos and Jappelli (2012) explain that higher opportunity cost lead wealthier and potentially better informed households to use financial planners even if they might be adequately informed to make their own financial plans.

For several decades, the Dalbar organization has annually published information contrasting the performance of stock mutual funds and investor returns. Year in and year 
out, the stock market has handily bested what individual investors have experienced in results. The most recent study, published in 2013, showed investors trailed stock mutual returns by an average of 3.96\%; from 1992 to 2011 the average stock mutual fund made $8.2 \%$, whereas the average stock mutual fund investor made only 3.5\%. Dalbar (2013) suggests this consistent underperformance is at least partially caused by emotions like fear and greed. How well do households understand investment characteristics, investment risk and fluctuation? Households with greater financial sophistication tend to invest more efficiently (Calvert, Campbell, \& Sodini, 2007). If that is the case, the challenge is to add to households' financial sophistication. Kimball and Shumway (2010) says that with more sophistication, investors would behave the way financial economists believe is in their best interest.

Clients pay financial planners to help them determine and articulate their goals and risk tolerance. If financial planners are to justify their existence in clients' financial lives, these two outcomes are minimal expectations for a professional relationship. Financial planners are expected to operate commensurate with a client's goals and risk tolerance. When and only when a common understanding of these important factors is reached can the team of client and planner implement any recommendations. Negative consequences can arise when households allow short term changes in economic or market conditions to sway application of well thought out strategies. If professional financial planners are to add value to households' financial lives, helping them weather the storms of uncertain conditions is a critical activity. 
This study uses data from the 1998-2010 Survey of Consumer Finances (SCF) to investigate whether use of a financial planner has a significant positive effect on observed consistency between reported risk attitude and portfolio allocation during each survey year. Comparisons will be made to examine whether households who use a financial planner are more likely to act in a manner consistent in their reported risk tolerance and equity/ investment asset ownership in their portfolio as compared with those who rely on themselves, their social network or media for information when making decisions about saving and investments. Does working with a financial planner increase the likelihood of maintaining consistency in risk attitude and behavior?

Households have various sources of financial information available to use in making financial decisions, financial planners being one of them. This dissertation investigates who uses what sources of financial information and whether there is a difference in outcomes depending on which source is used. In order to determine if there is a difference or effect in using a particular source or compared between the sources, this study evaluates consistency between households' self-perceived risk tolerance and the risk taken in the households' actual investment portfolio. Each source of financial information is subjected to a marginal cost-benefit analysis, in that a household will only search and utilize information up and until the point where the marginal benefit equals or the marginal cost. Implicit in the use of a particular information source is a relative cost benefit analysis the household has made. The information source used should not only benefit the household beyond its cost, but also be relatively superior in the cost benefit 
analysis as compared with other information sources. If there is a difference in the marginal benefit of different sources, the difference will affect which source gets utilized.

Bucher-Koenen and Koenen (2011) assert that it would be impossible or at least not economical for a household to collect the required information to make financial planning decisions themselves, therefore financial planners have ensured a role. This study will evaluate the contribution of financial planning services in households' financial life. For households to avoid mistakes that can hinder wealth accumulation, it is critical for them to save and invest in a manner consistent with their financial risk tolerance. If a household can tolerate more financial risks than what is reflected in his/her portfolio allocation, the household may incur opportunity costs for taking less risk. If a household's portfolio is riskier than what the household can tolerate, the household may experience undesirable volatility in investment returns and incur unnecessary investment losses by selling at inopportune times. Findings of this study will provide implications regarding the need for consumer education in financial risks and the need to improve planners' understanding and measurement of households' financial risk tolerance.

\subsection{Contributions of the Study}

This dissertation provides a comprehensive review of research on the concepts and measures, both objective and subjective, of risk tolerance, the effect of subjective risk tolerance on objective risk tolerance, factors that determine household risk tolerance, and 
the effect of using various sources of information, including a financial planner, on risk tolerance.

This dissertation is the first study to evaluate the effect of sources of information on households' consistency between their risk attitude when making savings and investment decisions and risk behavior exhibited when they actually do save and invest. This dissertation seeks to understand the effects of using various sources of information on households' construction of their portfolios. Specifically, it examines households' self-stated risk tolerance and investigates whether households' current portfolio is consistent with their desired level of risk. This study examines whether one source of information is relatively more effective than other sources in helping households act consistently with their self-stated risk tolerance and, if so, how.

This dissertation uses Age-Period-Cohort (APC) analysis to decompose the effect of age on the consistency of households' financial risk attitude and investment behavior. Previous studies that looked at factors that affect household financial risk attitude or investment behavior have typically included age as a factor. The effect of age is more complex than the mere observed difference between respondents' ages. This observed difference could have arisen from a respondent's aging process, the difference between the respondent cohorts, and the effect of the periods that the respondents were in. Simply including age as one variable independent of the cohort and the period effect cannot reveal the full picture of the effect of age. The APC analysis adopted in this dissertation takes all three factors together into account and improves the understanding of agerelated effects on portfolio design. 
This dissertation is the first study to look at the confluence between households' self-stated risk tolerance and the risk actually taken in their portfolios. The implications of this work apply to financial planning as well as other disciplines. If household action is consistent, which sources of information are the most effective in promoting that consistency? Should household action prove to be inconsistent, then we know it is a problem and can seek to address it.

\subsection{Organization}

This dissertation is organized as follows. The next chapter reviews the relevant literature on the relationship between risk and risk tolerance. Objective and subjective empirical measures of households' risk tolerance and factors that affect their current willingness and ability to accept risk and how and why it may change are discussed. Chapter 3 discusses the conceptual model of this dissertation: information search and expected utility theory. The chapter also proposes hypotheses based on the conceptual model. Chapter 4 introduces the data used for the analyses and justifies the empirical methodologies adopted. Chapter 5 discusses the results, including descriptions of the sample characteristics, uncontrolled relationship between sources of information, specifically, use of financial planners, and the consistency between household financial attitude and their financial behavior. The last chapter summarizes the findings and discusses implications of the findings. 


\section{CHAPTER II}

\section{REVIEW OF LITERATURE}

\subsection{Concepts of Risk and Risk Tolerance}

Pratt (1964) and Arrow (1965) developed two different yet related concepts of people's risk aversion when making decisions under risk. Under the assumption that wealth provides utility, Pratt (1964)'s absolute risk aversion was expressed as $\frac{-u^{\prime \prime}(x)}{u^{\prime}(x)}$ ( $x$ represents wealth). He showed that people that are more risk averse would invest a smaller portion of wealth in a risky asset. Arrow (1965) developed the concept of relative risk aversion, which was expressed as $\frac{-x u^{\prime \prime}(x)}{u^{\prime}(x)}(x$ represents wealth). He suggested if risk aversion decreases with wealth, people with more wealth would invest a larger portion of wealth in risky assets.

Risk aversion is how much households avoid risks. Risk tolerance, on the contrary, is how much households accept risks. Conceptually, risk tolerance is the opposite of risk aversion. Barsky et al. (1997) and Gron and Winton (2001) defined risk tolerance as the inverse of risk aversion. Grable (2000) defined risk tolerance as the most uncertainty a household would take when making a financial decision. 


\subsection{Empirical Measures of Risk Tolerance}

Risk tolerance is not directly observable and, therefore, is challenging to measure (Yao \& Curl, 2011). Two methods have been used in past research to measure risk tolerance: assessing risky investment behavior (objective measure) and using surveys to ask questions related to risk tolerance (subjective measure). This section of the literature review includes two parts: a description of objective and subjective measures of risk tolerance, and a discussion of the effect of subjective risk tolerance on objective risk tolerance.

\subsubsection{Objective Measures of Risk Tolerance}

Analyzing data collected from conducting a survey among 2,506 customers of a nation-wide retail brokerage firm, Cohn, Lewellen, Lease, and Schlarbaum (1975) defined risk tolerance as two ratios: risky assets to total assets and risky assets to total financial wealth. Friend and Blume (1975) analyzed cross-sectional data from the 1962 and 1963 Federal Reserve Board Surveys of the Financial Characteristics of Consumers and Changes in Family Finances to investigate consumer investment risk tolerance. The authors used the ratio of risky assets to net worth as the measure of risk tolerance. Risky assets included common and preferred stocks, equity in unincorporated businesses, investment real estate assets, and miscellaneous assets (such as patents, etc.). Homes were treated in three different ways: 1) not as risky assets; 2) home equity being part of risky assets; and 3) gross market value being part of risky assets. Net worth was found to have little value in explaining household relative risk aversion. Morin and Suarez (1983) 
studied the demand of risky assets of Canadian households, using the 1970 Survey of Consumer Finances conducted by Statistics Canada. The authors used the ratio of risky assets (defined as the sum of stocks, bonds, mutual funds, real estate other than owner occupied home, and equity in own business, and loans) divided by wealth (defined as net worth, the difference between total asset holdings and total indebtedness) as a measure of risk tolerance.

Riley and Chow (1992) developed an Arrow-Pratt relative risk aversion index, using the 1984 Survey of Income and Program Participation. The authors computed the ratio of risky assets to total wealth and used the difference between one and the numerical value of the ratio as the relative risk aversion value. Guiso, Jappelli and Terlizzese (1996) used cross-sectional data from the 1989 Bank of Italy Survey of Household Income and Wealth to analyze risk tolerance. The ratio of risky assets to total financial wealth was adopted as the measure of risk tolerance. The authors used two separate definitions of risky assets. The narrow definition of risky assets included long-term government bonds, corporate bonds, investment fund units and equities. The broad definition of risky assets included savings accounts, postal bonds, government paper, corporate bonds, investment fund units and equities. Using cross-sectional data from the 1989 Survey of Consumer Finances, Schooley and Worden (1996) examined the ratio of risky assets to total wealth. Both risky assets and total wealth included human capital. Risky assets included real estate held for investment purposes, the market value of mutual funds, corporate stock, and precious metals, the face value of all corporate and government bonds, amounts 
accumulated in all other pension accounts, loans to friends/relatives, and an estimate of human capital.

Bajtelsmit and VanDerhei (1997) collected data from a sample of 20,000 management employees in a large employer to examine the relationship between risk aversion and pension investment choices. The authors defined risk tolerance as the ratio of equities to total 401(k) wealth. Hinz, McCarthy and Turner (1997) used the 1990 survey of participants in the federal government's Thrift Savings Plan to examine the risk tolerance of men and women. Participants' portfolio investment decisions in the federal government's Thrift Savings Plan (TSP) was defined as the measure of risk tolerance. Jianakoplos and Bernasek (1998) examined gender difference in risk aversion, which was defined as the ratio of risky assets to wealth. Risky assets included balances in IRAs not invested in bank deposits, stock holdings minus outstanding margin loans, bonds, trust assets, equity in real estate except residential housing, businesses equity, and the net value of miscellaneous assets. Housing equity and human capital were excluded from total wealth. Using data from 1992 and 1995 Survey of Consumer Finances, Sundén and Surette (1998) examined gender difference in risk tolerance, which was measured as the asset allocation in retirement plans: mostly in stocks, mostly in bonds, and split between stocks and bonds.

Badu, Daniels and Salandro (1999) used the 1992 Survey of Consumer Finances to examine the race difference in risk tolerance. Risky assets divided by net worth was used as the measure of risk tolerance. The authors used three measures of risky assets: 1) common stock, real estate other than primary and secondary residents, business 
investments, mutual fund investments and quasi-liquid retirement funds; and 2) common stock, real estate other than primary and secondary residents, business investments, and mutual fund investments; and 3) common stock, real estate other than primary and secondary residents, and business investments. Bajtelsmit, Bernasek and Jianakoplos (1999) used the 1989 Survey of Consumer Finances to examine gender differences in risk tolerance, measured by the ratio of individual holdings of risky assets in defined contribution pension assets to total household wealth. Risky assets included balances in IRAs not invested in bank deposits, stock holdings minus outstanding margin loans, bonds, trust assets, equity in real estate except residential housing, businesses equity, and the net value of miscellaneous assets.

Bernasek and Shwiff (2001) collected data from a small sample of 270 individuals at five universities in Colorado and studied the percent of defined contribution pension assets invested in stocks. Females were found to be less risk tolerant than males. The results also indicated that among couples, males were more willing to take risks than their spouse or partner but females were less willing to do so. Having a professional degree or $\mathrm{PhD}$ had a negative effect on risk tolerance. Those who used a financial planner invested a higher percentage of retirement assets in stocks.

Using the 2001 Survey of Consumer Finances data, Chang, DeVaney and Chiremba (2004) examined determinants of both objective and subjective risk tolerance. Objective risk tolerance was measured as the ratio of risky assets to net worth. Risky assets included mutual funds, stocks, bonds, retirement accounts, other financial assets, and real estate but not owner-occupied home. Risk tolerance first increased and then 
decreased as age increased. Education positively affected risk tolerance. Workers, both self-employed and working for others, were more risk tolerant than those who were not working. White respondents were more risk tolerant than non-whites. Dwyer, Gilkeson and List (2002) used data from a national survey of nearly 2,000 mutual fund investors to investigate gender difference in mutual fund investment decisions. Findings showed that females were less risk tolerant than males in making mutual fund investment decisions.

Jianakoplos and Bernasek (2006) used the 1989, 1995 and 2001 Survey of Consumer Finances data to study differences in risk tolerance by age, generation and birth cohort. The authors used two measures of financial risk tolerance, one of which was the ratio of risky assets to investment wealth (defined as risky assets plus risk-free assets). Their definition of risk-free assets included dollar balances in checking, savings, money market, and brokerage call accounts, certificates of deposit, U.S. savings bonds, individual retirement accounts (IRAs) invested in CDs, and the cash value of life insurance policies. Their measure of risky assets included the dollar value of IRAs not invested in CDs, bonds, stocks, mutual funds, defined-contribution pensions less loans, trust and annuity assets, net value of businesses, net value of investment real estate, and the net value of other assets such as oil and gas leases, futures contracts, less outstanding credit card balances, lines of credit, and other miscellaneous debts. Value of residential housing, human capital, and expected defined-benefit pensions were excluded from the definition of investment wealth. Findings showed that older respondents had a smaller ratio of risky assets to investment wealth. However, the baby boomer generation held a larger proportion of investment wealth in risky assets than Generation X members. 
Using the same two measures of financial risk tolerance, Jianakoplos and Bernasek (2008) used the 2004 Survey of Consumer Finances and investigated household financial risk taking when the wife earned more. Regardless of who was the primary earner, the ratio of risky assets to investment wealth did not vary significantly. Objective risk tolerance was found to increase with wealth, home ownership and ownership of defined benefit pensions. Hispanics were found to have a higher level of objective risk tolerance than white households.

The objective measures of risk tolerance assume that people are rational, well informed and unconstrained. These assumptions do not always hold. People who face financial constraints may not have money to invest. Basic economic demand tenets assume that the consumer is both willing and able to invest. However, if and when they do, they may be willing to take some risks. Others may be in a lifecycle stage where holding investment assets may not be a good idea. For example, a graduate student with a negative net worth might not favor owning investment assets since it would require leveraging to invest in them and leveraging amplifies risk.

In theory, risk aversion measures the concavity of a household's utility function and can be mathematically calculated to be a very precise number if the household's utility function is known. However, in reality, there is no exact instrument that measures the absolute value of a household's risk tolerance. Given data limitations, existing objective measures of risk tolerance simply involve ratios of some measure of risky assets to a measure of total assets. Results may imply a more exact measurement of risk tolerance than what it may be in reality. 
Moreover, studies that used the Survey of Consumer Finances to construct estimates of these ratios needed to make some assumptions and the values of the ratios, therefore, are not exact in this case. For example, Bergstresser and Poterba (2004) discussed that they had to assume that assets in accounts with "mostly or all in stock" are all equity and assets in "split" accounts were allocated half to equities. Given all prior discussions, investment behavior in and of itself might not be a good risk tolerance measurement for all groups of people.

\subsubsection{Subjective Measures of Risk Tolerance}

McInish, Ramaswami and Srivastava (1993) used the 1987 data collected from a financial diary kept by a sample of 3,079 households to examine the relationship between risk tolerance and two aspects of household economic well-being: income and net worth. Respondents were given four investment alternatives in increasing order of riskiness. Risk aversion was determined by respondents' ranking of these four alternatives. Both income and net worth were found to positively affect risk tolerance.

Based on economic theory, Barsky et al. (1997) developed an index of risk tolerance by using the hypothetical income gamble questions in the Health and Retirement Study. Risk tolerance was found to be positively related to risky behaviors such as holding stocks and failing to have insurance. Schubert et al. (1999) assessed subjective risk tolerance by asking investment and insurance decisions and abstract gambling decisions. No statistically significant difference in risk tolerance was found between males and females. The authors suggested that gender-specific differences 
found in prior research may be due to gender differences in opportunity rather than in risk tolerance.

Halek and Eisenhauer (2001) used life insurance information in the 1992 Health and Retirement Study data to estimate the Pratt-Arrow relative risk aversion for 2,376 households. Age was found to be positively related to risk tolerance until age 65 when risk tolerance decreased with age. Net worth, including housing equity, negatively affected risk tolerance. The magnitude of such effect decreased as net worth increased. Other findings included: males were more risk tolerant than females; blacks and Hispanics were more risk tolerant than whites; and marriage and self-employment decreased risk tolerance.

Using the expected utility theory, Hartog, Ferrer-I-Carbonell and Jonker (2002) calculated individuals' risk aversion. The authors asked survey respondents for the amount of money they were willing to pay to participate in a certain lottery. From the answers, the authors derived the Arrow-Pratt measure of risk aversion. The findings showed that females were less risk tolerant than males and self-employed individuals were more risk tolerant than employees. Education, income and wealth were found to have a positive effect on risk tolerance. Chaulk, Johnson and Bulcroft (2003) used family development and prospect theory to predict variability in respondents' subjective risk tolerance. The authors conducted a survey of volunteer faculty, staff, and students who were married or had children and were living in a university housing complex. The hypotheses tested involved employment risk tolerance and investment risk tolerance. One disadvantage of this portion of their study was that it was a convenience sample 
instead of a random sample. Therefore, the results from analyzing this sample could not be extrapolated to the total population in general. The authors also used the Survey of Consumer Finances data to test the validity of their hypotheses related to investment risk tolerance. Findings showed that investment risk tolerance increased with income and decreased with age and presence of children. Males were found to be more risk tolerant than females. Young males were more risk tolerant than young females; however, as they age males' risk tolerance tended to decrease and females' tended to increase slightly. For younger respondents, marriage reduced risk tolerance; but for older respondents, marriage slightly increased risk tolerance.

Hallahan, Faff and McKenzie (2003) developed a psychometric measure of subjective risk tolerance and examined factors that affected such risk tolerance. Risk tolerance increased with income until the top income bracket, where risk tolerance decreased. Demographic variables such as education, marital status and presence of dependents were not found to have a significant effect on risk tolerance. Using the same data and the same psychometric measure of subjective risk tolerance, Hallahan, Faff and McKenzie (2004) studied individual financial risk tolerance. Risk tolerance decreased with age and number of financial dependents. Higher levels of education were associated with higher levels of risk tolerance. Females were less risk tolerant than males. Married respondents were less risk tolerant than unmarried respondents. Respondent's income, household income, and respondent's net assets were found to be positively related to risk tolerance. 
Using the 1989, 1995, and 2001 Survey of Consumer Finances data, Jianakoplos and Bernasek (2006) studied differences in risk tolerance by age, generation and birth cohort. The authors used two measures of financial risk tolerance and willingness to take financial risks was one of them. Findings showed that older respondents were less likely to be willing to take financial risks. However, Baby Boomers were found to be more willing to take financial risks than individuals of Generation X. Using the same subjective measure of financial risk tolerance, Jianakoplos and Bernasek (2008) studied household financial risk tolerance when the wife earned more. Income and wealth positively affected risk tolerance. Risk tolerance did not vary based on who was the primary earner, except for households where the husband was five or more years older than the wife. The preferences of younger wives led to less financial risk tolerance. Hispanics were found to be less willing to take financial risks than white households. Kimball, Sahm and Shapiro (2008) developed a cardinal proxy for risk tolerance by using the hypothetical income gambles in the Health and Retirement Study. The risk tolerance proxy was found to be significantly related to household asset allocation choices. The authors also found within-individual differences in risk tolerance but treated these differences as measurement errors. Grable, McGill and Britt (2009) adopted the 12-item assessment instrument developed by Grable and Lytton (1999) to measure risk tolerance and to study the age effect on risk tolerance and estimation bias. The authors collected data from a convenience sample of 466 residents in one of three municipalities within one Midwestern state in the United States. Findings showed that older working adults were more likely to underestimate their risk tolerance than younger 
working adults and married respondents were more likely to underestimate their financial risk tolerance than singles.

Van de Venter, Michayluk and Davey (2012) analyzed the 2002-2006 Smart Investor survey longitudinal dataset to study the changes in risk tolerance over time. The measurement of psychometric financial risk tolerance was developed by an Australianbased risk-profiling firm. The results showed that respondents' financial risk tolerance increased when the individual terminated the services of a financial planner. Decrease in household size decreased respondents' financial risk tolerance.

At least two American national surveys include an assessment of respondents' risk tolerance. The Survey of Consumer Finances (SCF) includes a risk tolerance question that asks the respondents to report the amount of financial risk they are willing to take when making decisions regarding savings or investments. The Health and Retirement Study (HRS) uses an income gamble question to assess risk tolerance. The question asks the respondents whether they would take a new job based on several combinations of probabilities and sizes of income changes, assuming that they were the only income earner in their household and they had to relocate due to health reasons. Some smaller surveys asked respondents about their investment choices. For example, Hartog, et al. (2002) asked respondents the price they were willing to pay to play a lottery. Other surveys asked a combination of investment choices and subjective perceptions. For instance, Grable and Lytton (1999) developed a 12-item assessment instrument to measure risk tolerance; Grable (2000) used a 20-item financial risk-tolerance assessment instrument to assess individuals' risk tolerance. 
In their work in 1997, Barsky et al. questioned whether respondents actually understood risk tolerance questions and were able and willing to provide accurate answers. However, they also pointed out that the survey method does provide important information about respondents' attitude toward risks based on past experience with risky

endeavors. Grable and Lytton (2001) asserted that the SCF measure of risk tolerance has some weaknesses and while not fully representing risk tolerance, may show respondents feelings colored by their past experience. Although the SCF risk question is not designed to directly reflect economic theories, it is part of a national survey that has been widely used for several decades. The SCF risk tolerance question is directly related to investment choices.

There has been a vast amount of literature on risk tolerance, either objective or subjective. However, to the best of my knowledge, none has assigned a level of subjective risk tolerance to a specific level or value of objective risk tolerance. This study is the first attempt to make this connection.

\subsubsection{The Effect of Subjective Risk Tolerance on Objective Risk}

\section{Tolerance}

Among past research that examined the effect of subjective risk tolerance on objective risk tolerance, most used the Survey of Consumer Finances (SCF) data, some used the Health and Retirement Study (HRS) data, and others collected their own data. Embrey and Fox (1997) used a sample of one person households from the 1995 SCF to examine households' objective risk tolerance. Two separate ratios were used as the 
measures of objective risk tolerance: 1) ratio of stock investments to financial assets; and 2) ratio of stock investments to total assets (including housing and business investments). Subjective risk tolerance (attitudes toward investment risks) was found to have positively affected men's objective risk tolerance.

Using the 2001 Survey of Consumer Finances data, Chang, DeVaney and Chiremba (2004) examined the effect of subjective risk tolerance on objective risk tolerance. The subjective risk tolerance measure was based on respondents' risk and expected return answers to the SCF risk tolerance question. Objective risk tolerance was measured as a ratio of risky assets (including mutual funds, stocks, bonds, retirement accounts, other financial assets, real estate assets other than primacy residence) to net worth. Results indicated that being willing to take at least some financial risks positively affected the ratio of risky assets to net worth. Fan and Xiao (2006) also used the SCF data and examined the effect of risk attitude on stock ownership. The authors found that willingness to tolerate financial risks positively affected American households'stock ownership.

Using the first wave of the Health and Retirement Survey (1992 HRS), Hariharan, Chapman and Domian (2000) assessed risky behavior in investments, including the proportion of financial assets invested in risk-free securities, stocks, and bonds, and the fraction of risky assets devoted to bonds. The results indicated that subjective risk tolerance was inversely related to an individual's probability to purchase risk-free assets; however, subjective risk tolerance did not affect the composition of an individual's portfolio of risky assets. Kimball, et al. (2008) found that a risk tolerance proxy 
calculated using the hypothetical income gambles in the Health and Retirement Study, significantly affected household asset allocation decisions.

After analyzing data collected from 1,740 respondents who participated in an internet survey, Grable et al. (2009) concluded that self-classified risk tolerance was significantly associated to proportion of equity holdings in their portfolio. Although the sample size was not small, there may be systematic differences between the people who participated in the Internet survey and those who chose not to participate. Interpretation of this result needs caution.

So far, the research on the effect of subjective risk tolerance on objective risk tolerance measures that are related to portfolio allocation indicates that households do take their subjective risk tolerance into consideration when making investment decisions.

\subsubsection{Determinants of Risk tolerance}

Previous research has found that factors that affect risk tolerance include demographic and economic characteristics and expectations of the future. Grable (2000) examined factors that affected the probability of households having a certain level of risk tolerance. He found that age, education, income, amount of financial knowledge, and economic expectations had positive effects on respondents' risk tolerance. Being a male and being married were also positively associated with a higher level of risk tolerance, which was also confirmed by findings in Yao and Hanna (2005). However, Gilliam, Goetz and Hampton (2008) found that husband's risk tolerance decreased with wife's education. 
Coleman (2003) found Whites held a higher percentage of risky assets in their net worth than Hispanics. The author also found that age and education had a positive effect and household size had a negative effect on the likelihood of being willing to take some financial risks. However, using the HRS measure of risk tolerance, Halek and Eisenhauer (2001) found that Blacks and Hispanics were more risk tolerant than Whites. The difference in the findings on the racial/ethnic effect on risk tolerance of these two studies may be related to how risk tolerance was measured. Coleman (2003) and Yao, Gutter and Hanna (2005) concluded that Blacks and Hispanics were less likely to be willing to take financial risks; however, among those who take some risks, Blacks and Hispanics were more willing to take substantial financial risks than Whites. It is likely that the HRS measure of risk tolerance coincides with the substantial financial risk tolerance measured in the SCF data. Given a small percentage of respondents who were willing to take substantial risks and a large percentage of respondents who were not willing to take some risks, it is reasonable that Blacks and Hispanics have a lower proportion of risky assets in their net worth on average.

Yao et al. (2005) found that income and wealth had a positive relationship with risk tolerance, and that self-employed respondents were more risk tolerant than employees. The authors also found that respondents with a good self-perceived health were more risk tolerant than those who reported fair or poor health. However, Halek and Eisenhauer (2001) concluded that self-employment decreased risk tolerance and that risk tolerance decreases with wealth until it reaches a certain level and then increases. Again, the differences in findings may be related to the measures of risk tolerance. Grable (2000) 
found that respondents who had more positive economic expectations were more risk tolerant than those with expectations that were not as positive.

All of the aforementioned studies suggest that subjective risk tolerance is a disposition that is somewhat malleable, given expectations as well as personal characteristics.

\subsubsection{Effect of Consulting a Financial Planner on Risk Tolerance:} Attitudes and Behavior

As households are being asked to be responsible for the outcomes of their financial planning efforts, some are turning to professional financial planners for advice. Are the planners up to the task? Several studies have attempted to provide answers to this question.

On one hand, research found that it was likely that households reach out to financial planners for information and assistance. Bae and Sandager (1997) discovered that households wanted advice from financial planners on investments and retirement planning. Chang (2005) said that financial information is complex, requires significant resources to acquire and then sort what is relevant and accurate from what is not, making it likely households would seek help from financial planners.

On the other hand, research also found that financial planners were qualified to provide accurate information and assistance to households. Nofsinger and Varma (2007) conducted a survey of more than 100 financial planners on their attitudes and behaviors including their risk tolerance. They found financial planners to have significant 
education, training, and experience that should help them assist their clients in the financial arena. Financial planners were found to be more analytical than the general public, with a significant intuitive bend that helps them in working with clients. Results showed that being analytical helped make the planner more financially patient than clients were, which could help weather inevitable bad markets. The planers also understood how choices affect households' financial wellbeing over time, an attribute that was important to providing good financial advice to clients.

Past research concluded that the information and assistance provided by financial planners helped households. Bluethgen et al. (2008) suggest that financial planning services have a significant influence on household behavior and enhance portfolio diversification. Bluethgen et al. (2008) point out that planners can provide investors with net utility by taking advantage of economies of scale in acquiring desirable knowledge and helping investors avoid material errors. Planners add discipline to investors' processes and help maintain a stable asset allocation over time (Bluethgen, et al. 2008).

Bluethgen, et al. (2008) tried to reconcile what Savage (1954) suggested about investor's rational choice biases with what Kahneman and Tversky (1979) suggested were important parts of investor's risk profile. Bluethgen, et al. (2008) suggested that an investor's behavioral risk tolerance bias may be an important part of the household's investment character and that a financial planner should not try to change it. Whether an investor has accurately assessed their appropriate "Savage" (see above) level of rational risk tolerance or not, it is the risk tolerance they have proclaimed and it is the one to be used as determinative in this dissertation. 
Bucher-Koenen and Keonen (2011) created an analytical model with several interesting results; namely that more financial literate households were more likely to seek financial advice because they were more likely to understand the advice and the advice they get would be better. The advice would be of better quality because the financial planner knew they understood and knew they were more likely to get several opinions - forcing a competitive spirit in the planners to do their best. Bhattacharya et al. (2011) results, however, implied that accurate, unbiased financial information is not enough to entice users of information to take action.

In summary, researchers have endeavored to model and quantify household decision making under uncertainty. It is a challenging task since risk tolerance is not directly observable. One either has to observe behavior or administer survey questions regarding investment preferences. Most researchers have used various ratios of risky assets to total assets to attempt to assess objective risk tolerance. Empirical measures of risky assets and total assets vary somewhat from researcher to researcher, but all measures attempt to quantify the concept that some investments expose the households to greater potential for loss than do other investments. Despite variation in measurement, however there does seem to be evidence that household choice of investment mix is related to their reported subjective risk tolerance obtained via survey measures. 


\section{CHAPTER III}

\section{CONCEPTUAL MODEL AND HYPOTHESES}

\subsection{A Conceptual Model}

Households constantly face decisions. In order to make a decision, some information about the available alternatives is needed. This section provides a conceptual model to explain how rational households make a savings and/or investment decision and how they decide which source of information to utilize.

\subsubsection{Expected Utility}

Economic theories suggest that people seek to maximize their utility. Expected utility theory is an often-used normative rule in decision-making under risk. Based on this theory, an individual will choose the decision that maximizes his or her expected utility.

According to Magrabi et al. (1991), neoclassical economic theory assumes that households are rational utility maximizers who have complete and accurate information. They are cognitively unconstrained so that they are able to process the information and independently make a rational decision that maximizes their utility. Households are also assumed to be consistent and that their taste and preferences are stable over time. Moreover, it is assumed that utility is measurable and homogeneous. 
Based on the above discussion, households must have complete and accurate information necessary to make rational decisions that maximize their utility, with no information withheld or misleading. When households come to the point of decisionmaking, they should have completed the information search, obtained adequate and accurate information, processed the information, and be able to make a rational decision that maximizes their utility. Households are assumed to understand the alternatives, their own preferences, and to not have biases. With respect to financial decisions, assuming households derive utility from wealth, consistency in household risk attitudes and behavior is one of the outcomes of rational decision-making. In other words, as a result of the information search and the decision-making, households' financial risk behavior should reflect their financial risk attitude.

Bailey, Olson and Wonnacott (1980) stated that most individuals are risk-averse. Therefore, when returns are equal, most people should choose the least-risky alternative. Some investments have larger fluctuations in their returns than others and, therefore, are riskier. Individuals with a lower risk tolerance level may be willing to accept lower expected returns in exchange for lower risks. In a similar vein, individuals with a higher risk tolerance level may be willing to accept higher risks in exchange for higher expected returns. Behavior that is inconsistent with the consumers' intention increases the probability of irrational financial behavior, which, in turn, decreases the probability of reaching their financial goals. Paying a financial planner would be an optimal decision if the service of the financial planner helps the consumer to be consistent regarding his/her financial risk tolerance and risk taking. 


\subsubsection{Information Search}

A consumer's decision is optimal when it leads to the best outcome under given constraints. Information is one of the constraints that consumers face when making investment decisions. Marginal analysis is central to economic theory. According to marginal analysis, consumers should continue pursuing additional information until the marginal cost of additional information is equal to its marginal benefit.

Stigler (1961) asserted that consumers tend to use information more extensively if it costs relatively little time and/or money to acquire. Understanding and managing risks in savings and investments is complex and requires substantial financial knowledge (Chang, 2005; Jacobs-Lawson \& Hershey, 2005). On average, people have inadequate financial knowledge (Hayslip, Bezerlein, \& Nichols, 1997) and tend to reduce the amount of effort they expend when decisions become more complex (Payne, Bettman, \& Johnson, 1993). It is reasonable that people seek information and assistance from professionals when making complex decisions, including investment decisions.

With the development of technology, the problem consumers are experiencing is not the scarcity of information but information overload. To sort through all information and decide what is accurate and useful takes not only time but also knowledge, experience and ability. Financial planners may have greater knowledge, experience and abilities than average consumers (Finke \& Huston, 2003; Finke, Huston, \& Winchester, 2011). They are expected to provide information that is accurate and useful for consumer decision-making. 
Hiring a financial planner makes economic sense as long as the expected benefit is more than its cost. In the investment market, households have many sources for investment information. Rational households would calculate the amount of search necessary so that they obtain information that can be processed and eventually help them achieve their goal at the lowest possible cost. Households are assumed to be capable of collecting and processing information. Consequently, the choice of information source should be a matter of preference. For example, paying a financial planner may have a higher out-of-pocket cost for the information obtained, per se, but it may reduce a households' opportunity cost (e.g., income from doing alternative work and frustration during the information search). Therefore, for some households, paying a financial planner is the optimal way of information search. However, for other households, the information search process is enjoyable and the activity in-and-in-itself provides utility, further, they may have time to do so with minimal opportunity costs. For these households, media may be the best source of information. Regardless of the choice for the source of information, the information collected from the source of choice should be complete, accurate, and adequate for making a rational decision.

\subsection{Hypotheses}

Taken together, assuming wealth provides utility to households and households are risk averse, the theories of expected utility and information search imply that households are rational so their financial decision should lead to consistency in their risk

attitude and behavior. Before they make a financial decision, households are expected to 
have completed the information search process and have chosen the optimal source of information to help them reach the consistency in their risk attitude and behavior. Therefore, the null hypothesis of this study is:

$H_{0}$ : Households using different sources of information should be equally likely to be consistent in their financial risk attitude and behavior.

The alternative hypothesis is:

$H_{A}$ : Households using different sources of information are not equally likely to be consistent in their financial risk attitude and behavior. 


\section{CHAPTER IV}

\section{DATA AND EMPIRICAL METHODOLOGY}

\subsection{Data}

This study pooled data from 1998, 2001, 2004, 2007 and 2010 Survey of Consumer Finances (SCF) to analyze the effect of information source on the consistency of financial risk attitude and behavior. The SCF is a cross-sectional survey conducted once every three years. This effort is supported by the Federal Reserve Board in cooperation with the Statistics of Income Division of the Internal Revenue Service. The survey provides detailed information on demographic characteristics at the individual level (such as age, gender and education attainment of the household heads and their spouse/partner, if any) and at the household level (such as number of dependent children), household financial situations (such as household income, types of assets and debts owned and the current balance of various types of assets and debts), and household's perceptions of financial situations (such as tolerance of financial risks and savings horizon, which is the amount of time before funds will be needed). The spouse's demographic characteristics were provided by the respondent.

In 1995, the SCF started to ask a question about the source of information used by households when making decisions about saving and investments. In the 1995 SCF, financial planners and brokers were included in one category. Starting with the 1998 SCF, financial planners and brokers were separated into two different categories. Since 
brokers are not planners, data prior to the 1998 SCF were excluded from this study. The dataset used in this paper was a combination of five cross-sectional SCF datasets. The number of households interviewed was 4,305 in the 1998 SCF, 4,442 in the 2001 SCF, 4,519 in the 2004 SCF, 4,418 in the 2007 SCF and 6,482 in the 2010 SCF. The combined sample size for all five SCF datasets was 24,166.

\subsection{Dependent Variable (Outcome Variable, Consistency)}

The financial risk attitude variable was constructed based on the response to the SCF risk tolerance question (Federal Reserve Board of Governors, 2010):

"Which of the statements on this page comes closest to the amount of financial risk that you and your (spouse/partner) are willing to take when you save or make investments?

1. Take substantial financial risks expecting to earn substantial returns.

2. Take above average financial risks expecting to earn above average returns.

3. Take average financial risks expecting to earn average returns.

4. Not willing to take any financial risks."

Substantial and above average financial risks were defined to be high financial risk; and the three risk categories other than "no financial risk" (i.e. substantial, above average, and average financial risks) were defined to be some financial risk. 
Although the question about the household's tolerance for investment risks was asked of the respondent, the question referred to household risk attitude as a whole rather than the respondent's perception about risks. It is possible that in a married/partnered household, two spouses/partners do not agree or collaborate regarding attitude toward financial risks; however, the surveys specifically framed the question so as to obtain a response for the household as a unit. Therefore, it was assumed that the respondent took this fact into consideration when s/he answered the question.

Having any financial assets invested in stock (either directly or indirectly through mutual funds or other managed assets such as annuities and trusts), stock options and futures contracts was defined as having equities, regardless of how the investment was split between stocks and other assets. Also included in equities were oil/gas/mineral leases and investments. These were included because, in public SCF datasets, these leases and investments were combined with stock options and futures contracts.

Investment asset ownership was defined as having any of the following assets: equities, total directly held non-equity mutual funds (excluding money market mutual funds), individually held bonds (including savings bonds), total quasi-liquid non-equity assets (including IRAs, thrift accounts, and future pensions), other managed non-equity assets (including trusts, annuities and managed investment accounts in which the household has an equity interest), net equity in nonresidential real estate (including real estate other than the principal residence, properties coded as 1-4 family residences, time shares, and vacation homes net of mortgages and other loans taken out for investment real estate), business interests, and selected other financial and nonfinancial assets. Also 
included in investment assets was cash value of whole life insurance. Life insurance cash values have evolved and now may include alternatives that participate in equity markets. Life insurance cash values are subject to the general credit risk of the insurance company and policy holders of several companies have experienced losses when companies were unable to make good on request policy cash values. Most of the time, life insurance policies have significant fees to access cash values, making these resources unreliable to act as cash equivalents, which are expected to be available without cost of risk of loss.

Households with equities were identified as objectively having high financial risks in their portfolio and households who own investment assets are identified as objectively having some financial risks in their portfolio. If respondents reported some household financial risk tolerance and some investment assets or no financial risk tolerance and no investment assets, they were defined to be consistent in their attitude and behavior at the first level of consistency. Similarly, if respondents reported a high level of household financial risk tolerance and equity ownership or a low level of financial risk tolerance and no equity assets, they are defined to be consistent in their attitude and behavior at the second level of consistency. This definition is illustrated in Figures 1a and 1b. Each level of consistency is measured as a dichotomous dependent variable in the logistic regression analyses. 


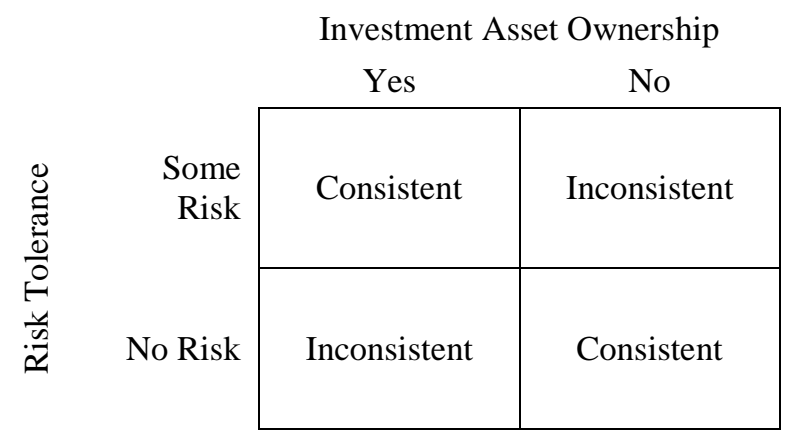

Figure 1a Definition of First Level Consistency in Reported Risk Tolerance and Asset Ownership

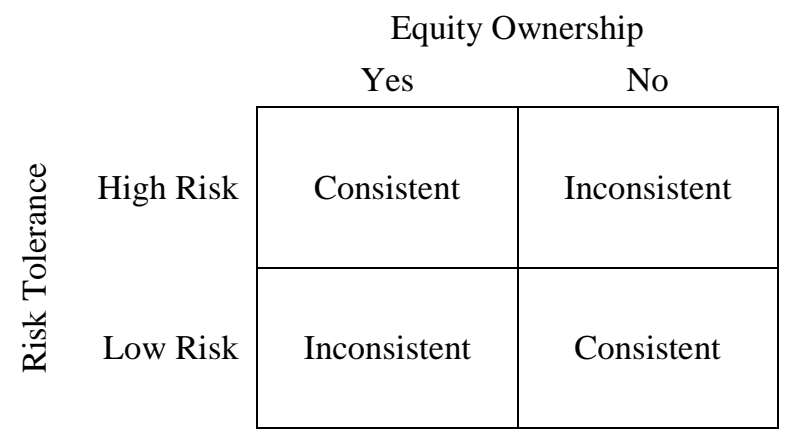

Figure 1b Definition of Second Level Consistency in Reported Risk Tolerance and Asset Ownership 


\subsection{Independent Variables}

Independent variables included five categories: 1) survey years; 2) source of information used by the household when making saving and investments decisions (reported by the respondent); 3) demographic characteristics of the respondent and the household; 4) economic characteristics of the household; and 5) household expectations of the future (reported by the respondent).

\subsubsection{Survey Years and Source of Information}

Survey years included the years when the SCF data were collected, which are 1998, 2001, 2004, 2007 and 2010. In both multivariate analyses, the year 1998 was used as the reference category.

In the SCF codebook (Federal Reserve Board of Governors, 2010), source of information used when making saving and investments decisions was obtained by asking the following question:

How do you (and your [spouse/partner]) make decisions about savings and investment? Do you call around, read newspapers, read materials you get in the mail, use information from television, radio, an online service or advertisement? Do you get advice from a friend, relative, lawyer, accountant, banker, broker, or financial planner? Or do you do something else? 
Answers were open-ended. Up to 10 responses in the 1998 SCF dataset and up to 15 responses in subsequent SCF datasets were recorded, in the order given. Based on the respondent's first answer, the source of information variable was categorized into five groups: 1) self and social network; 2) financial planner; 3) financial institutions; 4) media; and 5) other sources.

The self and social network category included calling around, shopping around, asking friends/relatives, consulting with self and/or spouse/partner, doing personal research, belonging to investment clubs, and using past experience and material from work/business contacts. The financial planner category is broadly defined as using lawyers and accountants as well as financial planners. The financial institutions category was comprised of bankers, brokers, investment seminars, stores, dealers, insurance agents, and other institutional sources such as a social service agency. The distinction between financial planners and financial institutions was based on a compensation methodology. The preponderance of what lawyers, accountants and financial planners provide is services, whereas those in the financial institutions category mainly provide products. The media category includes magazines/newspapers, books, material in the mail, television/radio, internet/ online services, advertisements, and telemarketers. Those who did not save or invest, did not shop around, always use same institution, or reported "other" when answering the information source question were placed into the "other" group. In multivariate analyses, the self and social network category was the reference category. 
The question about the household's search for information was asked of the respondent, even though the question referred to household behavior rather than individual behavior. It is possible that married/partnered household do not collaborate. However, the surveys specifically framed the question to obtain a response for the household as a unit. It is assumed that the respondent took this fact into consideration when s/he answered the question.

To estimate the effect of information source on consistency, it is necessary to control for attributes that may influence consistency. That is, variables that influence either reported risk tolerance or asset ownership should be controlled. Prior research found that respondent and household demographic variables, household financial situations, and respondents' expectations of the future affected risk tolerance and asset ownership.

\subsubsection{Demographic Characteristics of the Respondent and the}

\section{Household}

Demographic variables included age, education and race/ethnicity of the respondent, as well as household type (gender and marital status) and presence of dependent children. Age of the respondent was categorized into five groups: 1) less than 35 years old (reference category); 2) between 35 and 44; 3) between 45 and 54;4) between 55 and 64; and 5) 65 or older. Treating age as a categorical variable has advantages over just using age as a continuous variable. Using the main effect of age alone in the model requires the assumption that age has a linear effect. Including age and 
higher order terms of age allows age to have a non-linear effect. However, it does not necessarily fully capture the age effect because the higher order terms cannot describe multiple increases and decreases of the age effect. Therefore, age was divided into five categories in an effort to catch possible increases and decreases in the consistency of risk attitude and behavior over respondent life span. In multivariate analyses, respondents less than 35 years old served as the reference category.

Education of the respondent was categorized into five groups: 1) less than high school; 2) high school/GED; 3) some college; 4) bachelor's degree; and 5) graduate/professional degree. In multivariate analyses, respondents with less than high school education served as the reference category.

Race/ethnicity of the respondent included: 1) non-Hispanic White (including middle eastern/Arab with White, Caucasian); 2) non-Hispanic Black (African American); 3) Hispanic/Latino; and 4) non-Hispanic other race. The "other" category included Asian, American Indian/Alaska Native, Native Hawaiian/Pacific Islander, etc. In the public dataset, the "other" category could not be further divided into sub-groups. In multivariate analyses, non-Hispanic White respondents served as the reference category. In the United States, some couples are from different racial/ethnic groups. Because the SCF datasets only contain information on the race of the respondents, multi-racial/ethnic marriages could not be identified in this study.

Based on the respondents' gender and marital status, a household type variable was defined. The household type variable was categorized into four groups: 1) married males (including males who were married or living with a partner, regardless of the 
gender of the spouse or partner); 2) married females (including females who were married or living with a partner, regardless of the gender of the spouse or partner); 3) unmarried males; and 4) unmarried females. The reason that same-sex and mixed-sex marriages and life partnerships were not separated in this study was that these marriages and partnerships had similar traits in terms of resource management as a household unit, regardless of their sex or marital status. These traits should differ from those who were unmarried and not living with a life partner. Married males served as the reference category in the multivariate analyses. Presence of related children under 18 was coded 1 for yes and 0 for no. In multivariate analyses, households with no dependent children served as the reference category.

\subsubsection{Economic Characteristics of the Household}

Variables that reflect household economic situations included home ownership, debt ownership, adequacy of emergency fund, employment status, whether overspent; income, and nonfinancial assets. Home ownership had three categories: 1) renter; 2) homeowner with mortgage; and 3) homeowner without mortgage. Renters served as the reference category in the multivariate analyses.

Based on whether the household had debts other than mortgages, other debt ownership was coded 1 for yes and 0 for no. In multivariate analyses, households with no other debts served as the reference category. Adequacy of emergency fund was defined as having liquid assets greater than or equal to three months of normal household income. The purpose of the adequacy of emergency fund was to determine whether the 
household had resources to live a certain period of time in case a negative income shock were to happen. The normal income should be considered in measuring the adequacy because current income could be different from normal income if the household was experiencing an income shock (positive or negative). Because normal income is the denominator in the calculation of adequacy of emergency fund, a technical issue could occur when the value of normal income was zero. In order to correct this technical error, all non-positive normal income was made equal to one dollar before it entered the calculation. Because one dollar could only measure a very tiny amount of consumption in today's market, this method would not change the meaning of the ratio. In multivariate analyses, households who did not have an adequate level of emergency fund served as the reference category.

Employment status of the respondent included four categories: 1) employees (i.e. respondents who were working for someone else); 2) self-employed (including respondents who were mainly self-employed or mainly involved in some partnership); 3) retired (including those who were retired, disabled and not working, students, homemakers, and those who were age 65 or older and not currently working); and 4) not working (including those who were under 65 years old and currently out of the label force). Employees served as the reference category in the multivariate analyses. Depending whether the household spending exceeded household income, overspent was coded 1 for yes and 0 for no. Households that did not overspend served as the reference category in the multivariate analyses. 
In each survey year, households were asked "How much was the total income you and your family living here received in year X (note: one year before the survey year) from all sources, before taxes and other deductions were made?" Total household income was categorized into five groups: 1) less than $\$ 25,000 ; 2$ ) between $\$ 25,000$ and $\$ 49,999 ; 3)$ between $\$ 50,000$ and $\$ 74,999 ; 4)$ between $\$ 75,000$ and $\$ 99,999$; and 5) $\$ 100,000$ or more. The lowest income category (less than $\$ 25,000$ ) served as the reference group in the multivariate analyses.

The definition of non-financial assets was adapted from the SCF and included vehicles, primary residence, other residential real estate, business interests, and other miscellaneous non-financial assets such as jewelry, collections, royalties, etc. This variable was categorized into five groups: 1) less than $\$ 50,000 ; 2$ ) between $\$ 50,000$ and $\$ 149,999 ; 3)$ between $\$ 150,000$ and $\$ 249,999 ; 4)$ between $\$ 250,000$ and $\$ 499,999$; and 5) $\$ 500,000$ or more. Households that had less than $\$ 50,000$ in non-financial assets served as the reference group in the multivariate analyses.

To compare these dollar amounts across time, household income and amount of non-financial assets were converted into year 2010 dollars. Household income and amount of non-financial assets were measured by the total household income and nonfinancial assets in the year prior to the survey year (i.e. 1997, 2000, 2003, 2006, and 2009). The amounts were adjusted for inflation by multiplying the ratio of the Consumer Price Index in 2010 to the Consumer Price Index in the income year. 


\subsubsection{Expectations of the Future}

Expectations of the future were provided by respondents. Variables in this group included whether households expected to receive a substantial inheritance or transfer of assets in the future, saving horizon, and respondent self-perceived health status. Based on whether the household was expecting to receive a substantial inheritance or transfer of assets in the future, the inheritance expectation variable was coded 1 for yes and 0 for no. In the multivariate analyses, households that did not have such an expectation served as the reference category.

Households were asked which time periods were most important in making savings and spending decisions. Household savings horizon included four groups: 1) within the next year; 2) next few years; 3) next 5-10 years; and 4) longer than 10 years. Within the next year was the reference category in the multivariate analyses. Respondent self-perceived health condition included four groups: 1) excellent; 2) good; 3) fair; and 4) poor. Poor health was the reference category in the multivariate analyses.

\subsection{Method of Analysis}

\subsubsection{Sample Selection}

Households with financial constraints may be more likely to have a mismatch between self-reported risk tolerance and their investment behavior. These households may be willing to tolerate more risks in order to achieve higher returns; however, they are unable to invest as much as they would like to due to a lack of financial resources. 
Consequently, households with a negative net worth were excluded from this study.

After applying this sample selection criterion, the sample size for each survey year was

4,028 in the 1998 SCF, 4,197 in the 2001 SCF, 4,246 in the 2004 SCF, 4,153 in the 2007

SCF and 5,839 in the 2010 SCF. The total sample size was 22,463.

\subsubsection{Matching Demographic Characteristics and Respondent-} reported Household Risk Tolerance

In the SCF datasets, regardless of who was the respondent, the male in a mixedsex-couple household or the older individual in a same-sex-couple household was designated as the "head" of the household. All data for those two individuals were swapped when the respondent was the spouse/partner. In cases where information for both spouses/partners was collected, such attribution would not cause a misidentification of the response. For example, the age of the "head" of the household could be given by the spouse, but it would be recorded as the information for the "head". However, in cases where only the respondent was asked to provide information, the response could be identified as being provided at the household level, not identified as either the "head" or

the spouse. For example, although the risk tolerance question was intended to collect the risk tolerance of the household as a unit, the question was only asked to the respondent.

The SCF data provided a switch variable coded as 1 if the response was provided by the spouse and 0 if the response was given by the "head". In order to accurately determine the effect of using financial planners on the consistency of financial risk 
attitude and behavior, the present study used the switch variable to keep the response provided by each respondent in line with the respondent's information such as age and education.

\subsubsection{Multiple Imputation and the Repeated-imputation Inference}

\section{Technique}

The SCF data is complex due to the multiple imputation of missing data and oversample of wealthy households (Montalto, 1998). The Federal Reserve Board constructed a weight variable (Kennickell, 1999) to account for this oversampling and the systematic deviations from the Current Population Survey estimates of homeownership by racial/ethnic groups. The weight variable (X42001) recommended by the Federal Reserve was used in the descriptive analyses to obtain unbiased estimates for the entire sample households. Montalto and Sung (1996) noted that, with the SCF, parameter estimates from a weighted multivariate regression technique would be unbiased, but estimates of standard errors would not be valid. Therefore, significance tests would be invalid. Most published research using the SCF has used weighting in descriptive analyses but not in the multivariate analyses. Consistent with this prior practice, in this dissertation, weights were used in the descriptive analyses but not in the multivariate analyses.

Another issue that arises when using the SCF datasets is presence of missing values and the multiple imputations of the missing values. Deleting the missing data may be one reasonable approach if the missing values are a small percentage of the total data. 
However, missing values may not be missing at random. According to Kennickell (1998), the missing values in the SCF datasets display highly heterogeneous patterns. For this reason, deleting missing values may not only lose the information those values convey but also result in biased estimates. The multiple imputation method solves this problem.

Starting in 1989, the SCF imputed missing values using a consistent multiple imputation method to provide the best possible estimate for each missing value. As a result, five complete datasets (referred to as "implicates" by the SCF) are generated for each survey year. The five implicates can be combined into one dataset for statistical analysis using the "repeated-imputation inference" (RII) method (Kennickell \& Woodburn, 1999). This technique was employed in the multivariate logistic analyses in order to reduce the nonresponse bias and produce the best possible estimates for variables with missing data.

\subsubsection{Age-Period-Cohort Analysis}

According to Yao, Sharpe and Wang (2011), the effect of age on risk tolerance includes three separate effects: the aging effect, the period effect, and the cohort effect. People's remaining life expectancy decreases as they age. Therefore, they may move to safer assets and reduce their risk tolerance. Market news and events affect people's risk tolerance (Yao et al., 2011; Yao \& Curl, 2011); therefore, the period when people were interviewed affects their responses to risk tolerance questions. People of different cohorts may react to the same market news and events in different ways. This study will adopt the Age-Period-Cohort (APC) analysis employed in Yao et al. (2011) to 
decompose the effect of age to examine the effect of the three separate factors, as well as other independent variables, on the two levels of consistency in risk attitude and behavior. The first level of consistency was either being willing to take some financial risks and having some investment assets or being unwilling to take any financial risks and having no investment assets. The second level of consistency was either being willing to take high financial risks and having some equity assets or being unwilling to take high financial risks and having no equity assets.

One difference between the APC analysis in this study and the one in Yao et al. (2011) was that instead of using a vague definition of generations, of which there has been no consensus in past research (e.g. Lancaster \& Stillman, 2002; Meredith \& Schewe, 1994), this study simply divided respondents into birth cohorts in 15 -year intervals. There were two main reasons for dividing cohorts in this manner. One reason was that people born and raised in a common environment and time display similar characteristics. Some past research found generation differences in risk tolerance (e.g. Jianakoplos \& Bernasek, 2006) whereas other research found that generations did not affect risk tolerance (e.g. Yao et al., 2011). The other reason was more technical in nature. The difference between the survey year and the birth year was a respondent's age. In order to avoid the multicollinearity issue imbedded in including all three variables that had an exact linear relationship in the same model, this study employed a technique proposed by Yang and Land (2008) and categorized respondents into time intervals of different lengths so that given any two of the three variables, it was impossible to calculate the exact value of the third. The birth year of respondents ranged from 1903 to 1992 and, 
therefore, there were six cohorts: 1) cohort 1 (born between 1903 and 1917); 2) cohort 2 (born between 1918 and 1932); 3) cohort 3 (born between 1933 and 1947); 4) cohort 4 (born between 1948 and 1962); 5) cohort 5 (born between 1963 and 1977); and 6) cohort 6 (born between 1978 and 1992).

\subsubsection{Descriptive and Multivariate Analyses}

Descriptive analyses were conducted to show the percent being consistent in financial risk tolerance and financial behavior by information source. Results were evaluated to determine their statistical significance. Cross-tabulations of household characteristics and consistency at both levels were conducted to observe the percent distribution of the type of consistency for each of these household groups. Since the dependent variables were dichotomous, logistic regressions were used to analyze the controlled effect of information source on the consistency of financial risk tolerance and financial behavior.

The general null hypothesis of this study proposed in Chapter III was:

$H_{0}$ : Households using different sources of information should be equally likely to be consistent in their financial risk attitude and behavior. 
The general alternative hypothesis was:

$H_{A}$ : Households using different sources of information are not equally likely to be consistent in their financial risk attitude and behavior.

In order to accept the overall null hypothesis $H_{0}$, the following hypotheses have to be supported simultaneously:

$H_{01}$ : Households using self and social network for information when making savings and investment decisions are equally likely to be consistent in their financial risk attitude and behavior at the first level with households using financial planners.

$H_{02}$ : Households using self and social network for information when making savings and investment decisions are equally likely to be consistent in their financial risk attitude and behavior at the first level with households using financial institutions.

$H_{03}$ : Households using self and social network for information when making savings and investment decisions are equally likely to be consistent in their financial risk attitude and behavior at the first level with households using media. 
$H_{04}$ : Households using self and social network for information when making savings and investment decisions are equally likely to be consistent in their financial risk attitude and behavior at the first level with households using other sources.

$H_{05}:$ Households using financial planners for information when making savings and investment decisions are equally likely to be consistent in their financial risk attitude and behavior at the first level with households using financial institutions.

$H_{06}$ : Households using financial planners for information when making savings and investment decisions are equally likely to be consistent in their financial risk attitude and behavior at the first level with households using media.

$H_{07}$ : Households using financial planners for information when making savings and investment decisions are equally likely to be consistent in their financial risk attitude and behavior at the first level with households using other sources.

$H_{08}$ : Households using financial institutions for information when making savings and investment decisions are equally likely to be consistent in their financial risk attitude and behavior at the first level with households using media.

$H_{09}$ : Households using financial institutions for information when making savings and investment decisions are equally likely 
to be consistent in their financial risk attitude and behavior at the first level with households using other sources.

$H_{010}$ : Households using media for information when making savings and investment decisions are equally likely to be consistent in their financial risk attitude and behavior at the first level with households using other sources.

$H_{011}$ : Households using self and social network for information when making savings and investment decisions are equally likely to be consistent in their financial risk attitude and behavior at the second level with households using financial planners.

$H_{012}$ : Households using self and social network for information when making savings and investment decisions are equally likely to be consistent in their financial risk attitude and behavior at the second level with households using financial institutions.

$H_{013}$ : Households using self and social network for information when making savings and investment decisions are equally likely to be consistent in their financial risk attitude and behavior at the second level with households using media. 
$H_{014}$ : Households using self and social network for information when making savings and investment decisions are equally likely to be consistent in their financial risk attitude and behavior at the second level with households using other sources.

$H_{015}$ : Households using financial planners for information when making savings and investment decisions are equally likely to be consistent in their financial risk attitude and behavior at the second level with households using financial institutions.

$H_{016}$ : Households using financial planners for information when making savings and investment decisions are equally likely to be consistent in their financial risk attitude and behavior at the second level with households using media.

$H_{017}$ : Households using financial planners for information when making savings and investment decisions are equally likely to be consistent in their financial risk attitude and behavior at the second level with households using other sources.

$H_{018}$ : Households using financial institutions for information when making savings and investment decisions are equally likely to be consistent in their financial risk attitude and behavior at the second level with households using media.

$H_{019}$ : Households using financial institutions for information when making savings and investment decisions are equally likely 
to be consistent in their financial risk attitude and behavior at the second level with households using other sources.

$H_{020}$ : Households using media for information when making savings and investment decisions are equally likely to be consistent in their financial risk attitude and behavior at the second level with households using other sources.

Additional logistic analyses were conducted to examine whether there were any statistically significant differences in consistency between risk attitude and behavior at either the first or the second level among the five information source groups (self and social network, financial planner, financial institutions, media, and other sources). Figure 2a displays a diagram of the relationships among the five information sources at the first consistency level as stated in above hypotheses $H_{01}$ to $H_{010}$. Figure $2 \mathrm{~b}$ displays a diagram of the relationships among the five information sources at the second consistency level as stated in above hypotheses $H_{011}$ to $H_{020}$. 


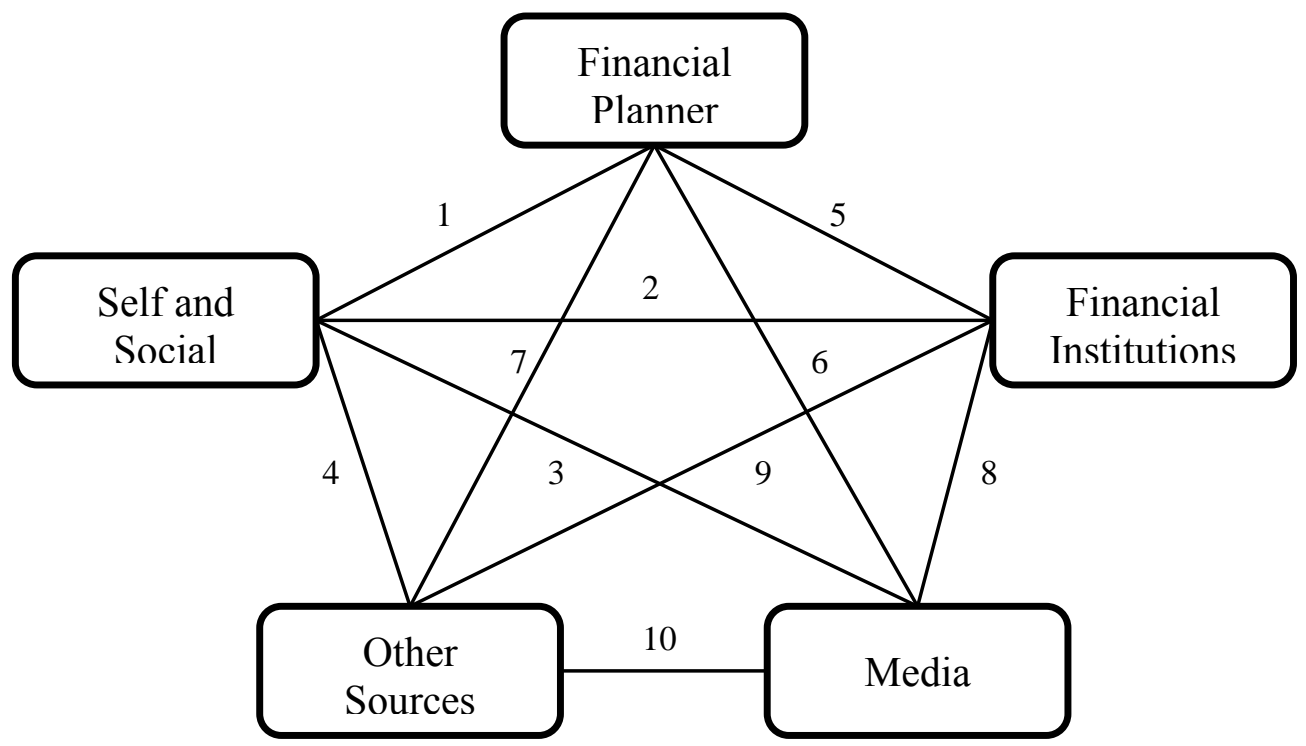

Note: Each line represents an equal relationship, controlling for other variables.

Figure 2a Relationship between Each Two Sources of Information at the First Level

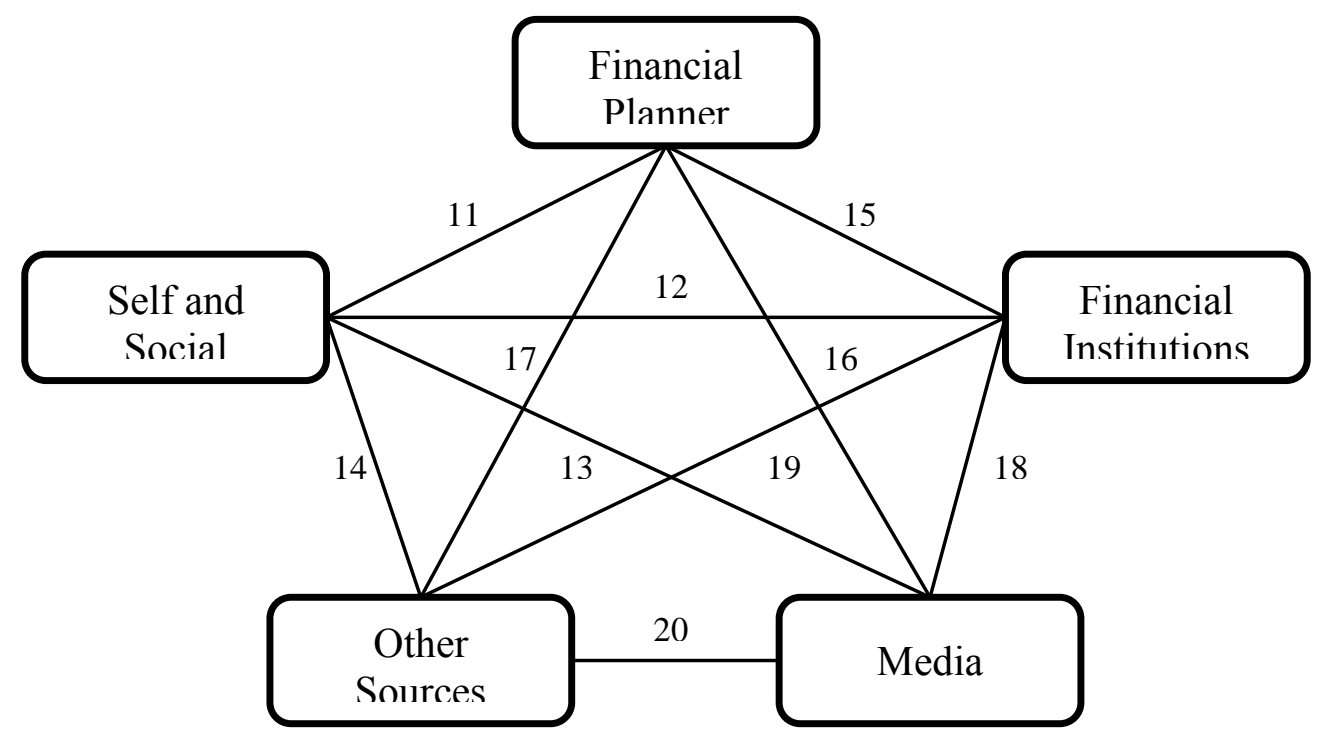

Note: Each line represents an equal relationship, controlling for other variables.

Figure $2 b$ Relationship between Each Two Sources of Information at the Second Level 
When being compared, after controlling for other variables in the model, households in each pair of the information sources categories should display an equal likelihood of being consistent in their risk attitude and behavior at both levels. If any one of these equal relationships was rejected by the hypotheses tests, then the overall null hypothesis $H_{0}$ would be rejected and the overall alternative hypothesis $H_{A}$ would be accepted. 


\title{
CHAPTER V
}

\author{
RESULTS
}

\subsection{Sample Characteristics}

\subsubsection{Sample Characteristics in Each Survey Year}

The characteristics of the sample households are reported in Table 1. As shown in the table, the mean and median of the respondent age was 50.8 and 49.0, respectively, in the total combined sample that included all survey years. Both mean and median age increased during the $1998-2010$ period, with the mean age rising slightly from 49.9 in 1998 to 51.9 in 2010 and the median age increasing from 48.0 in 1998 to 51.0 in 2010.

The amounts of income, investment assets, and nonfinancial assets were adjusted to 2010 dollars. The mean and median income was $\$ 84,513$ and $\$ 50,391$, respectively, in the total combined sample. Households surveyed in 1998 had the lowest mean income of $\$ 74,137$ and households in 2007 had the highest mean income of $\$ 92,569$. In 2010, mean income was $\$ 82,828$, second lowest among all survey years. Median income peaked in 2004 at $\$ 51,997$, which was a little higher than the $\$ 51,715$ in 2007. In 2010, median income dropped to $\$ 47,979$, also the second lowest amount in all survey years. Mean investment assets started at $\$ 284,822$ in 1998, researched the highest level in 2007 at $\$ 432,142$, and then dropped to $\$ 384,635$ in 2010 . 


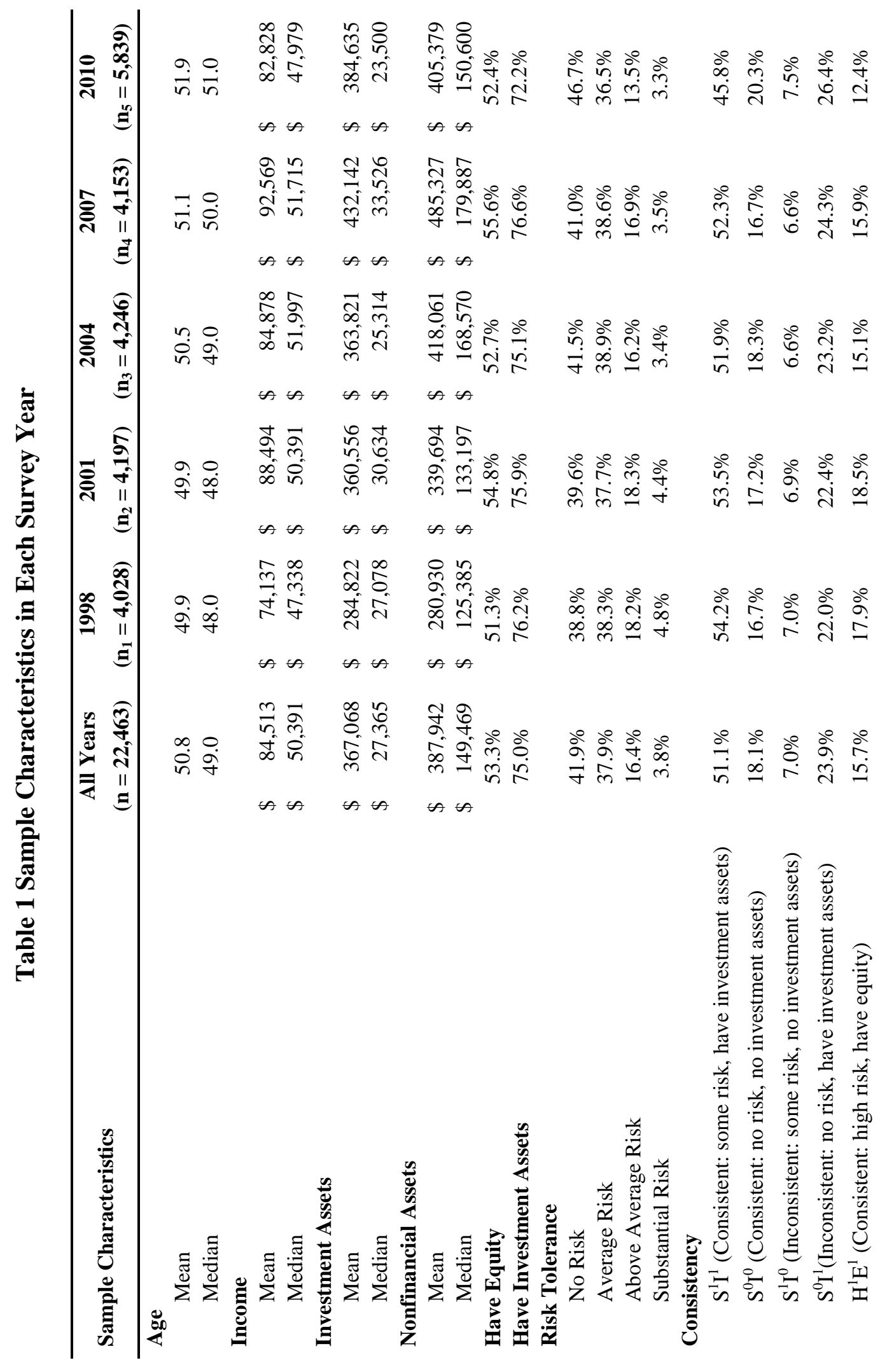




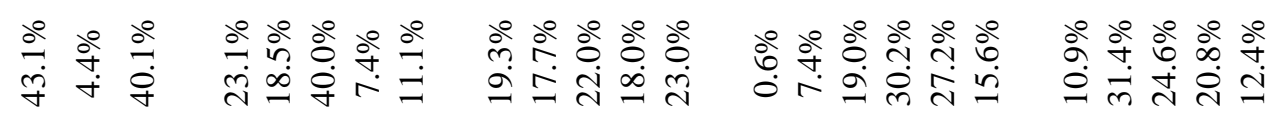

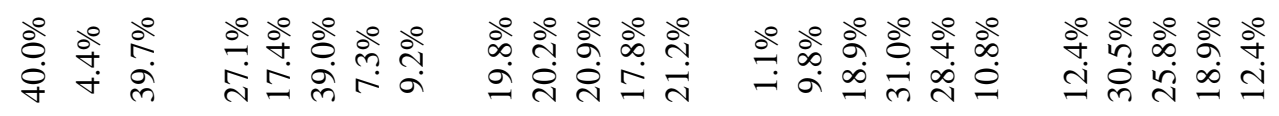

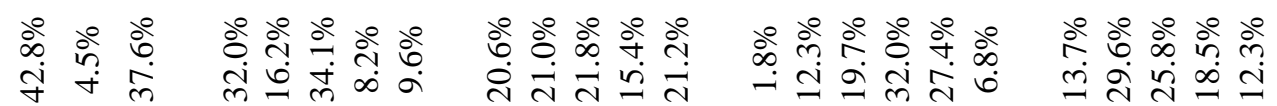

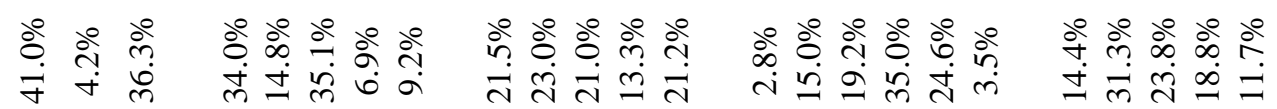

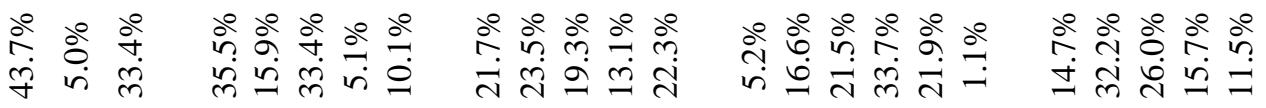

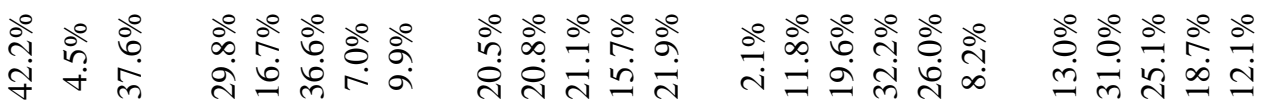

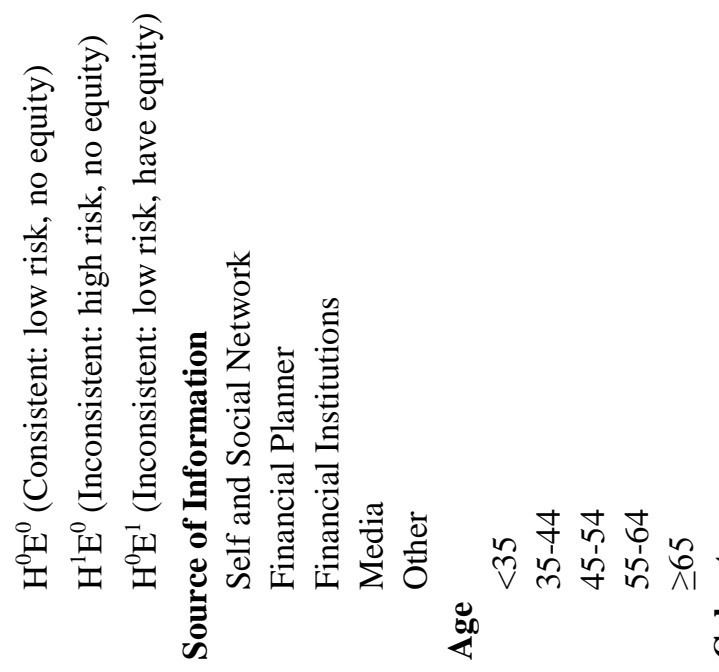

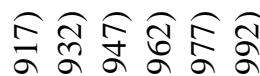

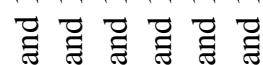

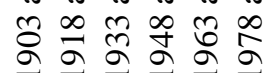

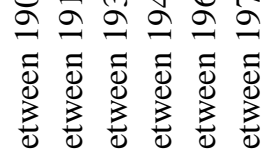

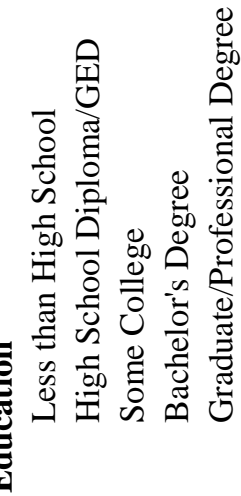




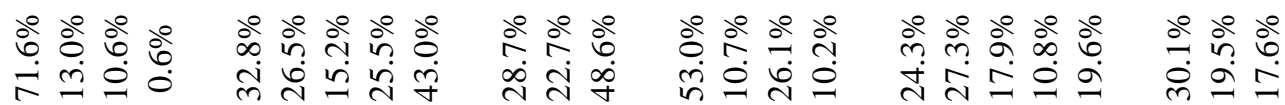

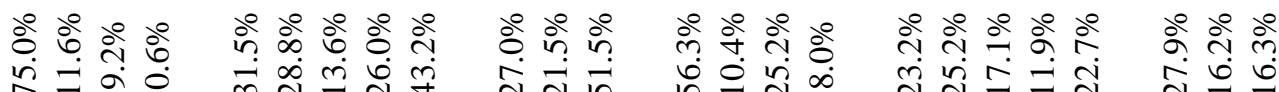

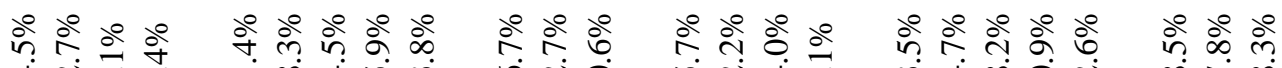

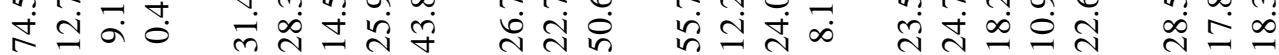

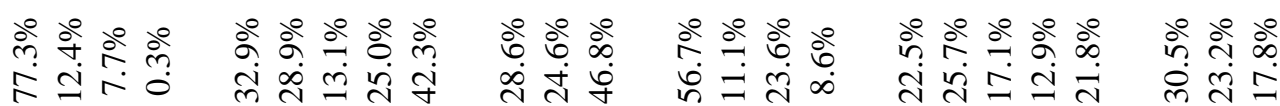

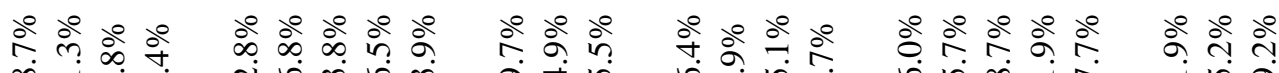

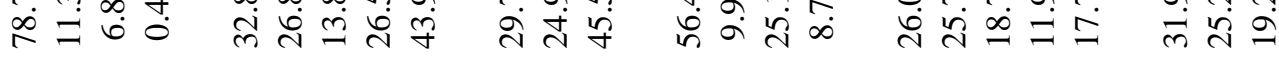

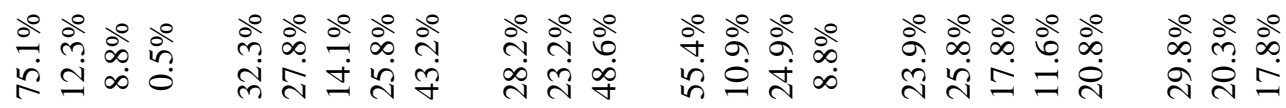

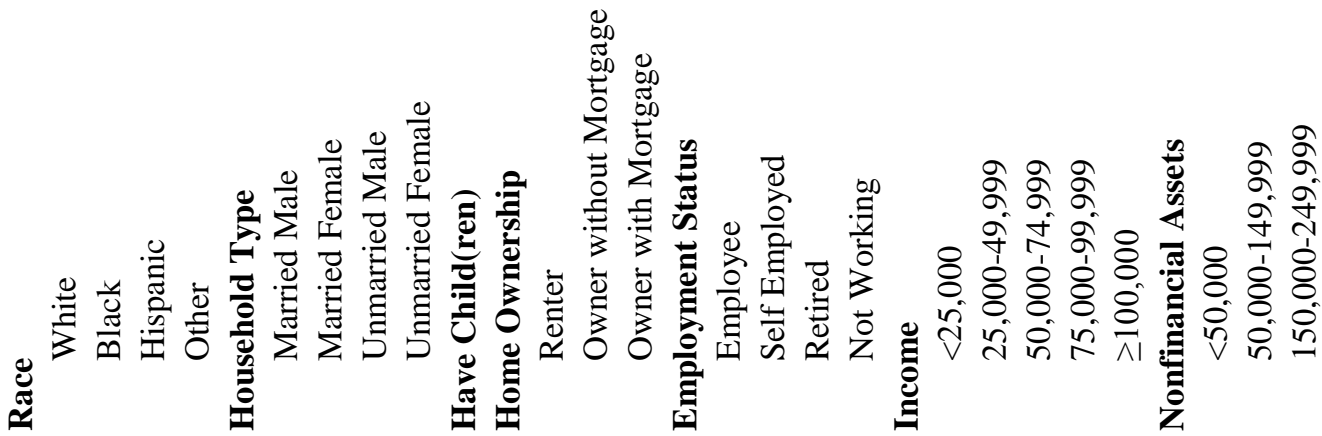




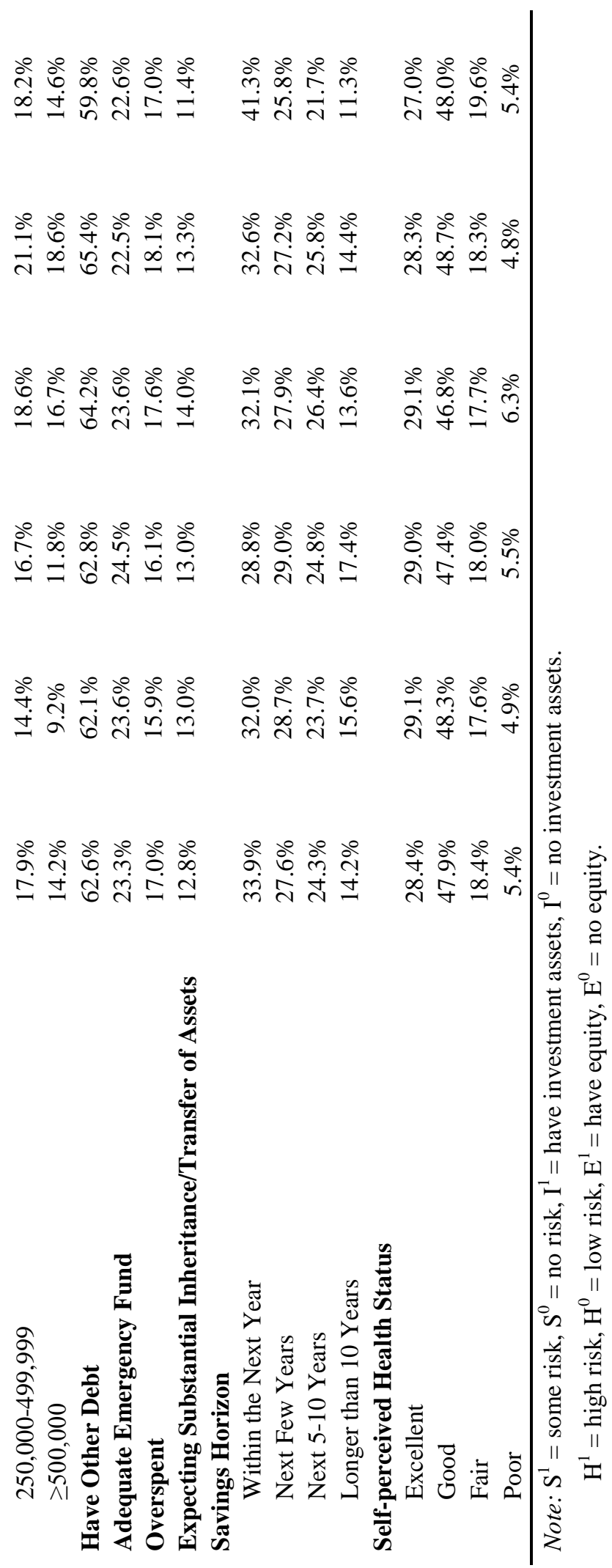


The median investment asset level was also the highest in 2007 (\$33,526) and lowest in $2010(\$ 23,500)$. Mean nonfinancial assets peaked at $\$ 485,327$ in 2007, followed by $\$ 418,061$ in 2004 and $\$ 405,379$ in 2010 . The overall mean of nonfinancial assets in the combined sample was $\$ 387,942$. Median nonfinancial assets followed the same pattern as the mean, with the highest level occurring in $2007(\$ 179,887)$ and the lowest level occurring in 1998 (\$125,385). On average, a little over half of the households had equity (mean=53.3\%) and three-fourths (mean=75.0\%) of households had investment assets in the combined sample including all survey years.

In all survey years, an overall average of two-fifths (41.9\%) of total respondents stated that their household was not willing to take any financial risks. A little over onethird (37.9\%) of respondents reported a willingness for the household to take average financial risks expecting to earn average returns and $16.4 \%$ reported an above average risk tolerance. Only 3.8\% of the total respondents said that their household was willing to take substantial financial risks expecting to earn substantial returns. The patterns of risk tolerance distribution in 2004, 2007, and 2010 were similar to the pattern in all survey years. However, the percentage reporting an unwillingness to take financial risks started at $38.8 \%$ in 1998 and reached $41.5 \%$ in 2004 . The percentage unwilling to take any financial risks was slightly lower in 2007 (41.0\%) but reached the peak in 2010 (46.7\%). On the contrary, the percentage willing to take substantial financial risks was high in $1998(4.8 \%)$ and reached a low level of 3.4\% in 2004. This percentage was slightly higher in 2007 (3.5\%) and then was low again in 2010 (3.3\%). 
About half (51.1\%) of the total respondents reported some household risk tolerance and ownership of investment assets. Less than one-fifth $(18.1 \%)$ reported the opposite: not willing to take any financial risks and not having any investment assets. Around one-third $(30.9 \%)$ of the respondents reported a mismatch between their household's risk tolerance and investment assets ownership: $7.0 \%$ were willing to take some financial risks but had no investment assets and $23.9 \%$ had some investment assets but were not willing to take any financial risks. The percentage of households having some risk tolerance and some investment assets was generally lower in later survey years (54.2\% in 1998 and $51.9 \%$ in 2004). This percentage was $52.3 \%$ in 2007 and $45.8 \%$ in 2010. The percentage of households with no financial risk tolerance and no investment assets started at $16.7 \%$ in 1998 and reached $18.3 \%$ in 2004 . This percentage was the lowest in 2004 and 2007 (16.7\%) but reached the highest level in 2010 (20.3\%). Households who had some risk tolerance but no investment assets accounted for less than one-tenth of the total sample in each survey year. The percentage started from $7.0 \%$ in 1998, reached a low point at 6.6\% in 2004 and 2007, and was the highest in 2010 (7.5\%). The percentage of households who were unwilling to take any financial risk but had some investment assets was consistently higher in later survey years (22.0\% in 1998 and $26.4 \%$ in 2010).

Among households in the combined sample that includes all survey years, $15.7 \%$ were willing to take high (above average or substantial) financial risks and had some equity assets, $42.2 \%$ were willing to take average or no financial risks and did not have equity assets. A good portion of them (37.6\%) had equity but were only willing to take 
average or even no risks. Only $4.5 \%$ of these households reported high risk tolerance but had no equity in their portfolio. The percentage of households willing to take high financial risks and had equity was relatively higher in 1998 (17.9\%) and $2001(18.5 \%)$ as compared with later years (e.g. 12.4\% in 2010). The percentage of households unwilling to take high financial risks and did not own any equity in their portfolio was two-fifths or more in each time period, with the highest percentage (43.7\%) in 1998 and lowest (40.0\%) in 2007. Households who had high risk tolerance but had no equity accounted for a very small portion of the sample in each year. The percentage ranged from $4.2 \%$ in 2001 to $5.0 \%$ in 1998 . The percentage of households who had some equity but were unwilling to take high risks was lower in earlier surveys and higher in later survey years $(33.4 \%$ in 1998 and $40.1 \%$ in 2010).

In all survey years, an average of $29.8 \%$ of households relied on self and/or their social network (calling around, shopping around, asking friends/relatives, consulting with self and/or spouse/partner, doing personal research, belonging to investment clubs, and using past experience and material from work/business contacts) for information when making savings and investments decisions. Less than one-fifth (16.7\%) used a financial planner (broadly defined as using lawyers and accountants as well as financial planners), 36.6\% used financial institutions (bankers, brokers, investment seminars, stores, dealers, insurance agents, and other institutional sources such as a social service agency), $7.0 \%$ used media (magazines/newspapers, books, material in the mail, television/radio, internet/ online services, advertisements, and telemarketers), and 9.9\% used other sources, did not shop around, or did not save or invest. 
The overall percent of respondents younger than 35 years of age accounted for one-fifth $(20.5 \%)$ of the combined sample including all survey years. This percentage started at $21.7 \%$ in 1998 and reached $19.3 \%$ in 2010 . The percentage of respondents between 35 and 44 years old also decreased during the same period of time from $23.5 \%$ in 1998 to $17.7 \%$ in 2010, with an overall percentage of $20.8 \%$ in the combined sample. The overall percentage of respondents who were $45-54$ years old was $21.1 \%$. This percentage was $19.3 \%$ in $1998,21.0 \%$ in $2001,21.8 \%$ in $2004,20.9 \%$ in 2007 , and $22.0 \%$ in 2010. The percent of respondents aged between 55 and 64 started at $13.1 \%$ in 1998 and reached $18.0 \%$ in 2010 , with the overall percentage in all years being $15.7 \%$. Respondents aged 65 or older was about one-fifth of the total sample in all survey years, ranging from $21.2 \%$ to $23.0 \%$ with an overall average of $21.9 \%$.

In the overall combined sample, $2.1 \%$ of the respondents were born between 1903 and 1917, 11.8\% were born between 1918 and 1932, 19.6\% were born between 1933 and 1947, 32.2\% were born between 1948 and 1962, 26.0\% were born between 1963 and 1977, 8.2\% were born between 1978 and 1992. In each of the five survey years, respondents born between 1948 and 1977 made up over half of the respondents. Because the sample size was big $(22,463)$, the small sample sizes of cohort 1 and cohort 6 did not cause an issue in the multivariate analysis.

Also for the combined sample including all survey years, an average of $13.0 \%$ of respondents did not complete a high school education, 31.0\% had a high school diploma, $25.1 \%$ had some college education, $18.7 \%$ had a bachelor's degree, and $12.1 \%$ had a graduate or professional degree. The percent that failed to complete a high school 
education was lower in later survey years (14.7\% in 1998 and $10.9 \%$ in 2010).

Respondents who received a high school diploma made up 32.2\% of the total sample in $1998,31.3 \%$ in $2001,29.6 \%$ in $2004,30.5 \%$ in 2007 , and $31.4 \%$ in 2010 . The percent of respondents who had some college peaked at $26.0 \%$ in 1998, followed by $25.8 \%$ in 2004 and 2007, 24.6\% in 2010, and 23.8\% in 2001. The percent of respondents who received a bachelor's degree was the lowest in 1998 (15.7\%) and highest in 2010 (20.8\%), with an overall mean percent of $18.7 \%$ for the combined sample including all survey years. More than one-tenth of the total respondents in the combined sample received a graduate or professional degree. This percentage was lower in earlier survey years and higher in later survey years (11.5\% in 1998 and 12.4\% in 2010).

The overwhelming majority of respondents were white (overall mean=75.1\%); however, this percentage was lower in later survey years $(78.7 \%$ in 1998 and $71.6 \%$ in 2010), except that the percentage was slightly higher in 2007 (75.0\%) than in 2004 (74.5\%). A little over one-tenth of the sample was black, with an overall average of 12.3\%. This percentage was higher in later survey years $(11.3 \%$ in 1998 and $13.0 \%$ in 2010), except that the percentage was slightly lower in 2007 (11.6\%) than in 2004 (12.7\%). The percent of Hispanics was higher in later survey years (6.8\% in 1998 and $10.6 \%$ in 2010) with a growth rate higher than $10 \%$ in most years. The percent of other races were less than $1 \%$ in all years.

Overall, married male respondents accounted for $32.3 \%$ of the total combined sample. Also in the combined sample, $27.8 \%$ were married females, $14.1 \%$ were unmarried males, and $25.8 \%$ were unmarried females. The percent distribution of 
household type did not vary much during the period of 1998-2010. Less than half (43.2\%)

of the sample respondents had children. This percentage was the highest in 1998 (43.9\%) and lowest in $2001(42.3 \%)$.

Less than one-third $(28.2 \%)$ of the total combined sample were renters. The percentage was the lowest in 2004 (26.7\%) and highest in 1998 (29.7\%). Homeowners without a mortgage made up $23.2 \%$ of the overall sample. The percentage started at $24.9 \%$ in 1998 and reached $21.5 \%$ in 2007. It was slightly higher in $2010(22.7 \%)$.

Homeowners with a mortgage accounted for $48.6 \%$ of the overall sample. This percentage was higher in later years (45.5\% in 1998 and $51.5 \%$ in 2007). However, the percentage in $2010(48.6 \%)$ was lower than that of 2007.

The majority (55.4\%) of the overall combined sample respondents worked for someone else, with about 56\% in all years except 2010 (53.0\%). Around one-tenth $(10.9 \%)$ of the total combined sample respondents worked for themselves. This percentage was the lowest in 1998 (9.9\%) and highest in 2004 (12.2\%). Retired respondents made up a quarter $(24.9 \%)$ of the total combined sample, with the highest percentage $(26.1 \%)$ in the last survey year and the lowest percentage $(23.6 \%)$ in 2001 . In all survey years, an average of $8.8 \%$ was not in the workforce for reasons other than retirement. This percentage was lower in later survey years $(8.7 \%$ in 1998 and $8.0 \%$ in 2007). However, this percentage was $10.2 \%$ in 2010 , highest among all survey years. In the combined sample including all survey years, an average of $23.9 \%$ of respondents reported a household income of less than $\$ 25,000$. This percentage was the highest in 1998 (26.0\%), following by 2010 (24.3\%). The percentage of households in 
the lowest income category was the lowest in 2001 (22.5\%). About one-quarter $(25.8 \%)$ of respondents reported a household income between $\$ 25,000$ and $\$ 49,999$, with $25.7 \%$ in 1998 and 2001, 24.7\% in 2004, 25.2\% in 2007, and 27.3\% in 2010. Households whose income was between $\$ 50,000$ and $\$ 74,999$ accounted for $17.8 \%$ of the overall combined sample households. This percentage was the highest in 1998 (18.7\%) and lowest in 2001 and 2007 (17.1\%). A little over one-ten (11.6\%) of the overall total sample respondents in all survey years reported a household income between $\$ 75,000$ and $\$ 99,999$, with $11.9 \%$ in $1998,12.9 \%$ in $2001,10.9 \%$ in $2004,11.9 \%$ in 2007 , and $10.8 \%$ in 2010 . There were an overall of $20.8 \%$ of households in the highest income category ( $\$ 100,000$ or higher). This percentage started at $17.7 \%$ in 1998 and reached $22.7 \%$ in 2007 . The percentage was $9.6 \%$ in 2010 , lowest among all survey years.

Less than one-third (29.8\%) of the overall combined sample households had less than $\$ 50,000$ in nonfinancial assets. This percentage started at 31.9\% in 1998 and reached $27.9 \%$ in 2007. The percentage was slightly higher in $2010(30.1 \%)$ than in 2007. The next category of nonfinancial assets was $\$ 50,000-\$ 149,999$. The overall percent of households in this category was $20.3 \%$, with the single year percentage being lower in later years (started at $25.2 \%$ in 1998 and reached $16.2 \%$ in 2007). This percentage was higher in 2010 (19.5\%). Households with between $\$ 150,000$ and $\$ 249,999$ nonfinancial assets accounted for $17.8 \%$ of the overall combined sample. The percentage was the highest at $19.2 \%$ in 1998 and the lowest in 2007 (16.3\%). The second highest category of nonfinancial assets was $\$ 250,000-\$ 499,999$, with an overall percentage of households being $17.9 \%$. This percentage was higher in later years (started at $14.4 \%$ in 1998 and 
reached $21.1 \%$ in 2007) and then was lower in 2010 (18.2\%). Households with at least $\$ 500,000$ in nonfinancial assets made up $14.2 \%$ of the overall combined sample. This percentage was higher in later survey years (started at $9.2 \%$ in 1998 and reached $18.6 \%$ in 2007) except that it was $14.6 \%$ in 2010, lower than the percentage in 2007.

Among the households in the combined sample including all survey years, the majority (62.6\%) had debt other than mortgage. This percentage started at $62.1 \%$ in 1998 and reached to $65.4 \%$ in 2007 . The percentage was $59.8 \%$ in 2010 , lower than that of 2007. About one quarter $(23.3 \%)$ of the households in the combined sample had an adequate level of emergency assets. This percentage was the highest in $2001(24.5 \%)$ and lowest in 2007 (22.5\%). Overall in the combined sample, 17.0\% of household spent more than their total household income. The percentage of households who overspent started at $15.9 \%$ in 1998 and reached $18.1 \%$ in 2007 . This percentage was $17.0 \%$ in 2010 . Over one-tenth $(12.8 \%)$ of the total combined sample households expected a substantial inheritance or assets transfer. This percentage was the highest in 2004 (14.0\%) and lowest in $2010(11.4 \%)$.

The percentage of households with reported savings and spending time horizons within the next year was $33.9 \%$ in the overall combined sample. This percentage peaked at $41.3 \%$ in 2010 and was the lowest in 2001 (28.8\%). Households with a "next few years" time perspective accounted for $27.6 \%$ of the overall combined sample and peaked in 2001 at $29.0 \%$. This percentage dropped to $25.8 \%$ in 2010 . Households in the next 510 years category accounted for $24.3 \%$ of the overall combined sample. This percentage started from $23.7 \%$ in 1998 and reached $26.4 \%$ in 2004 . In later years, this percentage 
was lower (e.g. 21.7\% in 2010). The longest time horizon category (longer than 10 years) made up $14.2 \%$ for the overall combined sample. This percentage peaked at $17.4 \%$ in 2001 and was the lowest $(11.3 \%)$ in 2010.

Respondents who reported an excellent health status made up $28.4 \%$ of the overall combined sample. The excellent health category was about the same (around $29.1 \%)$ in the first three survey years and was lower in later survey years $(28.3 \%$ in 2007 and $27.0 \%$ in 2010). In the combined sample including all survey years, an average of $47.9 \%$ of respondents reported having a good health. This percentage was the highest in $2007(48.7 \%)$ and lowest in $2004(46.8 \%)$. Less than one-fifth (overall mean=18.4\%) of respondents reported fair health. This health percentage was generally higher in later years (17.6\% in 1998 and 19.6\% in 2010), except that this percentage was lower in 2004 (17.7\%) than in $2001(18.0 \%)$. Respondents who reported having a poor health accounted for the smallest percentage $(5.4 \%)$ of the overall sample, with the peak at $6.3 \%$ in 2004 and the lowest in 2007 (5.4\%).

\subsubsection{Sample Characteristics by Information Source}

Table 2 displays sample characteristics by information source in the total combined sample including all survey years. Respondents reported their household risk tolerance in one of four levels: none, average, above average and substantial. The percent distribution of risk tolerance seemed to be very similar for those who used media 


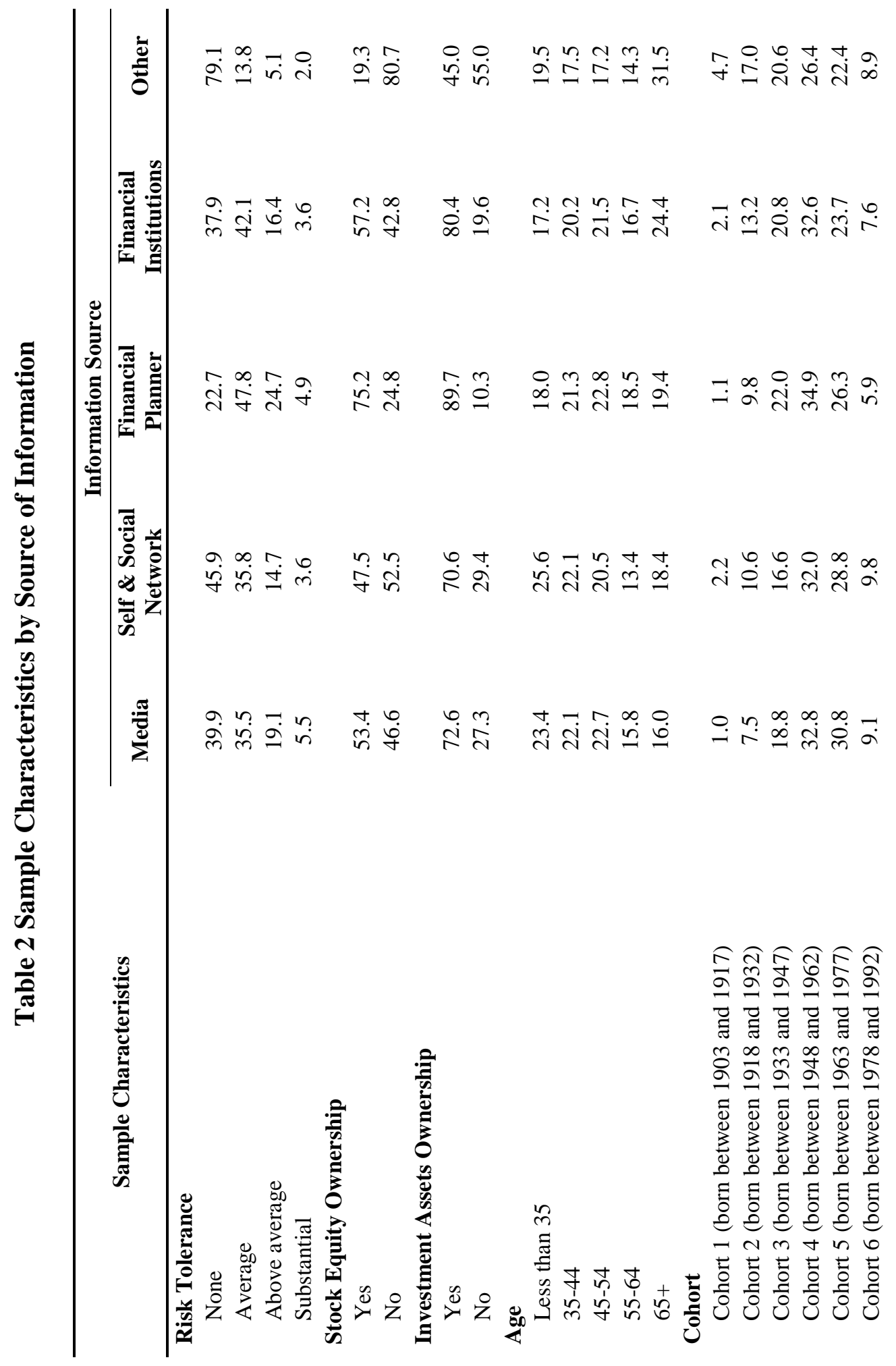




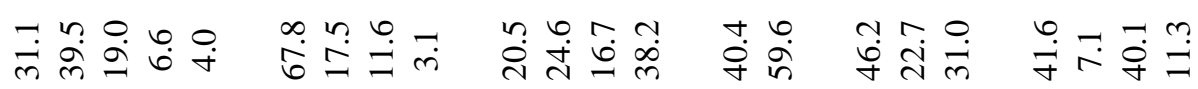

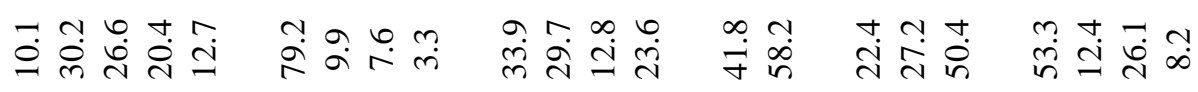

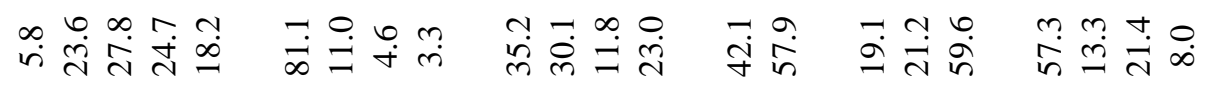

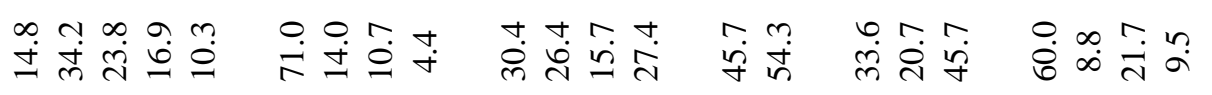

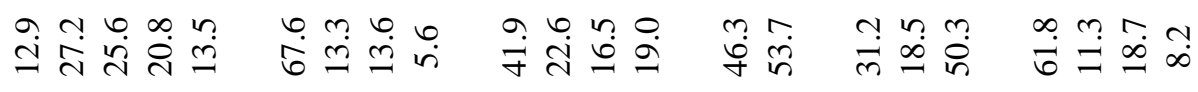

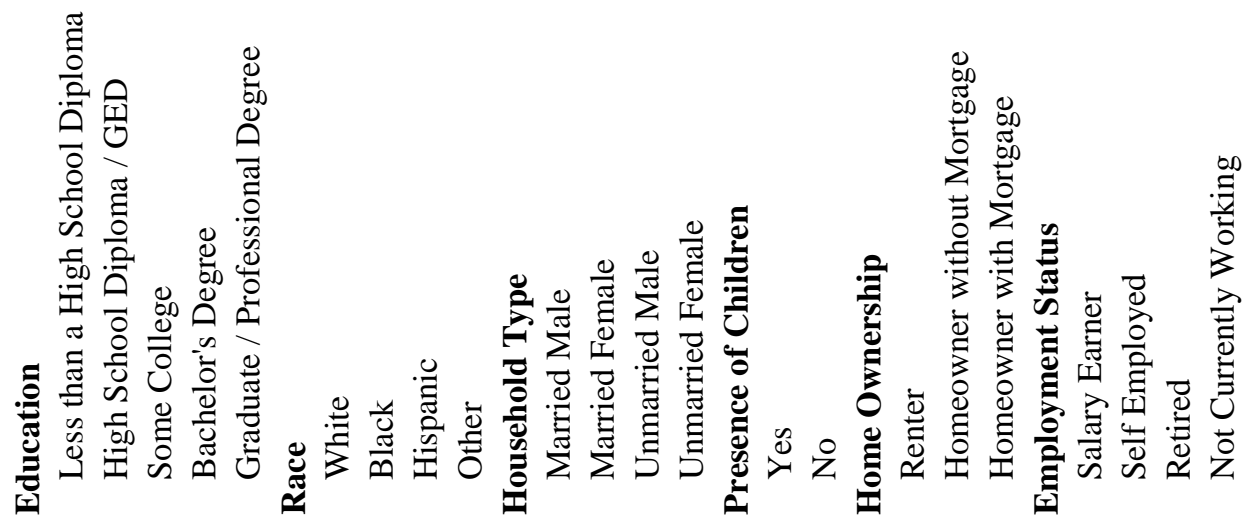




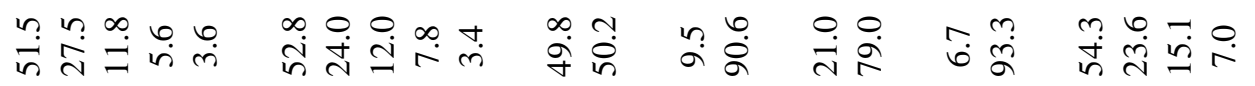

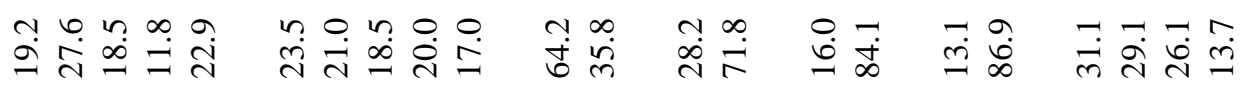

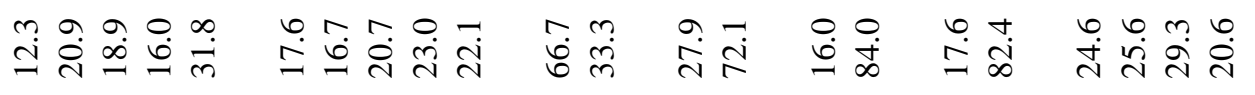

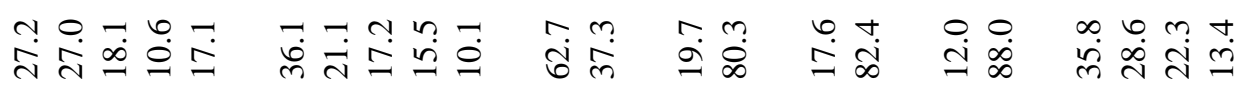

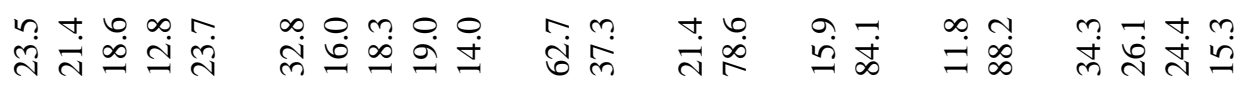

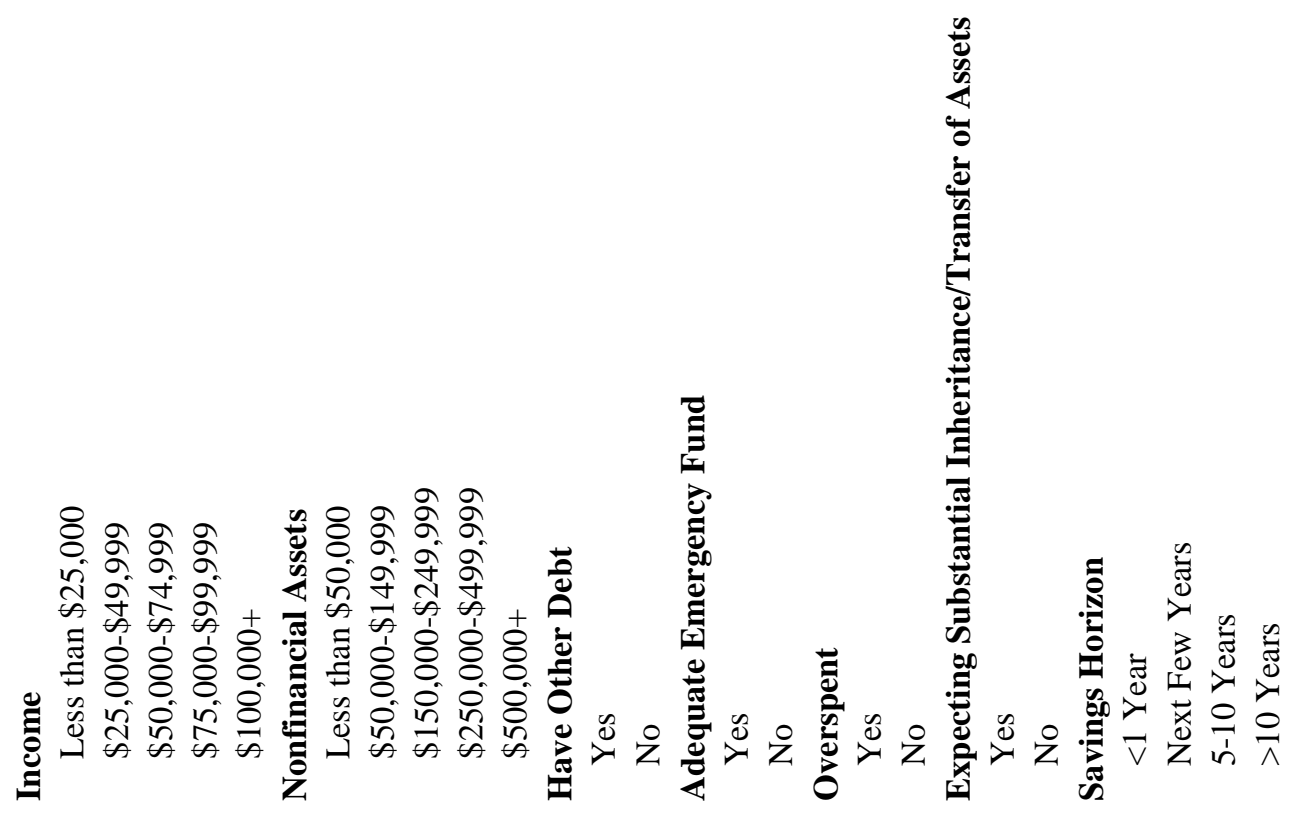




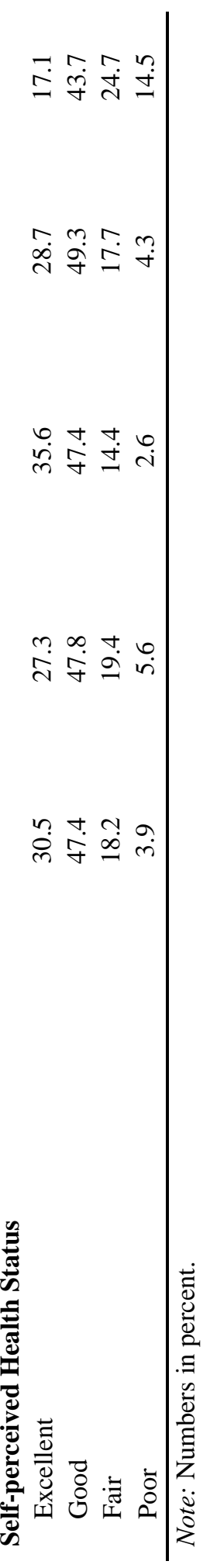


and those who used self and social network. The biggest percentage of these two groups reported no risk tolerance $39.9 \%$ for the media group and $45.9 \%$ for the self and social network group).

The next biggest risk tolerance group was average risk tolerance, which accounted for a little over one-third of both groups (35.5\% for the media group and $35.8 \%$ for the self and social network group). Relatively few respondents reported substantial household risk tolerance $(5.5 \%$ for the media group and $3.6 \%$ for the self and social network group). Among those who used financial planners, about one-fourth $(22.7 \%)$ reported no risk tolerance and another one-fourth (24.7\%) reported above average risk tolerance. Almost half (47.8\%) of them reported an average level of risk tolerance and 4.9\% reported substantial risk tolerance. Among those who used financial institutions, the percentages reporting above average (16.4\%) and substantial (3.6\%) risk tolerance were similar to those who used self and social network. However, the biggest percentage of this group reported an average (42.1\%) level of risk tolerance. Among households who used information other than from the above categories, the majority $(79.1 \%)$ reported no tolerance for financial risks; $13.8 \%$ reported average risk tolerance, $5.1 \%$ reported above average and only $2.0 \%$ reported an appetite for substantial risk tolerance.

Among households who used media for financial information when making savings and investment decisions, 53.4\% had stock equity ownership. The percentage of households who had stock equity ownership was slightly higher (57.2\%) among those who used financial institution for information when they made savings and investment decisions. Households who had stock equity accounted for $47.5 \%$ among those who used 
self and social network for information and $19.3 \%$ for those who searched information from other sources. About three-fourths (75.2\%) of households who worked with a financial planner had stock equity in their portfolio.

The majority of households had investment assets in their portfolio (percentage ranged from $70.6 \%$ for those who used self and social network to $89.7 \%$ for those who worked with a financial planner). The exception is the "other" category. Among households who searched information from other sources when they made savings and investment decisions, only $45.0 \%$ owned investment assets.

Among those who used media for information when making savings and investment decisions, $23.4 \%$ were less than 35 years old, $22.1 \%$ were between 35 and 44 years of age, $22.7 \%$ were between 45 and 54, $15.8 \%$ were between 55 and 64, and 16.0\% were 65 or older. The age distribution of the group who used self and social network was similar, with the highest percentage being less than 35 (25.6\%) and the lowest percentage being between 55 and 64 (13.4\%). The distribution of age was similar for the groups who worked with a financial planner and who used financial institutions for information when making savings and investment decisions. The highest percentage of those respondents was between 45 and 54 years old (22.8\% for the financial planner group and $21.5 \%$ for the financial institutions group). The highest percentage of households who searched information from other sources when making savings and investment decisions was 65 or older.

Among households who used media for information when making savings and investment decisions, 1.0\% was in cohort 1 (born between 1903 and 1917) and 32.8\% 
was in cohort 4 (born between 1962 and 1948). The distribution of cohort was very similar for all information groups. Among households who used media for information when making savings and investment decisions, $1.0 \%$ was in cohort 1 (born between 1903 and 1917) and 32.8\% was in cohort 4 (born between 1962 and 1948). Among households who worked with a financial planner when making savings and investment decisions, $1.1 \%$ belonged to cohort 1 and $34.9 \%$ was in cohort 4 .

Households who used financial planners appeared to be the most educated: $27.8 \%$ had some college education, $24.7 \%$ had a bachelor's degree, and $18.2 \%$ had a graduate or professional degree. Only $5.8 \%$ of those respondents did not complete high school. On the other hand, respondents who reported using other sources for information tended to be the least educated: $31.1 \%$ did not complete high school, 39.5\% completed high school, $19.0 \%$ had some college, $6.6 \%$ had a bachelor's degree, and only $4.0 \%$ had a graduate or professional degree. A majority of respondents who used media for information when making savings and investment decisions had a high school diploma or some college education (27.2\% and 25.6\%, respectively). A little over one-tenth of those respondents (12.9\%) did not complete high school and only $13.5 \%$ had a graduate or professional degree. The percent distribution of education was similar for the self and social network group and the financial institutions group. The highest percentage of these groups had a high school diploma (34.2\% and 30.2\%, respectively), followed by some college education (23.8\% and $26.6 \%$, respectively). The lowest percentage of these groups received a graduate or professional degree (10.3\% and $12.7 \%$, respectively). 
The racial distributions for the financial planner and the financial institutions groups were similar, with an overwhelming majority of respondents being white $(81.1 \%$ and $79.2 \%$, respectively), about one-tenth (11.0\% and 9.9\%, respectively) of them being black, and less than one-tenth being Hispanics or one of other races. Blacks accounted for $17.5 \%$ of the other information source group, and $14.0 \%$ of the self and social network group. The media group contained $13.3 \%$ blacks and $13.6 \%$ Hispanics. The self and social network group had $10.7 \%$ Hispanics and this percentage was $11.6 \%$ for the other information sources group.

Among respondents who used media for information when making savings and investments decisions, $41.9 \%$ were married males, $22.6 \%$ were married females, $16.5 \%$ were unmarried males, and $19.0 \%$ were unmarried females. The distribution of household composition for the group who used self and social network was more even with $30.4 \%$ being married males, $26.4 \%$ being married females, $15.7 \%$ being unmarried males, and $27.4 \%$ being unmarried females. The percent distribution of respondents who used financial planners and those who used financial institutions were similar: a little over one-third were married males (35.2\% for the financial planner group and 33.9\% for the financial institution group). A little less than one-third were married females (30.1\% for the financial planner group and $29.7 \%$ for the financial institution group). About onetenth were unmarried males (11.8\% for the financial planner group and $12.8 \%$ for the financial institution group). Almost one-quarter were unmarried females (23.0\% for the financial planner group and $23.6 \%$ for the financial institution group). The highest percentage of respondents who used other information sources when making savings and 
investment decision was unmarried females (38.2\%). About one-fifth (20.5\%) were married males, $24.6 \%$ were married females, and $16.7 \%$ were unmarried males.

The majority of households, regardless of how they search for information when making savings and investments decisions, did not have dependent children at home. The percentage of households with dependent children ranged from $40.4 \%$ for the other information sources group to $46.3 \%$ for the media group. The majority $(59.6 \%)$ of households who used financial planners were homeowners with a mortgage; $21.2 \%$ of them owned a home without a mortgage; and $19.1 \%$ of them were renters. Among households who used financial institutions, $50.4 \%$ of them owned a home with a mortgage; $27.2 \%$ owned a home without a mortgage; and $22.4 \%$ rented. The distributions of home ownership among households who used media and those who used self and social network for information were similar. About half of those households were homeowners with a mortgage $(50.3 \%$ for the media group and $45.7 \%$ for the self and social network group). About one-third were renters (31.2\% for the media group and $33.6 \%$ for the self and social network group). About one-fifth were homeowners with a mortgage (18.5\% for the media group and $20.7 \%$ for the self and social network group). Among those who used other sources for savings and investment information, $46.2 \%$ rented, $31.0 \%$ owned a home with a mortgage, and $22.7 \%$ owned a home with no mortgage.

The distributions of employment status for the media group and the self and social network group were similar. The majority of these respondents were employees $(61.8 \%$ for the media group and $60.0 \%$ for the self and social network group); about one-tenth 
were self-employed (11.3\% for the media group and $8.8 \%$ for the self and social network group); another one-tenth were not currently working $(8.2 \%$ for the media group and $9.5 \%$ for the self and social network group); and the remainder were retired (18.7\% for the media group and $21.7 \%$ for the self and social network group). Among respondents who used financial planners, $57.3 \%$ were employees, $13.3 \%$ were self-employed, $21.4 \%$ were retired, and $8.0 \%$ were not currently working. The distribution of employment status of the group who used financial institutions was very similar to the financial planner group, with $53.3 \%$ employees, $12.4 \%$ self-employed, $26.1 \%$ retired, and $8.2 \%$ not currently working. Among those who used other sources for information when making savings and investments decisions, only $41.6 \%$ were employees and $7.1 \%$ were self-employed, whereas $40.1 \%$ were retired.

As compared with other groups, the distribution of household income among households who used media is relatively even, with about one-fifth each of two income groups (18.6\% in the $\$ 50,000-\$ 74,999$ group and $21.4 \%$ in the $\$ 25,000-\$ 49,999$ group). A little less than one quarter of the households in each of two income groups $(23.5 \%$ in the less than $\$ 25,000$ group and $23.7 \%$ in the $\$ 100,000+$ group) and $12.8 \%$ of the households had between $\$ 75,000$ and $\$ 99,999$. Among households who used self and social network, a higher percentage was in the lowest two income categories $(27.2 \%$ had income less than $\$ 25,000$ and $27.0 \%$ had $\$ 25,000-\$ 49,999)$. Households who used financial planners reported higher incomes: $31.8 \%$ had a household income of $\$ 100,000$ or more and only $12.3 \%$ had less than $\$ 25,000$. About half of households who used financial institutions for information when making savings and investments decisions 
were in the lowest two income categories (19.2\% had income less than $\$ 25,000$ and $27.6 \%$ had $\$ 25,000-\$ 49,999)$. The majority $(51.5 \%)$ of households who used other sources of information were in the lowest income group (less than $\$ 25,000)$. More than a quarter $(27.5 \%)$ of them had a household income between $\$ 25,000$ and $\$ 49,999$. Only $5.6 \%$ of them were in the $\$ 75,000-\$ 99,999$ income group, and $3.6 \%$ of them were in the $\$ 100,000+$ income group.

Among households who used media for information when making savings and investments decisions, $32.8 \%$ had less than $\$ 50,000$ nonfinancial assets, $16.0 \%$ had between $\$ 50,000$ and $\$ 149,999,18.3 \%$ had between $\$ 150,000$ and $\$ 249,999,19.0 \%$ had between $\$ 250,000$ and $\$ 499,999$, and $14.0 \%$ had $\% 500,000$ or more. The majority of households in the self and social network group had less than $\$ 150,000$ in nonfinancial assets, with $36.1 \%$ in the less than $\$ 50,000$ group and $21.1 \%$ in the $\$ 50,000-\$ 149,999$ group. About one-tenth of these households had $\$ 500,000$ or more. The distribution of nonfinancial assets among households who used financial planners was more even, with $17.6 \%$ in the less than $\$ 50,000$ group, $16.7 \%$ in the $\$ 50,000-\$ 149,999$ group, $20.7 \%$ in the $\$ 150,000-\$ 249,000$ group, $23.0 \%$ in the $\$ 250,000-\$ 499,999$ group, and 22.1 in the $\$ 500,000+$ group. Among households who used financial institutions, $23.5 \%$ of them had less than $\$ 50,000$ in nonfinancial assets, $21.0 \%$ had between $\$ 50,000$ and $\$ 149,999$, $18.5 \%$ had between $\$ 150,000$ and $\$ 249,999,20.0 \%$ had between $\$ 250,000$ and $\$ 499,000$, and $17.0 \%$ had half million or more. The majority $(52.8 \%)$ of households who used other 
sources of information had less than $\$ 50,000$ in nonfinancial assets. Only $11.2 \%$ of them had $\$ 250,000$ or more $(7.8 \%$ had between $\$ 250,000$ and $\$ 499,999$ in nonfinancial assets and $3.4 \%$ had $\$ 500,000+)$.

The majority of households (percentage ranging from $62.7 \%$ for the media and self and network groups to $66.7 \%$ for the financial planner group) had debt other than a home mortgage, except for the group who used other sources of information (percentage $=49.8 \%$ ) when making savings and investment decisions. An overwhelming majority of the households did not have an adequate level of emergency fund and did not overspend. The percentage of households who had an adequate level of emergency fund was the lowest $(9.5 \%)$ for the group who used information from other sources and highest (28.2\%) for the group who searched information from financial institutions when making savings and investment decisions. The percentage of households who did not overspend ranged from $15.9 \%$ for the group who used media for information to $21.0 \%$ for those households who searched information from other sources when making savings and investment decisions.

Regardless of information sources, the overwhelming majority of the households did not expect substantial inheritance or asset transfers (percentage ranging from $82.4 \%$ for the financial planner group and $93.3 \%$ for the other information group). Among households who used media for information, 34.3\% reported less than one year as their savings horizon, $26.1 \%$ reported next few years, $24.4 \%$ reported next 5 to 10 years, and $15.3 \%$ reported longer than 10 years. The distributions of savings horizons of the self and social network group and the financial institution group were similar to this. The 
distribution of saving horizon for the financial planner group was more even: $24.6 \%$ reported less than one year, 25.6\% reported next few years, 29.3\% reported 5 to 10 years, and $20.6 \%$ reported longer than 10 years. The majority (54.3\%) of households who used other sources for information reported the shortest savings horizon. Only $6.5 \%$ had a savings horizon of longer than 10 years.

Regardless of information sources, the majority of respondents reported excellent or good health. The financial planner group had the highest percentage (35.6\%) of respondents reporting excellent health. The other information source group had the lowest percentage (17.1\%) of respondents reporting excellent health. More than twofifths of respondents in each group reported good health. This percentage ranged from $43.7 \%$ for the other information group to $49.3 \%$ for the financial institution group. Among respondents who searched information from other sources, $14.5 \%$ reported a poor health. Less than one-tenth of the rest of the respondents reported a poor health (percentage ranging from 2.6\% for the financial planner group and 5.6\% for the self and network group).

\subsubsection{Consistency in Risk Attitude and Behavior by Source of}

\section{Information and Survey Year}

Table 3 showed the consistency in households' reported level of risk tolerance and investment behavior across various sources of information categories in each survey year. Overall, the percentage of total households in the combined sample seeking information from financial planners when making savings and investment decisions was 


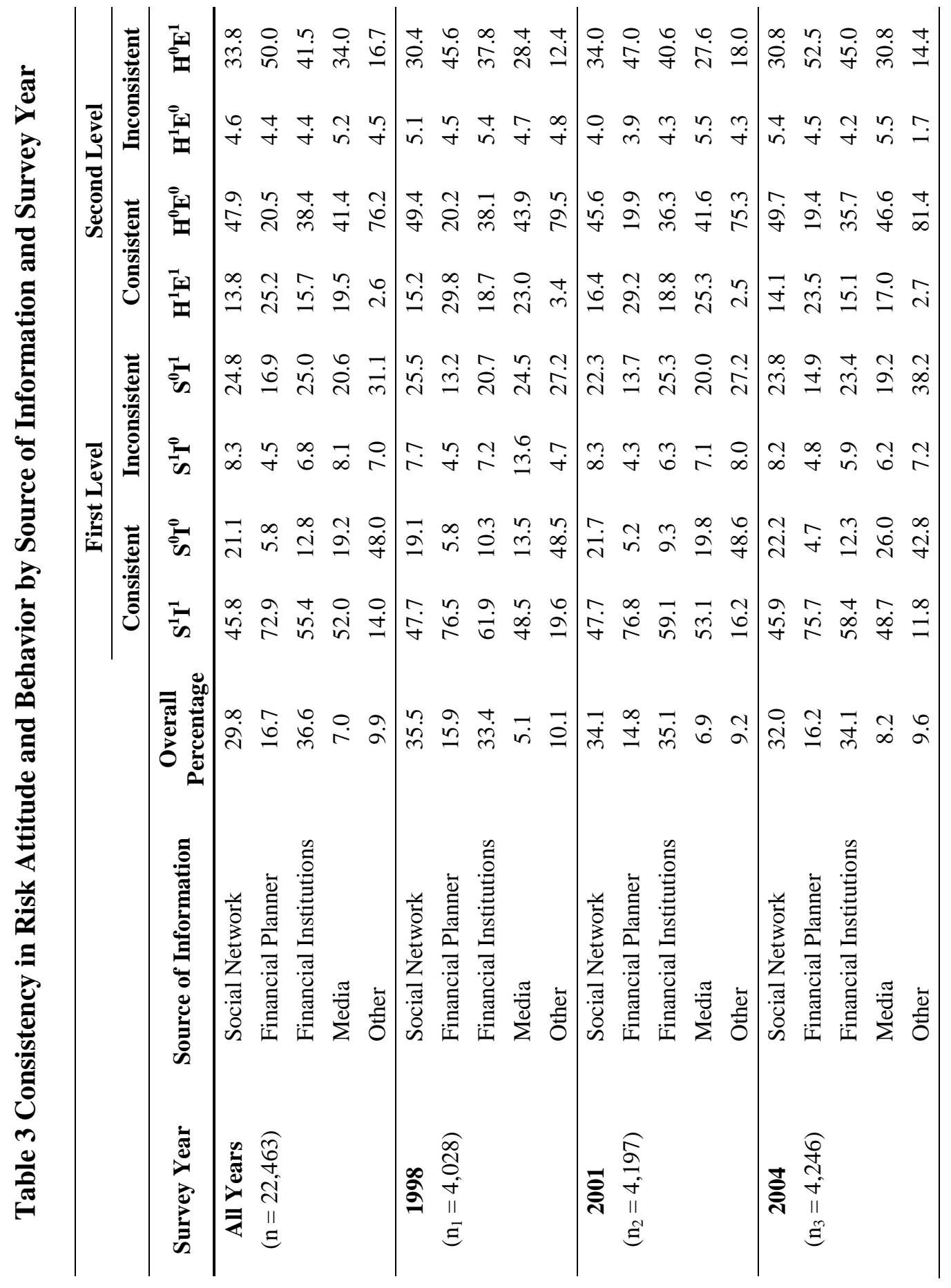




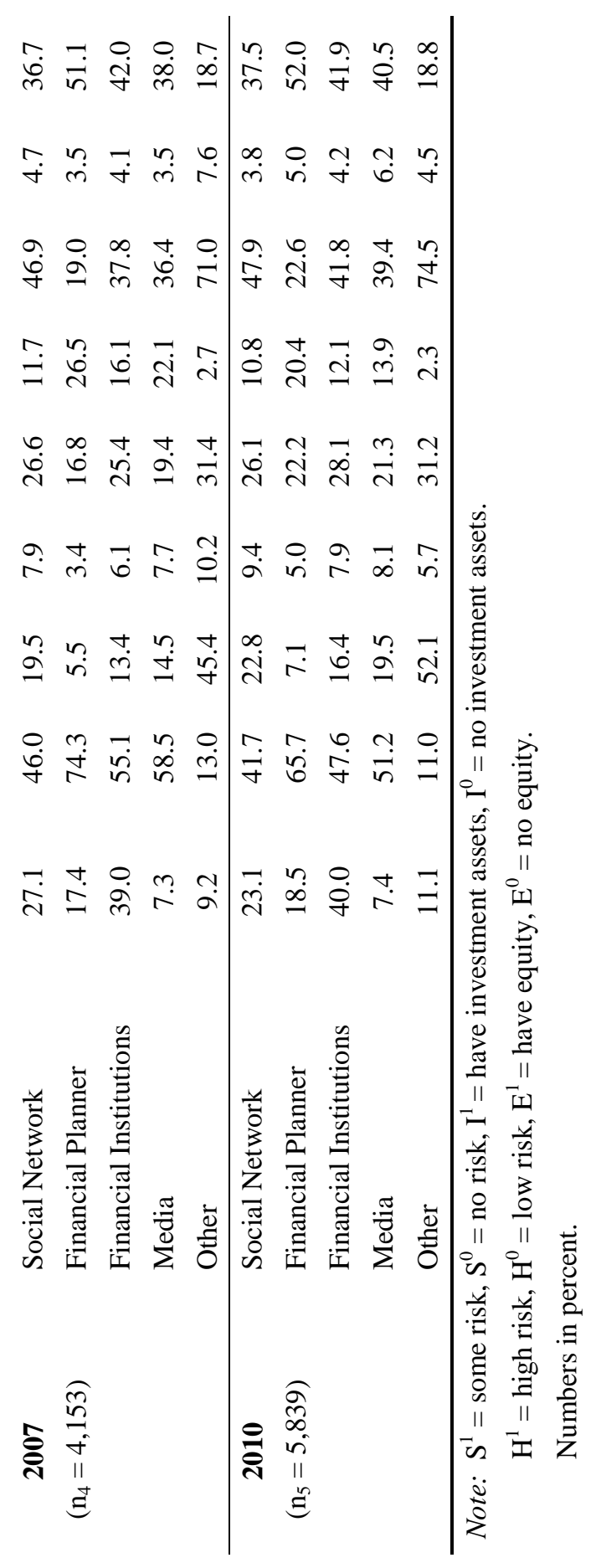


higher in later survey years (15.9\% in 1998 and 18.5\% in 2010), except for a slight dip in $2001(14.8 \%)$. The percentage of households who used self or social network for information was lower in late survey years (35.5\% in 1998 and $23.1 \%$ in 2010). The percentage of households using information from financial institutions when making savings and investment decisions started at $33.4 \%$ in 1998 and was higher in later years (40.0\% in 2010), except for a slight dip in 2001(34.1\%).

In all survey years, the majority of households were consistent in either having some risk tolerance and some investment assets or no risk tolerance and no investment assets, regardless of their sources of information when making savings and investment decisions. For example, $82.3 \%$ of households who used financial planners for information were consistent at the first level (some risk tolerance and some investment assets or no risk tolerance and no investment assets) in 1998. This percentage was $82.0 \%$ in $2001,80.4 \%$ in $2004,79.8 \%$ in 2007 , and $72.8 \%$ in 2010 . During the same period of time, the percentages of households who used financial institutions and showed the first level consistency were $72.2 \%$ in $1998,68.4 \%$ in $2001,70.7 \%$ in $2004,68.5 \%$ in 2007 , and $64.0 \%$ in 2010. The percentage of households in the self and social network group being consistent at this level peaked at $69.4 \%$ in 2001 and was the lowest in 2010 (64.5\%). The percentage of households who sought information from media when making savings and investment decisions and were consistent at this level ranged from $62.0 \%$ in 1998 to $74.7 \%$ in 2004 .

As compared with households using all other sources of information, those who sought information from financial planners demonstrated the highest consistency in risk 
attitude and behavior at the first level. From 1998 to 2004, more than two-thirds of households had some risk tolerance and some investment assets. This percentage dropped to $75.7 \%$ in 2004 and $65.7 \%$ in 2010 . The percentage of those who reported no risk tolerance and no investment assets started at 5.8\% in 1998 and reached $4.7 \%$ in 2004 . In 2010, this percentage was $7.1 \%$. Households who used other sources of information showed the highest percent of inconsistency at the first level in four of the five survey years. In $2004,45.4 \%$ of these households either had some risk tolerance but no investment assets or were not willing to take any financial risk tolerance but had some investment assets in their portfolio. On the other hand, households who used financial planners when making savings and investment decisions showed the lowest level of inconsistency in all survey years. This percentage was below $20 \%$ in the first three years and was $20.2 \%$ in 2007 and $27.2 \%$ in 2010 . However, within the group of households who used a financial planner, the percent of households who reported no tolerance for financial risks but had some investment assets was higher in later survey years $(13.2 \%$ in 1998 and $22.2 \%$ in 2010).

Table 3 also showed consistency in risk attitude and behavior at the second level (high risk tolerance and equity ownership or low risk tolerance and no equity ownership). Among all households, those who sought information from financial planners demonstrated the highest consistency in having a high risk tolerance and owning equity assets. In 1998, households who reported a high level of risk tolerance (above average or substantial) and had equity in their portfolio accounted for $29.8 \%$ of the group of households who used financial planners. In the same year, this percentage was $23.0 \%$ for 
the media group, $18.7 \%$ for the financial institution group, $15.2 \%$ for the self and social network group, and $3.4 \%$ for the other information group. The percentage having a high risk tolerance and owning equity assets for the financial planner was lower in the next two survey years (29.2\% in 2001 and $23.5 \%$ in 2004) and was $26.5 \%$ in 2007 and $20.4 \%$ in 2010. Households who used media for financial information showed the second highest consistency of having a high risk tolerance and owning equity assets. While only below $5 \%$ of households who used other sources of information reported high risk tolerance and equity ownership in all survey years, the overwhelming majority of households who used other sources of information reported a low level of risk tolerance (average or none) and no equity ownership. This percentage was $79.5 \%$ in $1998,75.3 \%$ in $2001,81.4 \%$ in $2004,71.0 \%$ in 2007 , and $74.5 \%$ in 2010 . Households who reported low risk tolerance and no equity ownership accounted for only between $19.0 \%$ and $22.6 \%$ of the group of households who used financial planners, lowest among all groups of information sources.

On the other hand, households who used financial planners information showed the highest percent of inconsistency at the second level in all five survey years, with most of them (percentage ranging from 50.1\% in 1998 to $57.0 \%$ in 2004 and 2010) either having high risk tolerance but no equity or having low risk tolerance but some equity. The percentage of households who used financial planners and reported low risk tolerance but some equity was also the highest among all groups of information source. This percentage was $45.6 \%$ in $1998,47.0 \%$ in $2001,52.5 \%$ in $2004,51.1 \%$ in 2007 , and $52.0 \%$ in 2010. Households who used financial institutions for financial information 
showed the second highest inconsistency at the second level. The percentage of households who used financial institutions and reported low risk tolerance but some equity ranged from $37.8 \%$ to $45.0 \%$. Only less than one-fifth of households who used other sources of information reported low risk tolerance and equity ownership in all survey years. This percentage ranged from $12.4 \%$ in 1998 to $18.7 \%$ in 2001 .

\subsubsection{Consistency in Risk Attitude and Behavior by Sample}

\section{Characteristics and Survey Year}

Some financial risk tolerance vs. investment asset ownership. In all survey years, as shown in Table 4, the majority (69.2\%) of households were consistent in risk attitudes and behavior at the first level (some risk tolerance and some investment assets or no risk tolerance and no investment assets). On the other hand, this percentage was lower in later survey years (70.9\% in 1998 and 66.1\% in 2010). During the same period of time, the overall inconsistency at the first level was 30.9\%, with $7.0 \%$ reporting some risk tolerance and no investment assets and $23.9 \%$ reporting no risk tolerance but some investment assets. As a result, $77.3 \%$ of the inconsistency at this level was from holding some investment assets but unwilling to take any financial risks. The percent of households reporting no risk tolerance but some investment assets started at $22.0 \%$ in 1998 and reached $26.4 \%$ in 2010.

Overall, $18.1 \%$ of households were unwilling to take any financial risks and did not hold any investment assets and $23.9 \%$ of households were unwilling to take any financial risks and had some investment assets. Therefore, among households who 


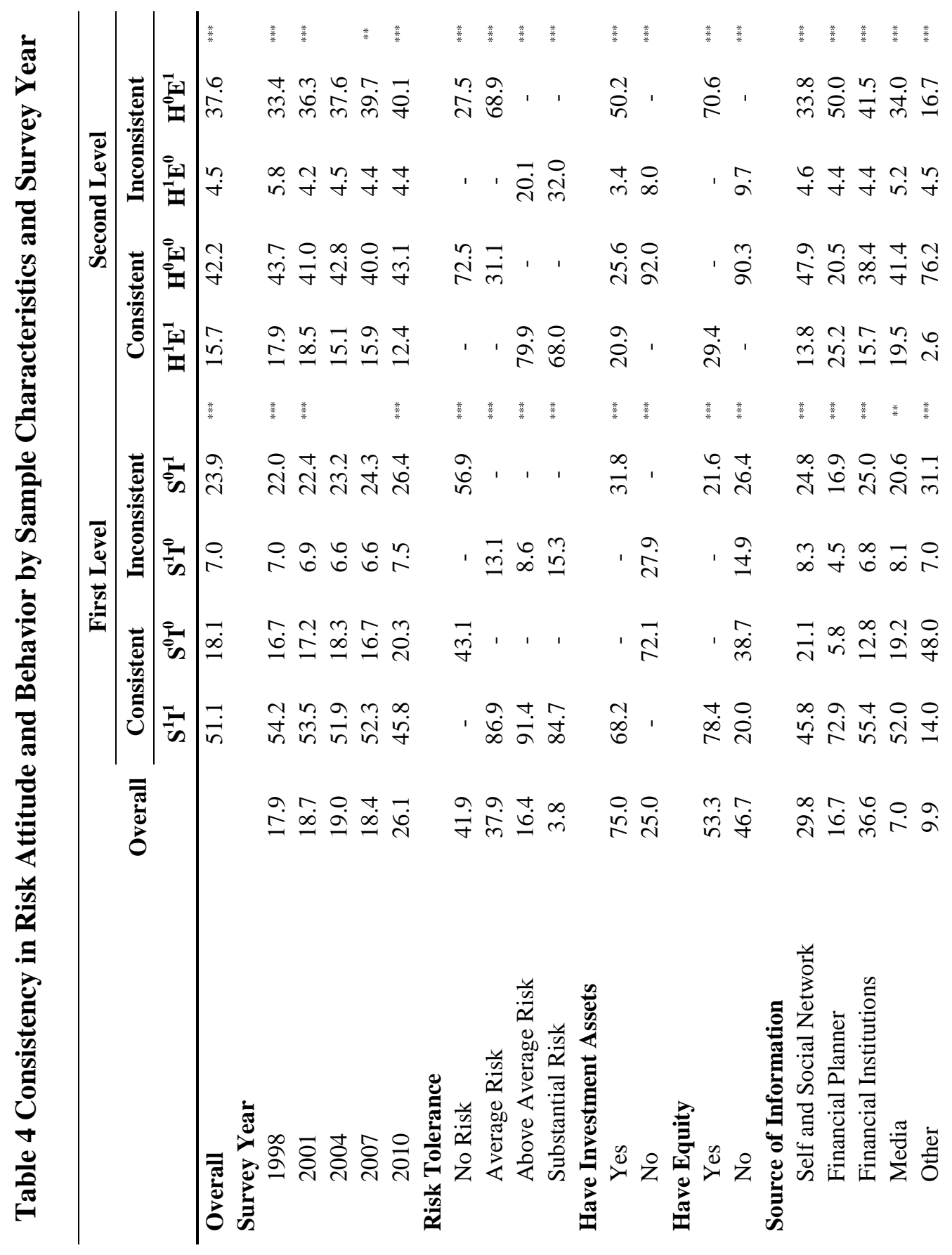




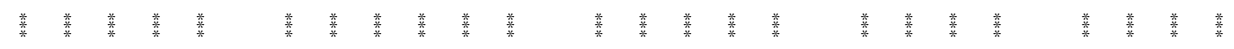

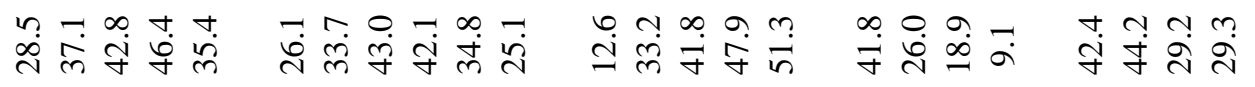
m

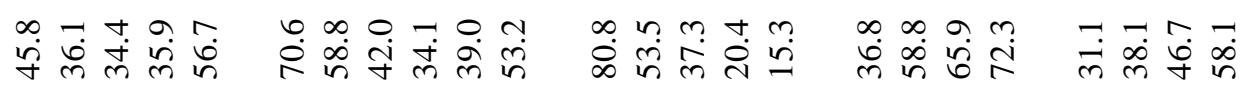

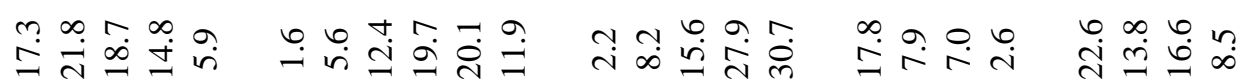

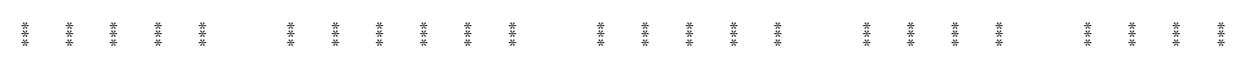

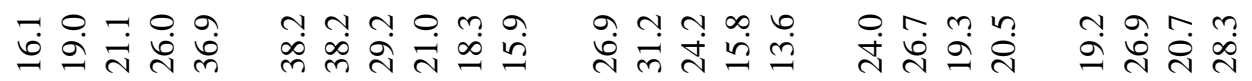

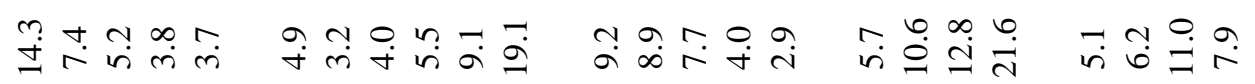

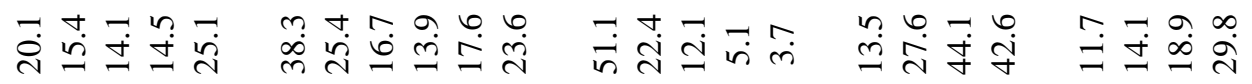

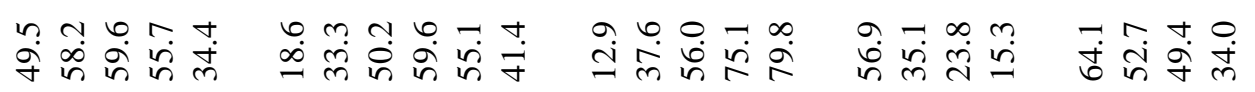

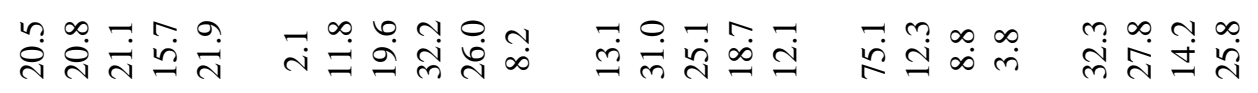

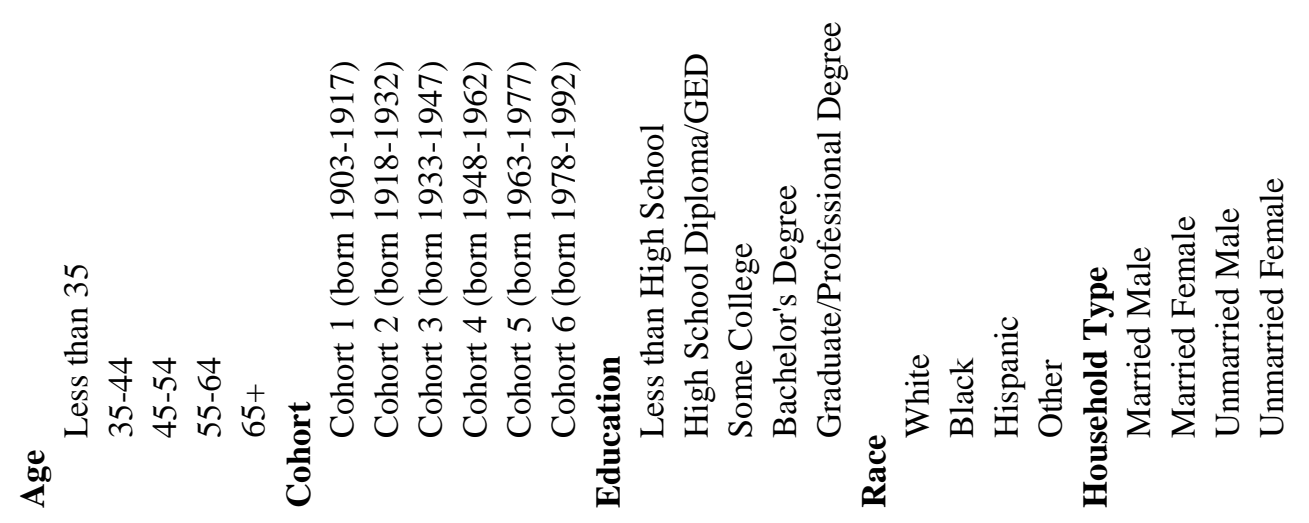




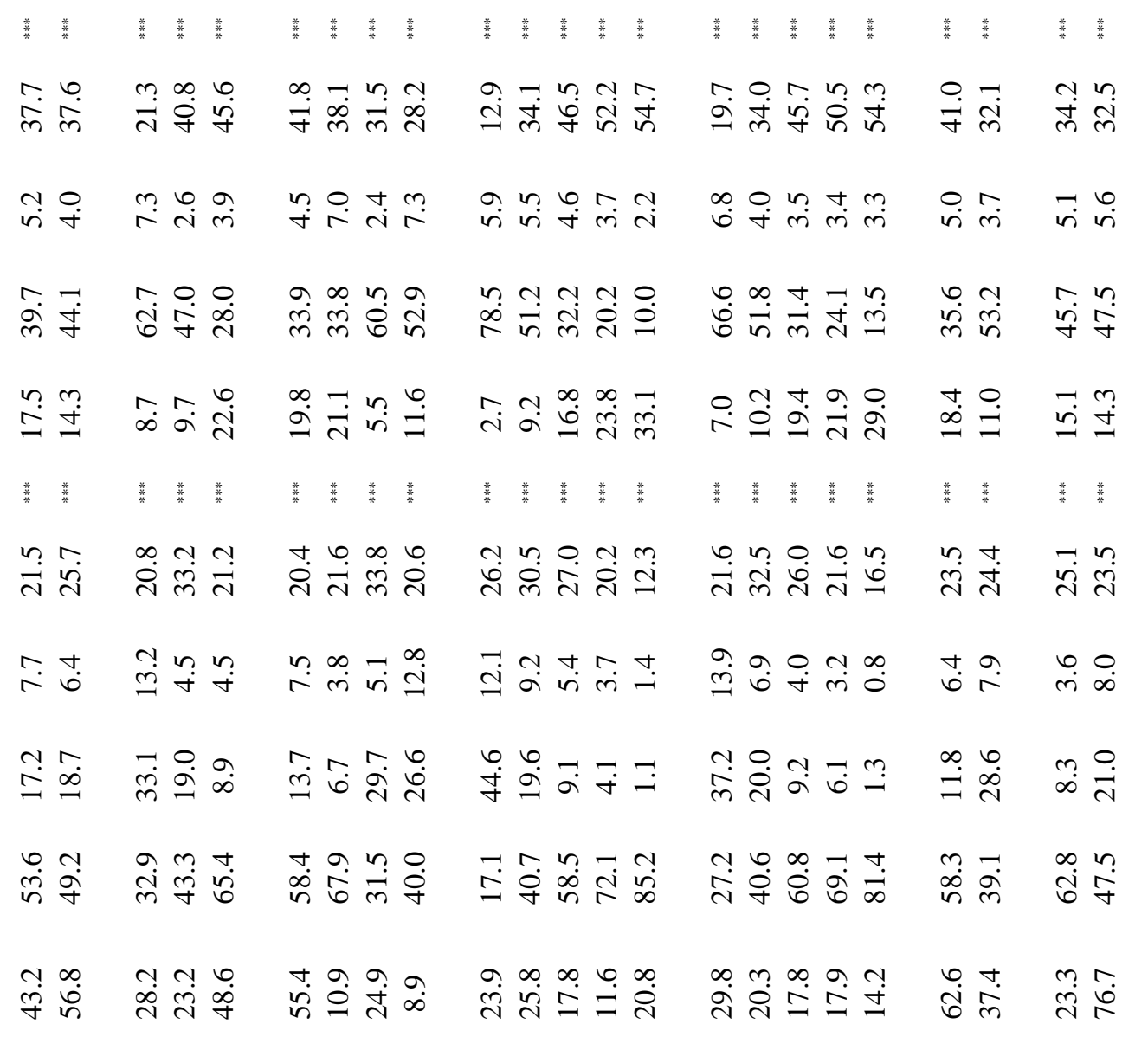

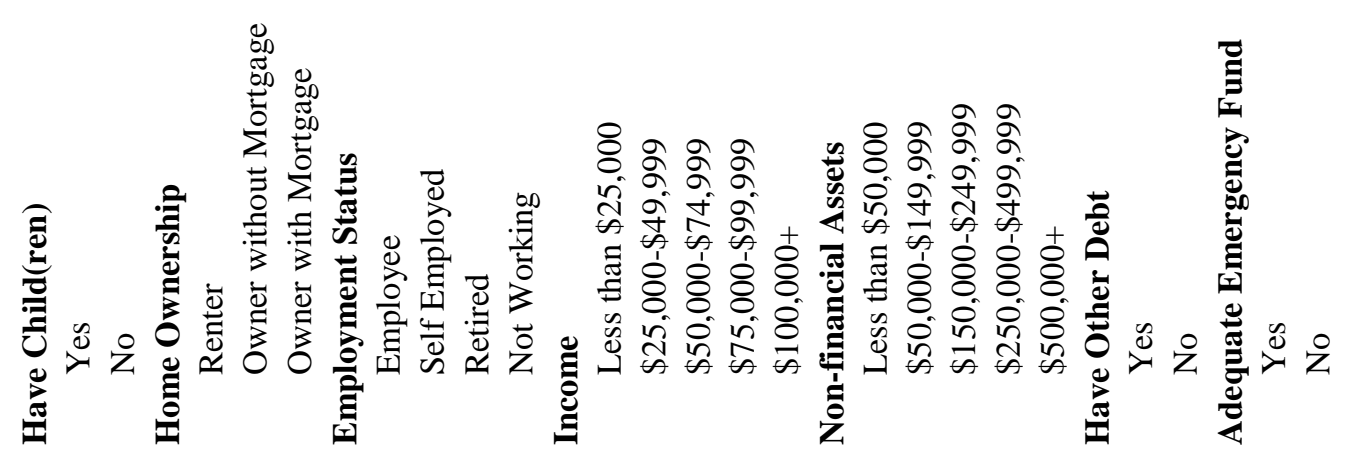




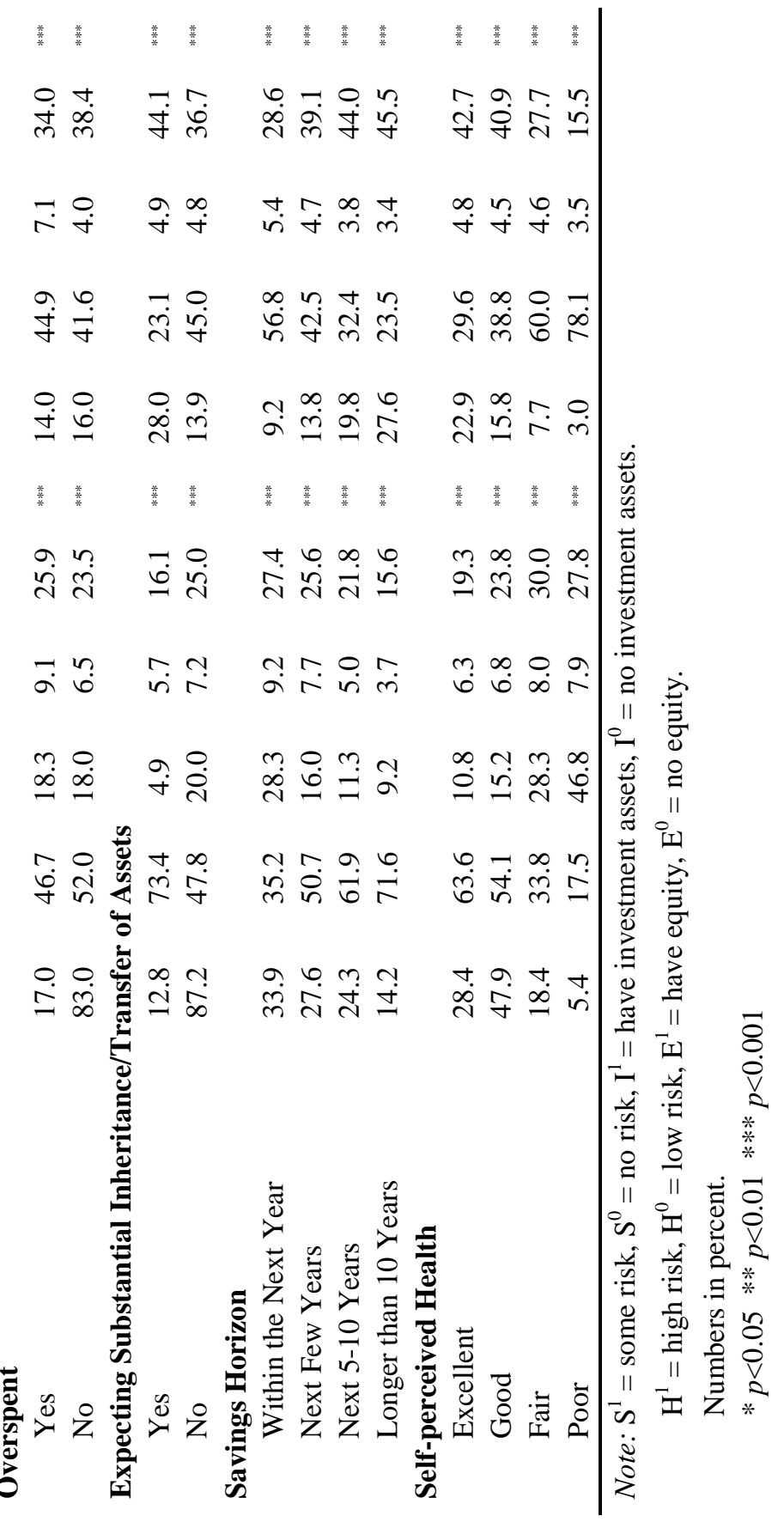


reported not being willing to take any financial risks, a majority of (56.9\%) of them had some investment assets. An overall of $58.1 \%$ of households expressed an appetite for some financial risks. Among them, $88.0 \%$ had some investment assets and only $12.0 \%$ did not.

Of those who had an average level of risk tolerance, $86.9 \%$ had investment assets and $13.1 \%$ did not. The majority of households who reported a willingness to take above average risks had investment assets (91.4\%). Similarly, the majority of households who reported a willingness to take substantial financial risks had investment assets $(84.7 \%)$. Most households who had investment assets reported some tolerance for financial risks $(68.2 \%)$, while $31.8 \%$ were not willing to take any financial risks. Also, most households who had equity reported at least some risk tolerance $(78.4 \%)$, while $21.6 \%$ reported no tolerance for financial risks.

Households using financial planners had the highest percentage of being consistent at the first level, with $72.9 \%$ having some risk tolerance and investment assets and $5.8 \%$ having no risk tolerance and no investment assets. They were also the least likely to be inconsistent in both ways. Only $4.5 \%$ of them would like to take some financial risks but did not have investment assets and $16.9 \%$ were not willing to take financial risks but had some investment assets. Households using other sources of information were the most likely to report no risk tolerance and no investment assets $(48.0 \%)$. They were also the most likely to own some investment assets but report no tolerance for financial risks $(31.1 \%)$. 
Respondents in the 45-54 age group had the highest percentage (59.6\%) of reporting some risk tolerance and some investment assets. They were also the least likely (14.1\%) to report no risk tolerance and no investment assets. Respondents in the 65+ group were the most likely to report no risk tolerance and no investment assets (25.1\%) and the least likely to report some risk tolerance and some investment assets (34.1\%). The percent of respondents having some risk tolerance but no investment assets decreased from $14.3 \%$ for the less than 35 age group to $3.7 \%$ for the $65+$ age group. The percent of respondents having no risk tolerance but some investment assets increased with age, with $16.1 \%$ for the less than 35 age group and $36.9 \%$ for the $65+$ age group.

Respondents in cohort 4 (born between 1948 and 1962) were the most likely to be consistent in their risk attitude and behavior at the first level (percentage $=73.5 \%$ ). They were also the most likely to report some financial risk tolerance and investment asset ownership (percentage $=59.6 \%$ ), which contributed to $81.1 \%$ of the first level consistency. The oldest cohort members (born between 1903 and 1917) were the most likely to be inconsistent in their risk attitude and behavior at the first level (percentage $=43.1 \%$ ). They were also the most likely to report no financial risk tolerance with investment asset ownership (percentage $=38.2 \%$ ), which contributed to $88.6 \%$ of the inconsistency at the first level. Members of cohort 6 (born 1978-1992) were the most likely to have some tolerance for financial risks but did not have any investment assets in their portfolio (percentage $=19.1 \%)$.

The percent of respondents willing to take some financial risks and having some investment assets increased with education, with $12.9 \%$ for the least educated (did not 
complete high school) group and $79.8 \%$ for the most educated (had a graduate or professional degree) group. The percent of respondents having no risk tolerance and no investment assets decreased with education, with $51.1 \%$ for the least educated group and $3.7 \%$ for the most educated group. Both types of inconsistency at the first level (some risk tolerance with no investment assets and no risk tolerance with some investment assets) generally decreased with education except that the percentages were lower for the least educated respondents (less than high school diploma) than those who completed high school (26.9\% and 31.2\%, respectively).

Whites were the most likely to report some risk tolerance and some investment assets (56.9\%), followed by blacks (35.1\%) and Hispanics (23.8\%). Respondents of other races were the least likely (15.3\%) to report the same consistency. Hispanic respondents were the most likely to be willing to take no financial risks and having no investment assets $(44.1 \%)$. Whites were the least likely to report some risk tolerance but have no investment assets (5.7\%). Over one-fourth (26.7\%) of blacks reported no risk tolerance but had some investment assets, highest among the four race/ethnicity groups.

Most of married respondents reported some risk tolerance and some investment assets (64.1\% for married males and $52.7 \%$ for married females). Only $34.0 \%$ of unmarried females reported the same type of consistency, lowest among all household types. Unmarried females were also the most likely to have no risk tolerance and no investment assets (29.8\%). Married males were the least likely to be inconsistent at the first level, with 5.1\% reporting some risk tolerance and no investment assets and 19.2\% reporting no risk tolerance but some investment assets. Among households with 
dependent children, $70.8 \%$ were consistent at the first level. A majority of them $(53.6 \%)$ reported some risk tolerance and some investment assets and $17.2 \%$ of them reported no risk tolerance and no investment assets. Only $21.5 \%$ of them reported no risk tolerance and some investment assets.

Homeowners with a mortgage on their home were the most likely to be consistent at the first level (74.3\%), with $65.4 \%$ having some risk tolerance and some investment assets and $8.9 \%$ being unwilling to take any financial risks and having no investment assets. Renters were the most likely to report an unwillingness to take some financial risks and no investment assets ownership (33.1\%) and to report some risk tolerance but no investment assets (13.2\%). However, they were the least likely (20.8\%) to report no risk tolerance and investment asset ownership. About one-third (33.2\%) of homeowners with no mortgage on their home were not willing to take financial risks but had some investment assets, highest among the three home ownership groups.

Respondents in the workforce were more likely to be consistent at the first level, with $72.1 \%$ of employees and $74.6 \%$ self-employed respondents either had investment assets and some risk tolerance or no investment assets and no risk tolerance. Most employees (58.4\%) and self-employed respondents $(67.9 \%)$ had some risk tolerance and some investment assets. About one-fifth of these respondents $(20.4 \%$ for employees and $21.6 \%$ for self-employed people) had some investment assets but was not willing to take any financial risks. One-third $(33.8 \%)$ of retired respondents reported no risk tolerance but had some investment assets. For those who were not working at the time of interview, the percentage who had some investment assets but no risk tolerance was $20.6 \%$. 
The percentage of households being consistent at the first level generally increased with household income. The percentage increased from $61.7 \%$ for the lowest income group (less than $\$ 25,000)$ to $86.3 \%$ for the highest income group $(\$ 100,000+$ ), except that the percentage was $60.3 \%$ for the second lowest income group $(\$ 25,000$ $\$ 49,999)$. The percentage of households reporting some financial risk tolerance and some investment assets was higher for households with higher household incomes. This percentage was $17.1 \%$ for households with less than $\$ 25,000$ household income, $40.7 \%$ for households with an income between $\$ 25,000$ and $\$ 49,999,58.5 \%$ for households with an income between $\$ 50,000$ and $\$ 74,999,72.1 \%$ for households with an income between $\$ 75,000$ and $\$ 99,999$, and $85.2 \%$ for households with an income higher than $\$ 100,000$. Conversely, the percentage of households reporting no financial risk tolerance and no investment assets was higher for households with lower household incomes. This percentage was $44.6 \%$ for households with less than $\$ 25,000$ household income, $19.6 \%$ for households with an income between $\$ 25,000$ and $\$ 49,999,9.1 \%$ for households with an income between $\$ 50,000$ and $\$ 74,999,4.1 \%$ for households with an income between $\$ 75,000$ and $\$ 99,999$, and only $1.1 \%$ for households with an income higher than $\$ 100,000$.

In a similar vein, the percent reporting some financial risk tolerance but no investment assets was also higher for households with lower household incomes. The percentage decreased from $12.1 \%$ for households with less than $\$ 25,000$ household income to $1.4 \%$ for households with total household incomes higher than $\$ 100,000$. The percentage of households who reported no risk tolerance but some investment assets was 
highest for households with a total household income between $\$ 25,000$ and $\$ 49,999$ $(30.5 \%)$ and lowest for household with a total household income of $\$ 100,000$ or higher $(12.3 \%)$.

The percent reporting some financial risk tolerance and some investment assets was higher for households with higher non-financial assets. The percentage increased from $27.2 \%$ for households with less than $\$ 50,000$ in non-financial assets to $81.4 \%$ for households with more than $\$ 100,000$ in non-financial assets. Conversely, the percent reporting no financial risk tolerance and no investment assets was higher for households with lower non-financial assets. The percentage was $37.2 \%$ for households with less than $\$ 50,000$ in non-financial assets, $20.0 \%$ for households with non-financial assets between $\$ 50,000$ and $\$ 149,999,9.2 \%$ for households with non-financial assets between $\$ 150,000$ and $\$ 249,999,6.1 \%$ for households with non-financial assets between $\$ 250,000$ and $\$ 499,999$, and $1.3 \%$ for households with more than $\$ 500,000$ in non-financial assets.

In a similar vein, the percent reporting some financial risk tolerance but no investment assets was also higher for households with lower non-financial assets. The percentage was $13.9 \%$ for households with less than $\$ 50,000$ in non-financial assets and $0.8 \%$ for households with more than $\$ 500,000$ in non-financial assets. The percentage of households who reported no risk tolerance but some investment assets was highest for households with between $\$ 50,000$ and $\$ 149,999$ in non-financial assets $(32.5 \%)$ and lowest for household with $\$ 500,000$ or more in non-financial assets $(16.5 \%)$.

Among households who had debts other than their home mortgage, 58.3\% had some risk tolerance and some investment assets and $23.5 \%$ had no risk tolerance but 
some investment assets. Only $18.2 \%$ of these households did not have any investment assets $(11.8 \%$ had no risk tolerance and no investment assets and $6.4 \%$ had some risk tolerance but no investment assets). Most households (62.8\%) with an adequate amount of emergency fund (amount of cash and cash equivalents more than or equal to three months of income) were willing to take some financial risks and had some investment assets. About a quarter of them (25.1\%) reported no financial risk tolerance but had some investment assets.

A higher percentage of households who did not overspend (52.0\%) had some risk tolerance and some investment assets than households who overspent (46.7\%). The percentage of households who reported some risk tolerance but no investment assets was higher for over-spenders $(9.1 \%)$ than those who did not overspend (6.5\%). Also, the percentage of households who reported no risk tolerance but had some investment assets was higher for over-spenders $(25.9 \%)$ than those who did not overspend $(23.5 \%)$.

A higher percentage of households who expected a large assets transfer (73.4\%) had some risk tolerance and some investment assets than households who did not have such an expectation (47.8\%). The percentage of households who reported some risk tolerance but no investment assets was higher for households who did not expect a large asset transfer (7.2\%) than those who did have such an expectation (5.7\%). Also, the percentage of households who reported no risk tolerance but had some investment assets was higher for households who did not expect a large asset transfer $(25.0 \%)$ than those who had such an expectation $(16.1 \%)$. 
The percent reporting some financial risk tolerance and some investment assets was higher for households with longer savings horizons. The percentage was $35.2 \%$ for households with a horizon of less than a year, 50.7\% for households with a horizon of a few years, $61.9 \%$ for households with a horizon of 5 to 10 years, and $71.6 \%$ for households with a horizon of longer than 10 years. Conversely, the percent reporting no financial risk tolerance and no investment assets was higher for households with shorter savings horizons. The percentage decreased from $28.3 \%$ for households with a horizon of less than a year to $9.2 \%$ for households with a horizon of longer than 10 years. In a similar vein, the percent reporting some financial risk tolerance but no investment assets was also higher for households with shorter savings horizons. The percentage was $9.2 \%$ for households with a horizon of less than a year and 3.7\% for households with a horizon of longer than 10 years. The percentage of households who reported no risk tolerance but some investment assets was also higher for households with shorter savings horizon. This percentage decreased from $27.4 \%$ for households with a horizon of less than a year to $15.6 \%$ for households with a horizon of longer than 10 years.

The percentage of respondents reporting some financial risk tolerance and some investment assets was higher for respondents with a better self-perceived health. The percentage was $63.6 \%$ for respondents with an excellent health, $54.1 \%$ for respondents with a good health, $33.8 \%$ for respondents with a fair health, and $17.5 \%$ for respondents with a poor health. Conversely, the percentage of respondents reporting no financial risk tolerance and no investment assets was higher for respondents with a poorer selfperceived health. The percentage increased from $10.8 \%$ for respondents with an 
excellent health to $46.8 \%$ for respondents with a poor health. The percent reporting some financial risk tolerance but no investment assets was highest for respondents with a fair health $(8.0 \%)$ and lowest for respondents with an excellent health (6.3\%). Similarly, respondents with a fair health also had the highest percentage who reported no financial risk tolerance but some investment assets (30.0\%).

High financial risk tolerance vs. equity ownership. In all survey years, the majority of households (57.9\%) were consistent in risk attitudes and behavior at the second level (high risk tolerance and equity ownership or low risk tolerance and no equity ownership). However, this percentage decreased from $61.6 \%$ in 1998 to $55.5 \%$ in 2010. During the same period of time, the overall inconsistency at the second level was $42.1 \%$, with $4.5 \%$ reporting high risk tolerance and no equity and $37.6 \%$ reporting low risk tolerance but some equity. As a result, $89.3 \%$ of the inconsistency at this level was from holding some equity but unwilling to take high financial risks. The percent of households reporting low risk tolerance but some equity increased from $33.4 \%$ in 1998 to $40.1 \%$ in 2010 .

Overall, $42.2 \%$ of households were unwilling to take high financial risks and did not hold any equity and $37.6 \%$ of households were unwilling to take high financial risks and had some equity in their portfolio. Therefore, among households who reported not being willing to take high financial risks, $47.1 \%$ of them had some equity. An overall of 20.2\% of households expressed an appetite for some financial risks. Among them, 77.7\% had some equity and only $22.3 \%$ did not. 
Among households who reported no tolerance for financial risks, $27.5 \%$ of them had equity and $72.5 \%$ of them did not. Of those who had an average level of risk tolerance, $68.9 \%$ had equity and $31.1 \%$ did not. The majority of households who reported a willingness to take above average risks owned some equity (79.9\%). Similarly, the majority of households who reported a willingness to take substantial financial risks had equity (68.0\%). Almost half of households who had investment assets reported ownership of equity (71.1\%). Most households who had equity reported a low risk tolerance $(70.6 \%)$, and only $29.4 \%$ reported high risk tolerance.

The percentage of households who had high risk tolerance and equity were the highest for the financial planner group (25.2\%). Only $20.5 \%$ of this group reported a low level of risk tolerance and had no equity, the lowest among across all information source groups. Households who used financial planners were also the least likely to report a high risk tolerance but no equity $(4.4 \%)$ and the most likely to have a low level of risk tolerance but had equity (50.0\%). However, overall, these households were also the most likely to be inconsistent at the second level (percentage=54.4\%). Having equity but having a low tolerance for financial risks was a major contributing factor (percentage $=91.7 \%$ ) to this consistency. Households using other sources of information were the most likely to report low risk tolerance and no equity $(76.2 \%)$. They were the least likely to own equity but report a low tolerance for financial risks (21.2\%). Although households who sought information from other sources when making savings and 
investment decisions were the most likely to be consistent at the second level (percentage $=78.8 \%$ ), $96.7 \%$ of this consistency was from not having equity and having a low tolerance for financial risks.

The percentage of respondents reporting high risk tolerance and equity ownership increased from $17.3 \%$ for the youngest age group (less than 35 ) to $21.8 \%$ for the $35-44$ age group, then decreased as age increased until it reached $5.9 \%$ for the $65+$ age group. The percent distribution of respondents reporting low risk tolerance and no equity ownership displayed a U shape. It first decreased from $45.8 \%$ for the youngest age group to $34.4 \%$ for the $45-54$ age group, and then increased to $56.7 \%$ for the $65+$ age group. The percentage of respondents having high risk tolerance but no equity decreased from $8.3 \%$ for the less than 35 age group to $2.0 \%$ for the $65+$ age group. The percent of respondents having low risk tolerance but some equity increased from $28.5 \%$ for the less than 35 age group to $46.4 \%$ for the $55-64$ age group and then dropped to $35.4 \%$ for the $65+$ age group.

Respondents in cohort 1 (born between 1903 and 1917) were the most likely to be consistent in their risk attitude and behavior at the second level (percentage $=72.2 \%$ ). They were also the most likely to report a low financial risk tolerance and no equity ownership (percentage $=70.6 \%)$, which contributed to almost all $(97.8 \%)$ of the second level consistency. Cohort 4 members (born between 1948 and 1962) were the most likely to be inconsistent in their risk attitude and behavior at the second level (percentage $=46.2 \%$ ). They were also the most likely to report a low level of financial risk tolerance but had equity in their portfolio (percentage $=42.1 \%$ ), which contributed to 
91.1\% of the inconsistency at the second level. Members of cohort 6 (born 1978-1992) were the most likely to have a high level of tolerance for financial risks but did not have equity in their portfolio (percentage $=9.8 \%$ ).

The percent of respondents willing to take high financial risks and having some equity assets increased with education, with $2.2 \%$ for those who did not complete high school, $8.2 \%$ for respondents with a high school diploma, $15.6 \%$ for respondents who had some college, $27.9 \%$ for respondents who had a bachelor's degree, and $30.7 \%$ for those who had a graduate or a professional degree. The percentage of respondents having low risk tolerance and no equity decreased with education. This percentage decreased from $80.8 \%$ for the least educated group and $15.3 \%$ for the highest educated group. The percentage of respondents having low risk tolerance with some equity assets increased from $12.6 \%$ for the least educated group to $51.3 \%$ for those who had a graduate or a professional degree.

White respondents were the most likely to report high risk tolerance and ownership of equity (17.8\%). This percentage was less than one-tenth for all three other race/ethnicity groups (7.9\% for blacks, $7.0 \%$ for Hispanics, and 2.6\% for other races). Respondents of other races were the most likely to report low risk tolerance and no equity assets $(72.3 \%)$, followed by Hispanics $(65.9 \%)$, blacks $(58.8 \%)$, and whites $(36.8 \%)$. Respondents of other races were also the most likely to report high risk tolerance and no equity (16.1\%) and whites were the least likely to report high risk tolerance and no equity (3.5\%). However, respondents of other races were the least likely to be willing to take low financial risks and having equity assets $(9.1 \%)$. White respondents were the most 
likely to be willing to take low financial risks and having equity assets (41.8\%), followed by blacks $(26.0 \%)$ and Hispanics $(26.0 \%)$.

Married males were the most likely to report high risk tolerance and equity ownership (22.6\%), followed by unmarried males (16.6\%), married females (13.8\%), and unmarried females $(8.5 \%)$. Married males were the least likely to report low risk tolerance and no equity assets $(31.1 \%)$, followed by married females $(38.1 \%)$, and unmarried males (46.7\%). Most of unmarried females had low risk tolerance and no equity assets $(58.1 \%)$. As compared with unmarried respondents, married respondents were more likely to have low financial risk tolerance but have some equity assets $(42.4 \%$ for married males and $44.2 \%$ for married females as versus $29.2 \%$ for unmarried males and $29.3 \%$ for unmarried females). Among households with dependent children, $57.2 \%$ were consistent at the second level with $17.5 \%$ having a high risk tolerance and some equity and $39.7 \%$ reporting a high risk tolerance with an equity ownership. About onethird $(37.7 \%)$ of these households had a low risk tolerance but had some equity in their portfolio and 5.2\% had a high risk tolerance but did not own equity.

Renters were the most likely to be consistent at the second level $(71.4 \%)$, with $8.7 \%$ having high risk tolerance and some equity and $62.7 \%$ having low financial risks and no equity. Therefore, having a low risk tolerance and no equity was a major contributing factor (percentage $=87.8 \%$ ) to this consistency. They were the least likely to have a low risk tolerance but with equity in their portfolio (percentage $=21.3 \%$ ). Homeowners with a mortgage on their home were the most likely to report a willingness to take high financial risks and equity ownership (percentage $=22.6 \%$ ). The percentage for homeowners 
without a mortgage on their home was 9.7\%. Homeowners with a mortgage on their home were the most likely to report a low financial risks with equity ownership (45.6\%). Renters were the most likely to report high risk tolerance but no equity assets (7.3\%). About one-fifth of employees (19.8\%) and self-employed respondents (21.1\%) had high risk tolerance and some equity. About one-third of these respondents (33.9\% for employees and 33.8\% for self-employed people) had some equity but was unwilling to take high financial risks. Most retired respondents (60.5\%) and non-working respondents (52.9\%) reported a low level of risk tolerance and did not have any equity. Respondents in the workforce were more likely to report a low risk tolerance with some equity in their portfolio (41.8\% for employees and $38.1 \%$ for self-employed respondents as versus $31.5 \%$ for retired respondents and $28.2 \%$ for respondents who were not working at the time of the survey interview).

The percentage of households being consistent at the second level generally decreased with household income. The percentage decreased from $81.2 \%$ for the lowest income group (less than $\$ 25,000)$ to $43.1 \%$ for the highest income group $(\$ 100,000+$ ). The percentage of households reporting a high financial risk tolerance and some equity assets was higher for households with higher household incomes. This percentage was $2.7 \%$ for households with less than $\$ 25,000$ household income, $9.2 \%$ for households with an income between $\$ 25,000$ and $\$ 49,999,16.8 \%$ for households with an income between $\$ 50,000$ and $\$ 74,999,23.8 \%$ for households with an income between $\$ 75,000$ and $\$ 99,999$, and $33.1 \%$ for households with an income higher than $\$ 100,000$. Conversely, the percentage of households reporting a low level of financial risk tolerance and no 
equity assets was higher for households with lower household incomes. This percentage was $78.5 \%$ for households with less than $\$ 25,000$ household income, $51.2 \%$ for households with an income between $\$ 25,000$ and $\$ 49,999,32.2 \%$ for households with an income between $\$ 50,000$ and $\$ 74,999,20.2 \%$ for households with an income between $\$ 75,000$ and $\$ 99,999$, and only $10.0 \%$ for households with an income higher than $\$ 100,000$.

In a similar vein, the percent reporting a high financial risk tolerance but no equity assets was also higher for households with lower household incomes. The percentage decreased from $5.9 \%$ for households with less than $\$ 25,000$ household income to $2.2 \%$ for households with total household incomes higher than $\$ 100,000$. The percentage of households who reported a low level of risk tolerance but some equity assets was higher for households with higher household incomes. This percentage increased from $12.9 \%$ for households with less than $\$ 25,000$ household income to $54.7 \%$ for households with total household incomes higher than $\$ 100,000$.

The percentage of households being consistent at the second level generally decreased with non-financial assets. The percentage decreased from $73.6 \%$ for the lowest income group (less than $\$ 25,000)$ to $42.5 \%$ for the highest income group $(\$ 100,000+)$. The percent reporting a high financial risk tolerance and some equity assets was higher for households with higher non-financial assets. The percentage increased from $7.0 \%$ for households with less than $\$ 50,000$ in non-financial assets to $29.0 \%$ for households with more than $\$ 100,000$ in non-financial assets. Conversely, the percent reporting a low level of financial risk tolerance and no equity assets was higher for households with lower non- 
financial assets. The percentage was $66.6 \%$ for households with less than $\$ 50,000$ in non-financial assets, $51.8 \%$ for households with non-financial assets between $\$ 50,000$ and $\$ 149,999,31.4 \%$ for households with non-financial assets between $\$ 150,000$ and $\$ 249,999,24.1 \%$ for households with non-financial assets between $\$ 250,000$ and $\$ 499,999$, and $13.5 \%$ for households with more than $\$ 500,000$ in non-financial assets.

In a similar vein, the percent reporting a high financial risk tolerance but no equity assets was also higher for households with lower non-financial assets. The percentage was $6.8 \%$ for households with less than $\$ 50,000$ in non-financial assets and $3.3 \%$ for households with more than $\$ 500,000$ in non-financial assets. The percentage of households who reported a low level of risk tolerance but some equity assets was higher for households with higher non-financial assets. This percentage increased from $19.7 \%$ for households with less than $\$ 50,000$ in non-financial assets to $54.3 \%$ for households with $\$ 500,000$ or more in non-financial assets.

Among households who had debts other than their home mortgage, $18.4 \%$ had high risk tolerance and some equity and $41.0 \%$ had low risk tolerance but some equity. About two-fifths (40.6\%) of these households did not have equity in their portfolio (35.6\% had low risk tolerance and no equity and 5.0\% had high risk tolerance but no equity). Most households (60.8\%) with an adequate amount of emergency fund (amount of cash and cash equivalents more than or equal to three months of income) were consistent at the second level, with $15.1 \%$ reporting a higher risk tolerance with equity and $45.7 \%$ reporting a low risk tolerance without any equity in their portfolio. About a third of them (34.2\%) reported a low level of financial risk tolerance but had some equity assets. 
A higher percentage of households who did not overspend (16.0\%) reported a high level of risk tolerance and had some equity than households who overspent (14.0\%). The percentage of households who had high risk tolerance but no equity was higher for over-spenders (7.1\%) than those who did not overspend (4.0\%). However, the percentage of households who reported a low level of risk tolerance but had some equity was higher for those who did not overspend (38.4\%) than over-spenders (34.0\%). A higher percentage of households who expected a large assets transfer (28.0\%) had high risk tolerance and some equity than households who did not have such an expectation (13.9\%). The percentage of households who reported low risk tolerance but had some equity was higher for households who expected a large asset transfer (44.1\%) than those who did not have such an expectation (36.7\%).

The percent reporting high financial risk tolerance and some equity was higher for households with longer savings horizons. The percentage was $9.2 \%$ for households with a horizon of less than a year and $13.8 \%$ for households with a horizon of a few years, 19.8 for households with a horizon of 5 to 10 years, and $27.6 \%$ for households with a horizon of longer than 10 years. Conversely, the percent reporting low financial risk tolerance and no equity was higher for households with shorter savings horizons. The percentage decreased from $56.8 \%$ for households with a horizon of less than a year to 23.5\% for households with a horizon of longer than 10 years. In a similar vein, the percent reporting high financial risk tolerance but no equity was also higher for households with shorter savings horizons. The percentage was $5.4 \%$ for households with 
a horizon of less than a year and $3.4 \%$ for households with a horizon of longer than 10 years. The percentage of households who reported low risk tolerance but some equity was highest for households with a horizon of longer than 10 years $(45.5 \%)$ and lowest for household with a horizon of less than a year (28.6\%).

The percent reporting high financial risk tolerance and equity ownership was higher for respondents with better self-perceived health. The percentage was $3.0 \%$ for respondents with a poor health and $22.9 \%$ for respondents with an excellent health. Conversely, the percent reporting low financial risk tolerance and no equity was higher for respondents with poorer self-perceived health. The percentage was $78.1 \%$ for respondents with a poor health and $29.6 \%$ for respondents with an excellent health. Respondents with an excellent health had the highest percentage who reported low financial risk tolerance but some equity $(42.7 \%)$ and respondents with a poor health had the lowest percentage who reported low financial risk tolerance but some equity (15.5\%).

\subsection{Logistic Results of Consistency in Risk Attitude and Behavior}

Table 5 shows the results from logistic analysis of consistency in risk attitude and behavior. Results from the first multivariate analysis present the likelihood of being consistent in risk attitude and risk behavior at the first level, which is to be either being willing to take at least some financial risks and having some investment assets or to be unwilling to take any financial risks and not owning any investment assets. Results from the second multivariate analysis present the likelihood of being consistent in risk attitude 
and risk behavior at the second level, which is to be either willing to take high financial risks (substantial or above average) and having some equity or to be willing to take low financial risks (average or none) and not owning any equity. 
Table 5 Logistic Analysis of Consistency in Risk Attitude and Behavior

\begin{tabular}{|c|c|c|c|c|c|c|}
\hline \multirow{3}{*}{$\begin{array}{l}\text { Parameter } \\
\text { Intercept }\end{array}$} & \multicolumn{3}{|c|}{$\begin{array}{c}\text { First Level: Some Risk } \\
\text { vs. Investment Asset } \\
\text { Ownership } \\
\end{array}$} & \multicolumn{3}{|c|}{$\begin{array}{l}\text { Second Level: High Risk } \\
\text { vs. Equity Ownership }\end{array}$} \\
\hline & \multicolumn{2}{|c|}{ Coefficient } & \multirow[t]{2}{*}{ Odds Ratio } & \multicolumn{2}{|c|}{ Coefficient } & \multirow[t]{2}{*}{ Odds Ratio } \\
\hline & 0.5733 & *** & & 2.5820 & ${ }^{* * * *}$ & \\
\hline \multicolumn{7}{|c|}{ Survey Year (reference category: 1998) } \\
\hline 2001 & -0.0163 & & 0.984 & -0.0719 & & 0.931 \\
\hline 2004 & -0.1389 & ${ }^{*}$ & 0.870 & -0.1907 & $* * *$ & 0.826 \\
\hline 2007 & -0.1618 & $* *$ & 0.851 & -0.1961 & $* * *$ & 0.822 \\
\hline 2010 & -0.3462 & $* * *$ & 0.707 & -0.3106 & $* * *$ & 0.733 \\
\hline \multicolumn{7}{|c|}{ Source of Information (reference category: Self and Social Network) } \\
\hline Financial Planner & 0.3363 & $* * *$ & 1.400 & -0.2991 & $* * *$ & 0.741 \\
\hline Financial Institutions & 0.0754 & & 1.078 & -0.1151 & ${ }^{* *}$ & 0.891 \\
\hline Media & 0.1112 & & 1.118 & 0.0541 & & 1.056 \\
\hline Other & 0.0594 & & 1.061 & 0.4291 & $* * *$ & 1.536 \\
\hline \multicolumn{7}{|c|}{ Age (reference category: Less than 35 ) } \\
\hline $35-44$ & 0.0461 & & 1.047 & 0.0746 & & 1.077 \\
\hline $45-54$ & 0.0918 & & 1.096 & -0.0365 & & 0.964 \\
\hline $55-64$ & -0.0096 & & 0.990 & -0.2029 & * & 0.816 \\
\hline $65+$ & -0.2050 & & 0.815 & -0.1953 & & 0.823 \\
\hline \multicolumn{7}{|c|}{ Cohort (reference category: Cohort 1, born 1903-1917) } \\
\hline Cohort 2 (born 1918-1932) & 0.2569 & $*$ & 1.293 & 0.0819 & & 1.085 \\
\hline Cohort 3 (born 1933-1947) & 0.4113 & ${ }^{* *}$ & 1.509 & 0.1232 & & 1.131 \\
\hline Cohort 4 (born 1948-1962) & 0.5517 & *** & 1.736 & 0.1413 & & 1.152 \\
\hline Cohort 5 (born 1963-1977) & 0.6440 & $* * *$ & 1.904 & 0.1666 & & 1.181 \\
\hline Cohort 6 (born 1978-1992) & 0.5716 & $* *$ & 1.771 & 0.2198 & & 1.246 \\
\hline \multicolumn{7}{|c|}{ Education (reference category: Less than High School) } \\
\hline High School Diploma/GED & -0.3373 & $* * *$ & 0.714 & -0.5913 & $* * *$ & 0.554 \\
\hline Some College & -0.1786 & $* *$ & 0.836 & -0.7507 & $* * *$ & 0.472 \\
\hline Bachelor's Degree & 0.2881 & $* * *$ & 1.334 & -0.6338 & $* * *$ & 0.531 \\
\hline Graduate/Professional Degree & 0.3607 & ${ }^{* * *}$ & 1.434 & -0.5843 & $* * *$ & 0.558 \\
\hline \multicolumn{7}{|l|}{ Race (reference category: White) } \\
\hline Black & -0.1578 & ** & 0.854 & 0.0835 & & 1.087 \\
\hline Hispanic & 0.0377 & & 1.038 & 0.2964 & $* * *$ & 1.345 \\
\hline Other & -0.1706 & & 0.843 & -0.4276 & & 0.652 \\
\hline \multicolumn{7}{|c|}{ Household Type (reference category: Married Male) } \\
\hline Married Female & -0.3757 & ${ }^{* * *}$ & 0.687 & -0.2604 & $* * *$ & 0.771 \\
\hline Unmarried Male & -0.0740 & & 0.929 & 0.0131 & & 1.013 \\
\hline Unmarried Female & -0.1638 & ** & 0.849 & -0.1064 & $*$ & 0.899 \\
\hline Have Child(ren) & -0.0514 & & 0.950 & 0.0816 & * & 1.085 \\
\hline \multicolumn{7}{|c|}{ Home Ownership (reference category: Renter) } \\
\hline Owner without Mortgage & -0.1340 & & 0.875 & -0.1018 & & 0.903 \\
\hline Owner with Mortgage & 0.0177 & & 1.018 & 0.0477 & & 1.049 \\
\hline
\end{tabular}




\begin{tabular}{|c|c|c|c|c|c|c|}
\hline \multicolumn{7}{|c|}{ Employment Status (reference category: Employee) } \\
\hline Self Employed & 0.0030 & & 1.003 & 0.3398 & $* * *$ & 1.405 \\
\hline Retired & 0.0633 & & 1.065 & 0.2503 & ${ }^{* * *}$ & 1.284 \\
\hline Not Working & -0.0227 & & 0.978 & 0.1779 & $* *$ & 1.195 \\
\hline \multicolumn{7}{|c|}{ Income (reference category: Less than $\$ 25,000$ ) } \\
\hline$\$ 25,000-\$ 49,999$ & -0.1787 & ** & 0.836 & -0.7043 & **** & 0.494 \\
\hline$\$ 50,000-\$ 74,999$ & -0.0434 & & 0.958 & -1.0080 & $* * *$ & 0.365 \\
\hline$\$ 75,000-\$ 99,999$ & 0.2131 & ** & 1.237 & -1.1193 & $* * *$ & 0.327 \\
\hline$\$ 100,000+$ & 0.7202 & *** & 2.055 & -0.9914 & $* * *$ & 0.371 \\
\hline \multicolumn{7}{|c|}{ Non-financial Assets (reference category: Less than \$50,000) } \\
\hline$\$ 50,000-\$ 149,999$ & -0.0971 & & 0.907 & -0.1868 & * & 0.830 \\
\hline$\$ 150,000-\$ 249,999$ & 0.0704 & & 1.073 & -0.3519 & $* * *$ & 0.703 \\
\hline$\$ 250,000-\$ 499,999$ & 0.1045 & & 1.110 & -0.4586 & $* * *$ & 0.632 \\
\hline$\$ 500,000+$ & 0.4775 & *** & 1.612 & -0.4254 & $* * *$ & 0.653 \\
\hline Have Other Debt & -0.0874 & * & 0.916 & -0.0670 & ${ }^{*}$ & 0.935 \\
\hline Adequate Emergency Fund & 0.0954 & * & 1.100 & -0.2316 & ${ }^{* * *}$ & 0.793 \\
\hline Overspent & -0.1092 & * & 0.897 & -0.1222 & $* *$ & 0.885 \\
\hline Expect Substantial Inherita & & & & & & \\
\hline Transfer of Assets & 0.2052 & *** & 1.228 & -0.0051 & & 0.995 \\
\hline \multicolumn{7}{|c|}{ Savings Horizon (reference category: Within the Next Year) } \\
\hline Next Few Years & 0.0500 & & 1.051 & -0.1077 & ** & 0.898 \\
\hline Next 5-10 Years & 0.1921 & **** & 1.212 & -0.0628 & & 0.939 \\
\hline Longer than 10 Years & 0.3785 & *** & 1.460 & -0.0408 & & 0.960 \\
\hline \multicolumn{7}{|c|}{ Self-Perceived Health (reference category: Poor) } \\
\hline Excellent & -0.0428 & & 0.958 & -0.4728 & *** & 0.623 \\
\hline Good & -0.0705 & & 0.932 & -0.5522 & **** & 0.576 \\
\hline Fair & -0.1720 & $*$ & 0.842 & -0.3738 & $* * *$ & 0.688 \\
\hline Concordance & $72.8 \%$ & & & $68.9 \%$ & & \\
\hline
\end{tabular}

Note: $* p<0.05 * * p<0.01 * * * p<0.001$ 


\subsubsection{Some Financial Risk Tolerance vs. Investment Asset}

\section{Ownership}

After controlling for all other variables in the multivariate model, households in 2004, 2007 and 2010 were less likely to be consistent at the first level as households in 1998. Households in 2004 were $87.0 \%$ as likely, households in 2007 were $85.1 \%$ as likely, and those in 2010 were $70.7 \%$ as likely to be consistent at the first level in their risk attitude and behavior as households interviewed in 1998. Compared with households who used self and social network for information when making saving and investments decisions, those who consulted with financial planners were 1.4 times as likely to be consistent at this level. Households who sought information from financial institutions, media, or other sources were not found to be significantly more or less likely to be consistent at the first level than households who used self and social network for information.

Demographic characteristics affected the likelihood of being consistent in their risk attitude and behavior at the first level. Respondents in younger cohorts were more likely to be consistent at this level than cohort 1 members (born 1903-1917). Cohort 2 members (born 1918-1932) were 1.3 times as likely as respondents in the oldest cohort to report some financial risk tolerance and ownership of investment assets. The odds ratio was 1.5 for cohort 3 (born 1933-1947), 1.7 for cohort 4 (born 1948-1962), 1.9 for cohort 5 (born 1963-1977), and 1.8 for cohort 6 (born 1978-1992), as compared with cohort 1.

Compared with respondents who did not complete high school, those who had a high school diploma were $71.4 \%$ as likely and those who had some college education 
were $83.6 \%$ as likely to be consistent in risk attitude and behavior at the first level. Respondents with a bachelor's degree or a graduate or professional degree were more likely to be consistent at this level (1.3 and 1.4 times as likely, respectively). Compared with white respondents with similar demographic and economic characteristics, black respondents were $85.4 \%$ as likely to be consistent in risk attitude and behavior at this level. Both married and unmarried females were less likely to be consistent than married males. Married females were $68.7 \%$ as likely and unmarried females were $84.9 \%$ as likely to be consistent at the first level.

Economic situations affected consistency in risk attitude and behavior at the first level. Consistency at the first level generally increased with household income, except that the difference between the lowest income group (less than $\$ 25,000$ ) and the $\$ 50,000$ $\$ 74,999$ income group was not statistically significant and that households in the second lowest income group $(\$ 25,000-\$ 49,000)$ were less likely to be consistent at this level. Compared with households whose total annual household income was less than $\$ 25,000$, those whose household income was between $\$ 25,000$ and $\$ 49,999$ were $83.6 \%$ as likely to be consistent at this level. Households whose total household income was between $\$ 75,000$ and $\$ 99,999$ and those whose household income was $\$ 100,000$ or higher were more likely to be consistent than households with a total household income of less than $\$ 25,000$ (1.2 times as likely and 2.1 times as likely, respectively). Households in the highest non-financial assets category ( $\$ 500,000$ or more) were 1.6 times as likely to be consistent as those with less than $\$ 50,000$ in non-financial assets to be consistent in risk attitude and behavior at the first level. 
Households who had debts other than a mortgage were $91.6 \%$ as likely to be consistent as those who did not have other debts. Households with an adequate level of emergency fund set aside were 1.1 times as likely to be consistent at the first level as those who did not. Households who overspent were $89.7 \%$ as likely as those who did not overspend to be consistent in their risk attitude and behavior at the first level.

Households who expected large asset transfers such as an inheritance were 1.2 times as likely to be consistent as those who did not have such an expectation. Consistency of risk attitude and behavior at the first level generally increased with savings horizon, except for that the difference between households whose horizon was less than a year and those whose horizon was a few years was not statistically significant. Compared with households whose savings horizon was less than a year, those whose saving horizon was 5-10 years were 1.2 times as likely and those whose saving horizon was longer than 10 years were 1.5 times as likely to be consistent in risk attitude and behavior at the first level. Compared with respondents with a poor self-perceived health, those with a fair health were $84.2 \%$ as likely to be consistent at the first level.

\subsubsection{High Financial Risk Tolerance vs. Equity Ownership}

After controlling for all other variables in the logistic model, households in later survey years were generally less likely to be consistent in risk attitude and behavior at the second level, except that the difference between households in 1998 and households in 2001 was not statistically significant. Compared with households in 1998, households in 2004 were $82.6 \%$ as likely, those in 2007 were $82.2 \%$ as likely, and those in 2010 were 
73.3\% as likely to be consistent at the second level. Compared with households who used self and social network for information when making saving and investments decisions, those who consulted with financial planners and those who sought information from financial institutions were less likely to be consistent at this level. Households who used financial planners were $74.1 \%$ as likely to be consistent at this level and those who used financial institutions were $89.1 \%$ as likely to be consistent at this level. Households who used other sources for information (those who did not save or invest, did not shop around, always use same institution, or reported "other" when answering the information source question) were 1.5 times as likely to be consistent at the second level as those who used self and social network.

The likelihood of being consistent at the second level varied with demographic characteristics. Respondents in the 55-64 age category were $81.6 \%$ as likely to be consistent in risk attitude and behavior at the second level as respondents in the youngest age category (less than 35 years old). Respondents who did not complete high school were the most likely to be consistent at the second level. Compared with the lowest education respondents, those who had a high school diploma were $55.4 \%$ as likely and those who had some college education were $47.2 \%$ as likely to be consistent in risk attitude and behavior at the second level. Respondents with a bachelor's degree or an education level higher than that were also less likely to be consistent at this level (53.1\% and 55.8\% as likely, respectively). Compared with white respondents with similar demographic and economic characteristics, respondents with a Hispanic heritage were 1.3 times as likely to be consistent in risk attitude and behavior at this level. Both married 
and unmarried females were less likely to be consistent at the second level than married males. Married females were $77.1 \%$ as likely and unmarried females were $89.9 \%$ as likely to be consistent at the second level as married males. Households with dependent children were 1.1 times more likely than those who did not have dependent children to be consistent in risk attitude and behavior at this level.

Economic situations affected consistency in risk attitude and behavior at the second level. Employees (respondents who worked for someone else) were the least likely to be consistent in risk attitude and behavior at this level. Compared with employees, those who were self-employed were 1.4 times as likely to be consistent. Retired respondents and respondents who were not working were also more likely to be consistent at this level than employees (1.3 times as likely and 1.2 times as likely, respectively).

Households whose total annual household income was less than $\$ 25,000$ were found to be the most likely to be consistent in risk attitude and behavior at the second level. Compared with these households, those whose household income was between $\$ 25,000$ and $\$ 49,999$ were $49.4 \%$ as likely and those household income was between $\$ 50,000$ and $\$ 74,999$ were $36.5 \%$ as likely to be consistent at this level. Households with a total household income between $\$ 75,000$ and $\$ 99,999$ and those whose household income was $\$ 100,000$ or higher were also less likely to be consistent than households with an income of less than $\$ 25,000$ (32.7\% as likely and $37.1 \%$ as likely, respectively). Households in the lowest non-financial assets category (less than $\$ 50,000$ ) were the most likely to be consistent in their risk attitude and behavior at the second level. Compared 
with these households, those whose non-financial assets was between $\$ 50,000$ and $\$ 149,999$ were $83.0 \%$ as likely, those whose non-financial assets was between $\$ 150,000$ and $\$ 249,999$ were $70.3 \%$ as likely, those whose non-financial assets was between $\$ 250,000$ and $\$ 499,999$ were $63.2 \%$ as likely, and those in the highest non-financial assets category ( $\$ 500,000$ or higher) were $65.3 \%$ as likely, to be consistent in risk attitude and behavior at the second level.

Households who had debts other than a mortgage were found to be $93.5 \%$ as likely to be consistent at this level as household who did not have such debt. Households who had an adequate level of emergency fund were $79.3 \%$ as likely to be consistent at this level as those who did not have an adequate level of emergency fund set aside. Households who overspent were $88.5 \%$ as likely as those who did not overspend to be consistent in their risk attitude and behavior at the second level. Compared with households whose savings horizon was less than a year, those whose saving horizon was a few (less than five) years were $89.8 \%$ as likely to be consistent in risk attitude and behavior at this level. Respondents with a poor self-perceived health were the most likely to be consistent at this level. Compared with them, those with a fair health were $68.8 \%$ as likely, those with a good health were $57.6 \%$ as likely, and those with an excellent health were $62.3 \%$ as likely to be consistent at the second level. 


\subsection{Hypothesis Tests Results}

Additional logistic analyses were conducted to examine whether there were any statistically significant differences, among various information source groups, in consistency between risk attitude and behavior at either the first or the second level. Table 6 showed the results from the hypothesis tests.

After controlling for all other variables in the model, those who sought information from a financial planner were the most consistent in their risk attitude and behavior at the first level. Hypotheses $H_{01}, H_{05}, H_{06}$, and $H_{07}$, were rejected. Compared with these households, those who used self and social network was $71.4 \%$ as likely, those who consulted with financial institutions were $77.0 \%$ as likely, those who used media were $79.8 \%$ as likely, and those who sought information from other sources were $75.8 \%$ as likely to be consistent at the first level.

Further logistic analyses results, after controlling for all other variables, showed that households who worked with a financial planner when making savings and investment decisions were the least consistent in their risk attitude and behavior at the second level. Hypotheses $H_{011}, H_{015}, H_{016}$, and $H_{017}$, were rejected. Compared with these households, those who used self and social network was 1.3 times as likely, those who consulted with financial institutions were 1.2 times as likely, those who used media were 1.4 times as likely, and those who sought information from other sources were 2.1 times as likely to be consistent at the second level.

Furthermore, households who sought information from other sources were the most likely to be consistent at this level. Hypotheses $H_{013}, H_{014}, H_{017}$, and $H_{020}$, were 


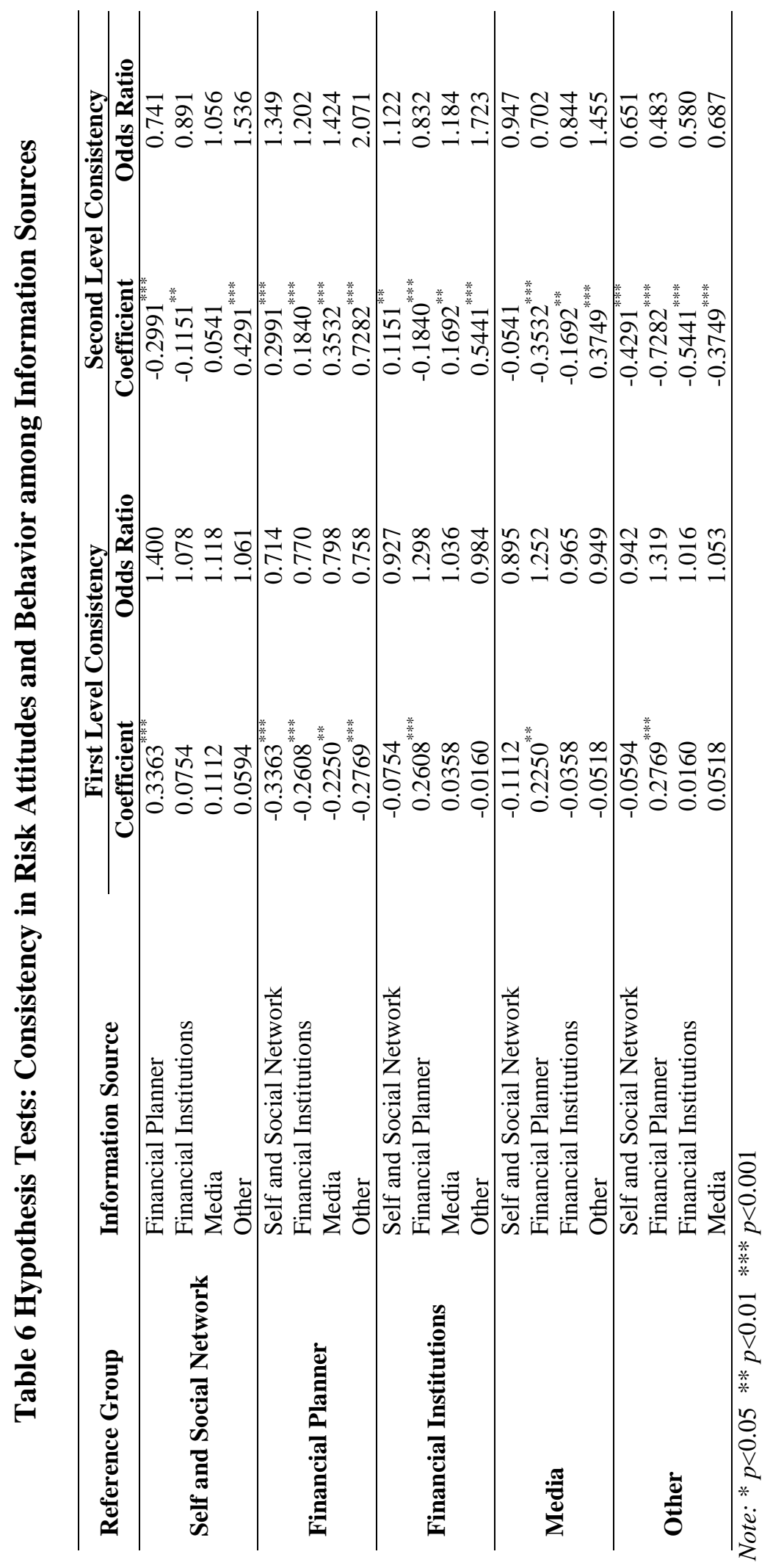

132 
rejected. Compared with these households, those who used self and social network was $65.1 \%$ as likely, those who worked with a financial planner were $48.4 \%$ as likely, those who consulted with financial institutions were $58.0 \%$ as likely, and those who used media for information were $68.7 \%$ as likely to be consistent at the second level. Although the difference between households in the self and social network category and those in the media group was not statistically significant, households in these information categories were more likely than households in the financial institution category to be consistent at the second level (odds ratio=1.1 and 1.2, respectively). Hypotheses $H_{012}$ and $H_{018}$ were rejected. 


\section{CHAPTER VI}

\section{SUMMARY, DISCUSSION AND IMPLICATIONS}

This study used cross-sectional data from 1998-2010 Surveys of Consumer Finances to investigate the effect of financial information source on consistency in financial risk attitude and behavior. Consistency was measured at two levels. The first level consistency was between being willing to take some versus no financial risks and investment ownership. Households were considered to be consistent at this level if they were willing to take some financial risks in exchange for some investment returns and had some investment assets or if they were unwilling to take any financial risks and did not have any investment assets. The second level of consistency was between being willing to take high versus low financial risks and equity ownership. Households were considered to be consistent at this level if they were willing to take high financial risks (above average or substantial) in exchange for some investment returns and had some equity in their portfolio or if they were unwilling to take high financial risks but had some equity assets in their portfolio.

There were five categories of financial information sources: 1) self and social network; 2) financial planner; 3) financial institutions; 4) media; and 5) other sources. Because of the number of the information sources and the hypothesis that households using different sources of information should be equally likely to be consistent in their financial risk attitude and behavior, ten hypotheses that anticipate no difference between each pair of the information sources were required to be accepted simultaneously at each 
of the two levels. Therefore, looking at both levels of consistency, there were 20 hypotheses each anticipating no statistically significant difference between the likelihood of being consistent for households using two sources of information when making savings and investment decisions.

Because most of these 20 hypotheses were rejected, the general hypothesis that households using different sources of information should be equally likely to be consistent in their financial risk attitude and behavior was rejected at both consistency levels. Findings indicated that households searching information from various sources when making savings and investment decisions were not equally likely to be consistent in their risk attitude and behavior at either level.

After examining the results presented in Table 6, it can be concluded that working with a financial planner increased households' likelihood of being consistent in their risk and attitude at the first level of consistency but decreased their likelihood of being consistent in their risk and attitude at the second level of consistency. However, the effect of working with a financial planner when making savings and investment decisions on the consistency between financial risk attitude and portfolio risk should be examined in further detail using Table 3. 


\subsection{Summary of Results at the First Level of Consistency}

Households who used a financial planner were the most likely to be consistent at the first level of consistency. Differences between any other pairs of information source groups were not statistically significant. Further examination of Table 3 revealed that overall, as well as in each survey year, most of the consistency at the first level by households who used a financial planner was from being willing to take some financial risks and having some investment assets. More than three-fourths (78.7\%) of the households who worked with a financial planner in the total combined sample was consistent in their risk attitude and behavior at the first level; and $92.6 \%$ of the consistency at this level came from being willing to take some financial risks and having some investment assets. In each survey year, this percentage ranged from $90.2 \%$ in 2010 to $94.2 \%$ in 2004 (Table 3), highest among all five information sources. Less than onetenth $(5.8 \%$ in the combined sample and $4.7 \%-7.1 \%$ in individual survey years) of households who worked with a financial planner were unwilling to take at least some financial risks and did not have any investment assets in their portfolio. The percentages for all other information groups in this category (no risk and no investment assets) were double digits.

Three of the other four information source categories (self and network, financial institutions and media) displayed the similar distribution of the percentage being consistent and the percentage of the source of consistency. However, one noteworthy fact was that the consistency of the "other" group showed considerable differences from the rest of the four information categories. In the combined sample including households 
in all survey years, although the majority (62.0\%) of the households who searched information from other sources were consistent at the first level, only $22.6 \%$ of such consistency came from having some risk tolerance and owning some investment assets; the majority $(77.4 \%)$ of this consistency came from not being willing to tolerate any financial risks and having no investment assets in the portfolio.

In the combined sample, including all survey years, between $21.4 \%$ and $38.1 \%$ of households were inconsistent in their risk attitude and behavior at the first level depending the source of information they used when making savings and investment decisions. Based on results in Table 3, the majority of this inconsistency came from being unwilling to take any financial risks but having some investment assets in their portfolio (percentage ranged from $71.8 \%$ for households who used media to $81.6 \%$ for those who used other sources).

\subsection{Summary of Results at the Second Level of Consistency}

Households using other sources for information were the most likely to be consistent in their risk attitude and behavior at the second level, followed by households in the self and social network group and those in the media group, and then followed by households who consulted with financial institutions. Households who worked with a financial planner when making savings and investment decisions were the least likely to be consistent in their risk attitude and behavior at the second level. Further examination of the results in Table 3 revealed that overall, as well as in each survey year, most households who consulted with a financial planner when making savings and investment 
decisions were inconsistent at the second level. The only exception was year 1998 when half of households were consistent and the other half were inconsistent. In contrast, most households who searched information elsewhere when making savings and investment decisions were consistent at the second level.

Most of the consistency at the second level by households who used a financial planner was from being willing to take high (above average or substantial) financial risks and having some equity assets, except for year 2010 when $52.6 \%$ of the consistency came from being willing to take low (average or none) financial risks and not owning equity in their portfolio. On the contrary, the majority of the consistency for households using sources of information other than a financial planner came from being willing to take low financial risks and not owning equity in their portfolio in all survey years. It appears that consistency at the second level might be interpreted as households differing approaches to risk in their portfolios. One way to approach a risk is to avoid it, if households use risk avoidance they can do it themselves. If the household wishes to accept risk then maybe some professional help from a financial planner was an acceptable alternative.

In the combined sample including all survey years, between $21.2 \%$ and $54.4 \%$ of households were inconsistent in their risk attitude and behavior at the second level, depending the source of information they used when making savings and investment decisions. Based on results in Table 3, the majority (54.4\%) of the households were inconsistent in their risk attitude and behavior at the second level; and $91.9 \%$ of the inconsistency at this level came from being unwilling to take high financial risks and 
having some equity in their portfolio. In each survey year, this percentage ranged from 91.0\% in 1998 to $93.6 \%$ in 2007 (Table 3), highest among all five information source groups.

\subsection{Discussion}

At the first level of consistency, it appears that financial planners provide significant value to households regarding the consistency of their risk tolerance and portfolio. At the second level of consistency, it seems that financial planners may influence households to take on equity exposure to a degree higher than households desire to. It may be that, in theory, households need equity exposure since the historically higher returns that equities yield would help households reach their financial goals. Still, financial planners are ethically constrained to do one of the following (Bluethgen et al., 2008): 1) educate them about financial risks and convince them that they need equity exposure; or 2) help them construct a portfolio consistent with the risk tolerance they believe is appropriate for themselves.

\subsubsection{Taking less Portfolio Risks than Desired}

As displayed by the results of this study, a mismatch between one's risk attitude and investment behavior is not rare. Anecdotal evidence from over three decades of my own financial planning practice indicates that some households do take risks in their portfolio that seem inconsistent with their station in life. As shown Table 5, income was a major factor that contributed to first level consistency $\left(\mathrm{S}^{1} \mathrm{I}^{0}\right.$ and $\left.\mathrm{S}^{0} \mathrm{I}^{1}\right)$ after controlling 
for all other variables in the model. A higher level of household income increased the likelihood of being consistent at the first level. Having the highest level of non-financial assets ( $\$ 500,000$ or more) also positively affected consistency at the first level. Income and non-financial assets negatively affected the likelihood of being consistent at the second level. Also, education positively affected the first level consistency but had a negative effect on consistency at the second level. The effect of income, non-financial assets and education seemed difficult to understand at its face. However, further examination of Table 4, which separated components of both level of inconsistencies ( $\mathrm{S}^{1} \mathrm{I}^{0}$ and $\mathrm{S}^{0} \mathrm{I}^{1}$ as well as $\mathrm{H}^{1} \mathrm{E}^{0}$ and $\mathrm{H}^{0} \mathrm{E}^{1}$ ), revealed that some mismatches between risk attitude and behavior may not be due to ignorance of financial risks.

As shown in Table 4, in the combined sample including all survey years, $7.0 \%$ of households had some appetite for financial risks but did not have any investment assets $\left(\mathrm{S}^{1} \mathrm{I}^{0}\right)$ and $4.5 \%$ were willing to take high financial risks but did not have equity $\left(\mathrm{H}^{1} \mathrm{E}^{0}\right)$. This mismatch between risk attitude and investment behavior may not be completely due to ignorance about financial risks. As shown by Table 4, the percentage for both $\mathrm{S}^{1} \mathrm{I}^{0}$ and $\mathrm{H}^{1} \mathrm{E}^{0}$ decreased with education. Although education may indicate, to a certain extent, how much someone understands risks; it is far from being an adequate measure of such understanding. Experience with the investment market and interest in investment topics, which is not information collected by SCF data, can also influence households' understanding of financial risks.

More importantly, the percentage for both $\mathrm{S}^{1} \mathrm{I}^{0}$ and $\mathrm{H}^{1} \mathrm{E}^{0}$ also clearly decreased with age, income and non-financial assets. A young household with limited income and 
non-financial assets may be financially constrained and unable to own investment assets or equity. Therefore, at the lower end of the income and non-financial asset spectrum, $\mathrm{S}^{1} \mathrm{I}^{0}$ and $\mathrm{H}^{1} \mathrm{E}^{0}$ may not be an irrational choice but rather a lack of choice. It is possible that while willing to take some financial risks or even a high level of financial risks, these households do not have the ability to do so. At the higher end of the income or nonfinancial asset spectrum, being willing to take some financial risks but having no investment assets or being willing to take high financial risks but having no equity in their portfolio could simply be an irrational choice, albeit inconsistent.

The disadvantage of this type of mismatch between risk attitude and behavior $\left(\mathrm{S}^{1} \mathrm{I}^{0}\right.$ or $\left.\mathrm{H}^{1} \mathrm{E}^{0}\right)$ is mainly opportunity cost that these household would suffer. At both levels of inconsistency between financial risk attitude and behavior, households that take less portfolio risks than desired are potentially suffering some opportunity cost by giving up higher returns that could be generated by a higher level of portfolio risk that is consistent with what their risk tolerance indicates that they would be willing to take. However, when financial situations change (e.g. more income), it is possible that these households could move to a certain level of consistency $\left(\mathrm{S}^{1} \mathrm{I}^{1}\right.$ and/or $\left.\mathrm{H}^{1} \mathrm{E}^{1}\right)$. Financial planners should do one of the two things mentioned above to help these households smoothly transition to a consistent status where their financial risk tolerance and portfolio risks are in alignment. This would allow these households to take a desired level of portfolio risk and obtain a return that is in line with that level of financial risks. 


\subsubsection{Taking more Portfolio Risks than Desired}

As displayed by the results of this study (Table 4), the other type of mismatch between households' risk attitude and investment behavior $\left(\mathrm{S}^{0} \mathrm{I}^{1}\right.$ and $\left.\mathrm{H}^{0} \mathrm{E}^{1}\right)$ is more prevalent than the previously mentioned mismatch $\left(\mathrm{S}^{1} \mathrm{I}^{0}\right.$ and $\left.\mathrm{H}^{1} \mathrm{E}^{0}\right)$. Further examination

of Table 4, which separated components of both level of inconsistencies $\left(\mathrm{S}^{1} \mathrm{I}^{0}\right.$ and $\mathrm{S}^{0} \mathrm{I}^{1}$ as well as $\mathrm{H}^{1} \mathrm{E}^{0}$ and $\mathrm{H}^{0} \mathrm{E}^{1}$ ), revealed that $23.9 \%$ of the households in the combined sample fell into the $\mathrm{S}^{0} \mathrm{I}^{1}$ category and $37.6 \%$ of the total households fell into the $\mathrm{H}^{0} \mathrm{E}^{1}$ category. This result is consistent with findings by Bernasek and Shwiff (2001), which stated that households who use a financial planner invested a higher percentage of retirement assets in stocks. This type of mismatch between financial risk attitude and behavior may be due to reasons such as misunderstanding of financial risks and inadequate measure of risk tolerance. Whatever the reason may be, the problem of this type of mismatch could bring unnecessary financial losses to households. During market downturns, unless a sale of investment assets and/or equity was due to a need (e.g. an employment interruption, other unexpected decreases in income, or an unexpected increase in household expenses), such behavior would be an emotional reaction to the market movement that was probably caused by this type of mismatch between risk attitude and behavior (i.e. taking more portfolio risks than desired). This emotional reaction is not in the households' best interest and could being unnecessary financial losses.

To help these households transition to consistency (e.g. $\mathrm{S}^{1} \mathrm{I}^{1}, \mathrm{H}^{1} \mathrm{E}^{1}, \mathrm{~S}^{0} \mathrm{I}^{0}$, or $\mathrm{H}^{0} \mathrm{E}^{0}$ ) where financial risk tolerance and portfolio risks are in alignment, financial planners should, as suggested by (Bluethgen et al., 2008), either educate them about financial risks 
and convince them that they should not have investment assets or equity exposure, or help them construct a portfolio that is consistent with the risk tolerance (none or low) they believe is appropriate for themselves.

\subsection{Implications for Financial Planners}

Households are being asked as never before to be responsible for the outcome of their financial planning efforts and some are turning to professional financial planners for advice. Are financial planners up to the task? Nofsinger and Varma (2007) conducted a survey of more than 100 financial planners and found them to have significant education, training and experience that should help them assist their clients.

Implicit in households' use of a particular source of financial information is not only a cost benefit analysis, but a relative cost benefit analysis. The chosen information source not only benefits the household but relatively benefits the household more than the use of alternative sources.

Economic theory suggests that one way financial planners can justify their existence in a household's financial life is to take advantage of economies of scale in searching and acquiring information compared to households acting on their own and exploit this additional and better information to improve on portfolio performance.

Research suggests households are not so good at taking care of themselves (Keister, 2000).

If using a financial planner adds value to households' financial wellbeing, those who use a financial planner would be expected to act in a fashion more consistent with 
their stated risk tolerance. The implication would be for consumers to consider using financial planners. If using a financial planner does not make a difference or even decreases the probability of an individual's consistency in risk tolerance and risk behavior, then the financial planning industry should reassess their value proposition and/ or improve their services.

It is possible that financial planners focus on a household's objective risk tolerance (e.g. age, saving horizon, level of assets) and overlook the true financial risk attitude of the household. Kahneman and Tversky (1979) suggested that a household's biases are an important part of their risk profile. The following two hypothetical cases serve as examples to illustrate circumstances that may seem like a mismatch on the surface but in fact are rational choices. Some young households might be very risk adverse even though their savings horizon is very long and investments with wide variations in returns would end up accumulating significantly more wealth for them. However, their low risk tolerance demands that they do not take a high level of investment risk. Similarly, some elderly households might desire a risky portfolio because they have a high financial risk tolerance even though, in most cases, objective measurers (e.g. short saving horizon) might make it seem inappropriate.

The objective of a financial planner should be to make sure the household understands the risks and opportunities of financial products, the risks taken in their portfolio, and how a given portfolio would perform over time, not only during periods when the market is up but also during periods when the market is down. If a young household has an exceedingly high level of income and a conservative life style, maybe a 
conservative portfolio that matches their life style is appropriate. Also, if an older household desires a high level of financial risks and has a saving objective that justifies such risks, letting them have a risky portfolio may be a good choice. For example, a young orthopedic surgeon with no debt, and a modest life style might very well accumulate a sufficient retirement nest egg by investing conservatively. If the young orthopedic surgeon making a \$350,000 annual income at age 30 maximized retirement savings, lives with a modest house and cars and does not desire an expensive lifestyle, a conservative portfolio would accomplish this household's objective of maintaining this lifestyle in retirement while avoiding undesired financial risks. Why should a financial planner encourage the young doctor household to incorporate equities into its portfolio if it is not necessary and outside the household's comfort zone?

Conversely, if an elderly retired household with a vast amount of wealth but a relatively modest lifestyle wishes to accumulate a legacy to fund a charitable foundation after their death, focusing on equities may be a rational choice. If an elderly household has $\$ 10,000,000$ in wealth and an annual household budget of $\$ 60,000$ per year (a desired level of income equal to only six-tenths of one percent) even the accidental income generated by a mostly equity portfolio would satisfy the household's income requirement. Why should not the elderly risk-tolerant household invest primarily in equities?

Challenges facing all financial information sources, to include professional financial planners, include being trusted by households and being able to motivate the household to take action. The best prescription left on the shelf does the household no good and is a waste of resources. According to Hertzum et al. (2002) for information to 
have an influence on households, motivate them to take action, the information must be trusted and the household must believe that taking the action will produce a net beneficial outcome.

\subsection{Implications for Policy Makers}

Households have plenty of motivations and challenges to maximize the utility they receive from their savings. Households have always had plenty of reasons to accumulate wealth and the demands for their resources have been increasing. Households members are living longer (United Nations, 2012) and old age support systems are not as certain as they once were (Social Security Administration, 2013). The one common assumption is that an informed household is a better consumer of financial services and ergo more likely to achieve a better result (more likely to maximize their utility). So how might the effectiveness of various financial information providers be judged?

To draw an analogy, the United States Food and Drug Administration (FDA) has existed since the early 1900 s concerning itself at first simply with the safety of drugs. It was not until the 1960s that the FDA concerned itself with the efficacy of drugs. Since then, drug manufacturers have been required not only to prove that their drugs were safe, but that their drug actually is effective and helpful. Drugs now have to prove their economic value. This study examines the efficacy of financial information sources, specifically financial planners. Perhaps at some future point, a regulatory body should not only assure the truth in investments but their efficacy as well. 
Households may have enough information and understanding to accurately determine an appropriate risk tolerance for their household; and if so, that is great. Households may have enough understanding to accurately assess the risk nature of their portfolio; and if so, that is great as well. If households do not understand what an appropriate risk level for their investments is, that is one issue. If households do not understand the risk inherit in a portfolio, then that is another problem. If households understand both types of risks but act inconsistently for some reason, identified or not, it is a separate but very important problem. If professionals wish to have their training and involvement effectual in the market place, they need to know how it is perceived and how to transition it to being not simply useful and interesting, but used.

\subsection{Limitations and Implications for Future Research}

There are a few limitations of this study. The first one is that the self-reported risk tolerance measure was obtained from the respondent. Although the question asked for the household's risk tolerance (respondent and the spouse/partner), it is at best an estimation of the household's risk tolerance in a household where the respondent was married or living with a partner. It is possible that spouses/partners communicate very well with each other and the respondent understands the risk tolerance of the spouse/partner and incorporated it into his/her answer to the SCF risk tolerance question. However, it is also possible that such communication was not adequate. The spouse/partner is likely to contribute to the investment decision-making in the household. Therefore, the self-reported household risk tolerance may or may not accurately reflect 
the household's risk tolerance for married/partnered households. SCF reveals no decision-making information and, therefore, how decisions were made within the household could not be examined.

The second limitation is the definition of the second level of consistency. Assets were arbitrarily divided into two risk levels: high and low. There is no universal agreement on which assets have high risks and which ones have low risks. A 30-year United States, full faith and credit, zero-coupon bond may display a standard deviation in returns higher than the S\&P 500 index of 100\% stocks. However, based on the categorization of this study, those bonds were part of the low risk group and stocks were part of the high risk group.

Consistency in household risk attitude and behavior is an important ongoing task for households, their financial planners, consumer educators and researchers. A mismatch in risk attitude and behavior may cause opportunity cost or unnecessary realized financial loss, which is counterproductive to households making efforts to accomplish their financial goals. While topics related to this area have been examined in some detail; to the best of my knowledge, this is the first research to investigate the influence of various sources of information on household's correlation between the risk they say they want and what they do have.

Several studies have shown that, almost without regard to source, households do not plot a path for financial goals (Keister, 2000). This fact would seem to point to a field ripe for investigation. There is reason to hope that research will help financial 
planners and public policy makers develop effective ways to engage households in the process of planning for their own financial security. Future research should expand this study to further examine how to better align household financial risk tolerance and portfolio risk, how to accurately measure the financial risk tolerance for all household types, how to help households identify their true risk tolerance level, and how to help them act consistently with their risk tolerance when making savings and investment decisions.

When the Nobel Prize recipients for physics were announced this year, I found myself a little envious. Fifty years ago, scientists were suspicious that an important particle existed. This year, the partial called the Higgs Bosen was confirmed. Peter Higgs had suggested that certain things could not be as they were without this particle's existence, but could never prove it existed. But, the Standard Model of physics could not work without the existence of the Higgs Bosen particle. So scientists around the world operated as if it did exist even though they could not prove that it did.

The source of my envy is that in CERN, Switzerland, at the particle accelerator lab located there, the physical scientist actually found the elusive Higgs Bosen particle and confirmed that they had been right. In the fiscal science arena, that day will have to wait, as we have no lab to experiment in or way to concretely say this or that is the elusive missing element. The physical scientist spent 50 years teasing out what was behind the effect that the Higgs Bosen particle had on the particles around it, with some particles picking up mass when it came in contact, and some not. Likewise, the economic 
scientist in the fiscal world will have to keep on trying to discover the true drivers of behavior. Maybe behavioral economics will lead us on a path that will help identify the missing element that we suspect exists. 


\section{BIBLIOGRAPHY}

Arrow, K. J. (1965). Aspects of the theory of risk bearing. Helsinki: Yrjo Jahnsson Foundation. (Reprinted in Arrow, K. J., 1971. Essays in the Theory of Risk-bearing. Chicago, Markham Pub. Co.)

Badu, Y. A., Daniels, K. N., \& Salandro, D. P. (1999). An empirical analysis of differences in Black and White asset and liability combinations. Financial Services Review, 8(3), 129-147.

Bae, S. C., \& Sandager, J. P. (1997). What consumers look for in financial planners. Financial Counseling and Planning, 8(2), 9-16.

Bailey, M. J., Olson, M., \& Wonnacott, P. (1980). The marginal utility of income does not increase: Borrowing, lending, and Friedman-Savage gambles. American Economic Review, 70(3), 372-379.

Bajtelsmit, V. L., Bernasek, A., \& Jianakoplos, N.A. (1999). Gender differences in defined contribution pension decisions. Financial Services Review, 8(1), 1-10.

Bajtelsmit, V. L., \& VanDerhei, J. L. (1997). Risk aversion and pension investment choices. In Michael S. Gordon, Olivia S. Mitchell, and Marc M. Twinney (Eds.), Positioning Pensions for the Twenty-First Century. Philadelphia: University of Pennsylvania Press. pp 45-66.

Bandura, A. (2010). Self-efficacy. In The Corsini Encyclopedia of Psychology (4 ${ }^{\text {th }}$ Ed. pp. 1534-1536). Hoboken, New Jersey: John Wiley \& Sons.

Barsky, R. B., Juster, T., Kimball, M. S., \& Shapiro, M. D. (1997). Preference parameters and behavioral heterogeneity: An experimental approach in the Health and Retirement Study, Quarterly Journal of Economics, 112(2), 537-579.

Bergstresser, D., \& Poterba, J. (2004). Asset allocation and asset location: Household evidence from the Survey of Consumer Finances. Journal of Public Economics, 88(9), 1893-1915.

Bernasek, A., \& Shwiff, S. (2001). Gender, risk and retirement. Journal of Economic Issues, 35, 345-356. 
Bhattacharya, U., Hackethal, A., Kaesler, S., Loos, B., \& Meyer, S. (2012). Is unbiased financial advice to retail investors sufficient? Answers from a large field study. Review of Financial Studies, 25(4), 975-1032.

Bluethgen, R., Gintschel, A., Hackethal, A., \& Mueller, A. (2008). Financial advice and individual investors' portfolios. SSRN Working Paper No. 968197. Retrieved from http://papers.ssrn.com/sol3/papers.cfm?abstract_id=968197.

Bucher-Koenen, T., \& Koenen, J. (2011). Do Smarter Consumers Get Better Advice? An Analytical Framework and Evidence from German Private Pensions. Retrieved from http://www.netspar.nl/files/Evenementen/2012\%20jan\%20IPW/26\%20jan/bucher\%2 0koenen.pdf.

Calvert, L. E., Campbell, J. Y., \& Sodini, P. (2007). Down or out: Assessing the welfare cost of household mistakes. Journal of Political Economy, 115, 707-747.

Carlson, C. N. (2003, September). Information overload, retrieval strategies and Internet user empowerment. In The Good, the Bad and the Irrelevant (pp. 3-5), Helsinki, Finland.

Chang, M. L. (2005). With a little help from my friends (and my financial planner). Social Forces, 83(4), 1469-1497.

Chang, C., DeVaney, S. A., \& Chiremba, S. T. (2004). Determinants of subjective and objective risk tolerance. Journal of Personal Finance, 3, 53-67.

Chaulk, B., Johnson, P. J., \& Bulcroft, R. (2003). Effects of marriage and children on financial risk tolerance: A synthesis of family development and prospect theory. Journal of Family and Economic Issues, 24(3), 257-279.

Cohn, R. A., Lewellen, W. G., Lease, R. C., \& Schlarbaum, G. G. (1975). Individual investor risk aversion and investment portfolio composition. The Journal of Finance, 30(2), 605-620.

Coleman, S. (2003). Risk tolerance and the investment behavior of Black and Hispanic heads of household. Financial Counseling and Planning, 14(2) 43-52.

Dalbar. (2013, March 26). DALBAR Introduces Asset Allocator Ratings as Antidote for Investor Behavior. NASDAQ OMX's News Release Distribution Channel. Retrieved from http://search.proquest.com/docview/1319501758? accountid=14576.

Dwyer, P. D., Gilkeson, J. H., \& List, J. A. (2002). Gender differences in revealed risk taking: Evidence from mutual fund investors. Economics Letters, 76, 151-158. 
Embrey, L. C., \& Fox, J. J. (1997). Gender differences in the investment decision-making process. Financial Counseling and Planning, 8(2), 33-40.

Fan, J. X., \& Xiao, J. J. (2006). Cross-cultural differences in risk tolerance: a comparison between Chinese and Americans. Journal of Personal Finance, 5(3), 54-75.

Federal Reserve Board of Governors. (2010). Codebook for 2010 Survey of Consumer Finances. Retrieved from http://www.federalreserve.gov/econresdata/scf/files/codebk2010.txt.

File, T. (2013). Computer and internet use in the United States. Current Population Survey Reports, 20-568. U.S. Census Bureau, Washington, DC.

Finke, M. S., \& Huston, S. J. (2003). The brighter side of financial risk: Financial risk tolerance and wealth. Journal of Family and Economic Issues, 24(3), 233-256.

Finke, M. S., Huston, S. J., \& Winchester, D. D. (2011). Financial advice: Who pays. Journal of Financial Counseling and Planning, 22(1), 18-26.

Friend, I., \& Blume, M. E. (1975). The demand for risky assets. The American Economic Review, 65(5), 900-922.

Gathergood, J. (2012). Self-control, financial literacy and consumer over-indebtedness. Journal of Economic Psychology, 33(3), 590-602.

Gilliam, J. E., Goetz, J. W., \& Hampton, V. L. (2008). Spousal differences in financial risk tolerance. Financial Counseling and Planning, 19(1), 3-11.

Grable, J. E. (2000). Financial risk tolerance and additional factors that affect risk taking in everyday money matters. Journal of Business and Psychology, 14(4), 625-630.

Grable, J. E., \& Lytton, R. H. (1999). Financial risk tolerance revisited: The development of a risk assessment instrument. Financial Services Review, 8, 163-181.

Grable, J. E., \& Lytton, R. H. (2001). Assessing the concurrent validity of the SCF risk tolerance question. Financial Counseling and Planning, 12(2), 43-52.

Grable, J.E., McGill, S., \& Britt, S. (2009). Risk tolerance estimation bias: The age effect. Journal of Business and Economics Research, 7(7), 1-12.

Grable, J., Roszkowski, M., Joo, S. H., \& O'Neill, B. (2009). A test of the relationship between self-classified financial risk-tolerance and investment risk-taking behavior. International Journal of Risk Assessment and Management, 12(2), 396-419. 
Gron, A., \& Winton, A. (2001). Risk overhang and market behavior. The Journal of Business, 74(4), 591-612.

Guiso, L., Jappelli, T., \& Terlizzese, D. (1996). Income risk, borrowing constraints, and portfolio choice. American Economic Review. 86(1), 158-172.

Hackethal, A., Haliassos, M., \& Jappelli, T. (2012). Financial advisors: A case of babysitters? Journal of Banking \& Finance, 36(2), 509-524.

Halek, M., \& Eisenhauer, J. G. (2001). Demography of risk aversion. Journal of Risk and Insurance, 68, 1-24.

Hallahan, T., Faff, R., \& Mckenzie, M. (2003). An exploratory investigation of the relation between risk tolerance scores and demographic characteristics. Journal of Multinational Financial Management, 13, 483-502.

Hallahan, T., Faff, R., \& Mckenzie, M. (2004). An empirical investigation of personal financial risk tolerance. Financial Services Review, 13, 57-78.

Hariharan, G., Chapman, K. S., \& Domian, D. L. (2000). Risk tolerance and asset allocations for investors nearing retirement. Financial Services Review, 9(2), 159170.

Hartog, J., Ferrer-I-Carbonell, A., \& Jonker, N. (2002). Linking measured risk aversion to individual characteristics. Kyklos, 55(1), 3-26.

Hayslip, B., Bezerlein, M., \& Nichols, S. (1997). Assessing anxiety about retirement: The case of academicians. International Journal of Aging and Human Development, 44, $15-36$.

Hertzum, M., Andersen, H.H.K., Andersen, V., \& Hansen, C.B. (2002). Trust in information sources: Seeking information from people, documents, and virtual agents. Interacting with Computers, 14(5), 575-599.

Hilgert, M., Hogarth, J., \& Beverly, S. (2003). Household financial management: The connection between knowledge and behavior. Federal Reserve Bulletin, 309-322.

Hinz, R. P., McCarthy, D. D., \& Turner, J. A. (1997). Are women conservative investors? Gender differences in participant-directed pension investments. In Michael S. Gordon, Olivia S. Mitchell, and Marc M. Twinney (Eds.), Positioning Pensions for the Twenty-First Century. Philadelphia: University of Pennsylvania Press. pp 91-103. 
Ho, J., \& Tang, K. (2001). Towards an optimal resolution to information overload: An infomediary approach. In S. Ellis, T. Rodden, \& I. Zigurs (Eds.), Proceedings of the 2001 International ACM SIGGROUP Conference on Supporting Group Work (pp. 91-96). Boulder, CO: ACM Press.

Huston, S. J. (2010). Measuring financial literacy. Journal of Consumer Affairs, 44(2), 296-316.

Jacobs-Lawson, J. M., \& Hershey, D. A. (2005). Influence of future time perspective, financial knowledge, and financial risk tolerance on retirement saving behaviors. Financial Services Review, 14, 331-344.

Jianakoplos, N. A., \& Bernasek, A. (1998). Are women more risk averse? Economic Inquiry, 36(4), 620-630.

Jianakoplos, N. A., \& Bernasek, A. (2006). Financial risk taking by age and birth cohort. Southern Economic Journal 72(4), 981-1001.

Jianakoplos, N. A., \& Bernasek, A. (2008). Family financial risk taking when the wife earns more. Journal of Family and Economic Issues, 29, 289-306.

Kahneman, D., \& Tversky, A. (1979). Prospect theory: An analysis of decision under risk. Econometrica, 47, 263-291.

Keister, L. A. (2000). Race and wealth inequality: The impact of racial differences in asset ownership on the distribution of household wealth. Social Science Research, 29, 477-502.

Kennickell, A. B. (1998). Multiple imputation in the Survey of Consumer Finances. Federal Reserve Board SCF Working Paper. Retrieved from http://www.federalreserve.gov/pubs/oss/oss2/method.html.

Kennickell, A. B. (1999). Revisions of the SCF weighting methodology: Accounting for race/ethnicity and homeownership. Washington, DC: Board of Governors of the Federal Reserve System. www.federalreserve.gov/pubs/oss/oss2/method.html.

Kennickell, A. B., \& Woodburn, L. R. (1999). Consistent weight design for the 1989, 1992, and 1995 SCFs and the distribution of wealth. Review of Income and Wealth, 45(2), 193-215.

Kimball, M. S., Sahm, C. R., \& Shapiro, M. D. (2008). Imputing risk tolerance from survey responses. Journal of the American Statistical Association, 103(483), 10281038. 
Kimball, M. S., \& Shumway, T. (2010). Investor sophistication and the home bias, diversification, and employer stock puzzles. SSRN Working Paper No. 1572866. Retrieved from http://ssrn.com/abstract=1572866.

Kramer, M., \& Lensink, R. (2012, March). The impact of financial advisors on the stock portfolios of retail investors. SSRN Working Paper No. 2021883. Retrieved from http://ssrn.com/abstract=2021883.

Lancaster, L.C., \& Stillman, D. (2002). When generations collide. Who they are. Why they clash. How to solve the generational puzzle at work. New York: Collins Business.

Larson, J. (1993). Getting professional help. American Demographics, July, 34-38.

Lin, Q., \& Lee, J. (2004). Consumer information search when making investment decisions. Financial Services Review, 13, 319-332.

Lusardi, A., \& Mitchell, O. S. (2011). Financial literacy and planning: Implications for retirement wellbeing. NBER working paper, No. 17078. Retrieved from http://deepblue.lib.umich.edu/bitstream/handle/2027.42/49432/wp108.pdf;jsessionid= 41C52738B2582B9DC3F2D3F13A1C7494? sequence=1.

Magrabi, F.M., Chung, Y.S., Cha, S.S., \& Yang, S-J. (1991). The Economics of Household Consumption. New York: Praeger.

McInish, T. H., Ramaswami, S. N., \& Srivastava, R. K. (1993). Do more risk-averse investors have lower net worth and income? The Financial Review, 28(1), 91-106.

Meredith, G.P., \& Schewe, C. (1994). The power of cohorts. American Demographics, 16(12), 22-31.

Montalto, C. P. (March 1998). Everything you always wanted to know about the Survey of Consumer Finances. Paper presented at the 1998 Annual Meeting of the American Council on Consumer Interests. Retrieved June 15, 2013 from http://legacy.ehe.osu.edu/cs/scf/cmacci98.htm.

Montalto, C. P., \& Sung, J. (1996). Multiple imputation in the 1992 Survey of Consumer Finances. Financial Counseling and Planning, 7(1), 133-146.

Morin, R. A., \& Suarez, A. F. (1983). Risk aversion revisited. The Journal of Finance, $38(4), 1201-1216$.

Nofsinger, J. R., \& Varma, A. (2007). How analytical is your financial advisor? Financial Services Review, 16, 245-260. 
Payne, J. W., Bettman, J. R., \& Johnson, E. J. (1993). The Adaptive Decision Maker. Cambridge, England: Cambridge University Press.

Pratt, J. W. (1964). Risk aversion in the small and in the large. Econometrica, 32(1/2), 122-136.

Riley, W. B., \& Chow, K. V. (1992). Asset allocation and individual risk aversion. Financial Analysts Journal, 48, 32-37.

Savage, L. J. (1954). The Foundations of Statistics. New York: John Wiley.

Schooley, D. K., \& Worden, D. D. (1996). Risk aversion measures: Comparing attitudes and asset allocation. Financial Services Review, 5(2), 87-99.

Schubert, R., Brown, M., Gysler, M., \& Brachinger, H. W. (1999). Financial decisionmaking: Are women really more risk-averse? American Economic Review, 89(2), 381-385.

Social Security Administration. (2013). Social security board of trustees: No change in projected year of trust fund reserve depletion [Press release]. Retrieved from http://www.ssa.gov/pressoffice/pr/trustee13-pr-alt.pdf.

Society of Actuaries. (2012, June). Key findings and issues, longevity. 2011 Risks and Process of Retirement Survey Report. Retrieved from http://www.soa.org/files/research/projects/research-key-finding-longevity.pdf.

Stigler, G. J. (1961). The economics of information. Journal of Political Economy, 69(3), 213-225.

Sundén, A. E., \& Surette, B. J. (1998). Gender differences in the allocation of assets in retirement savings plans. The American Economic Review, 88(2), 207-211.

Van de Venter, G., Michayluk, D., \& Davey, G. (2012). A longitudinal study of financial risk tolerance. Journal of Economic Psychology, 33, 794-800.

United Nations, Department of Economic and Social Affairs, Population Division (2012). World Mortality Report 2011. Retrieved from http://www.un.org/en/development/desa/population/publications/pdf/mortality/world MortalityReport2011.pdf.

Yang, Y., \& Land, K.C. (2008). Age-period-cohort analysis of repeated cross-section surveys: fixed or random effects? Sociological Methods and Research, 36(3), 297326. 
Yao, R., \& Curl, A. L. (2011). Do market returns influence risk tolerance? Evidence from panel data. Journal of Family and Economic Issues, 32(3), 532-544.

Yao, R., Gutter, M. S., \& Hanna, S. D. (2005). The financial risk tolerance of Blacks, Hispanics and Whites. Financial Counseling and Planning, 16(1), 51-62.

Yao, R., \& Hanna, S. D. (2005). The effect of gender and marital status on financial risk tolerance. Journal of Personal Finance, 4(1), 66-85.

Yao, R., Sharpe, D. L., \& Wang, F. (2011). Decomposing the age effect on risk tolerance. Journal of Socio-Economics, 40, 879-887.

Willis, L. E. (2008). Against financial literacy education. Iowa Law Review, 94, 197-285. 
Donald "Eric" Park graduated from high school in Washington, MO and after serving in the United States Army returned to the area to get an Associate Degree from East Central College. He has a Bachelor of Science in Business, Summa Cum Laude, from Lindenwood University. Eric has two Master Degrees, one in Financial Services from The American College, the other in Personal Financial Planning from the University of Missouri, where in December, 2013 he received a PhD in Consumer and Family Economics. He has a postgraduate certificate in ERISA Law \& Retirement Plans and is a member of the American Society of Pension Professional \& Actuaries. He is a peer reviewer for the Journal of Family and Economic Issues.

Eric began his investment and financial planning career in 1981 as a representative for the Pioneer Fund Group. He then joined AG Edwards \& Sons as an Investment Broker and went on to become a Vice President for the JJB Hilliards, WL Lyons investment firm. In 1994 Eric founded and was for the first twelve years President of his own firm. In 2013 Eric opened an office for LPL Financial. Eric is a CERTIFIED FINANCIAL PLANNER ${ }^{\text {TM }}$.

Eric was a member of the Missouri State Commission charged with regulatory oversight of credit unions. Publications such as FORTUNE magazine and the St. Louis Post Dispatch and several industry journals have quoted Eric on financial and investment matters. Eric is a 2005 Registered Representative Magazine "Outstanding Broker of The Year" and a 2007 Research Magazine inductee to their "Advisors Hall of Fame." Eric was listed as one of Reuters' "Top Advisors". St. Louis Magazine included him in their regional listing of "Five Star Wealth Managers" every year from 2008 to 2014

Eric is involved with several charities, founded the local Humane Society Shelter and was 2011/2012 District Governor for Rotary International. Eric has traveled the world working with organizations to establish micro-credit programs to help people raise themselves out of poverty. 